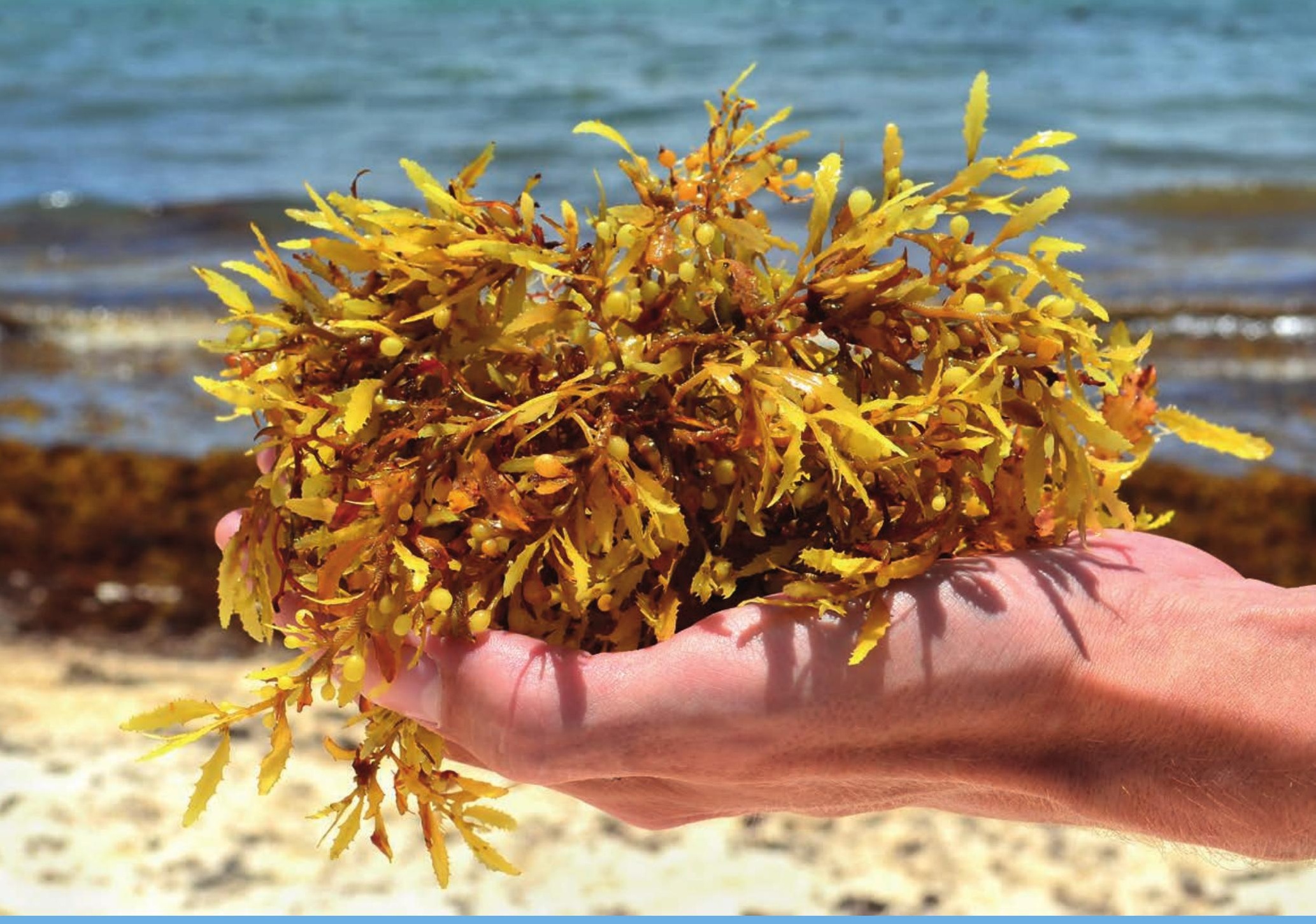

Opportunities for valorisation of pelagic Sargassum in the Dutch Caribbean

Ana M. López-Contreras, Matthijs van der Geest, Bea Deetman, Sander van den Burg, Hanneke Brust, Truus de Vrije

WAGENINGEN

UNIVERSITY \& RESEAREH 



\section{Opportunities for valorisation of pelagic Sargassum in the Dutch Caribbean}

Authors: Ana M. López-Contreras, Matthijs van der Geest, Bea Deetman, Sander van den Burg, Hanneke Brust, Truus de Vrije

This study was carried out by Wageningen Food \& Biobased Research (coordinator), Wageningen Marine Research, Wageningen Economic Research and Wageningen Food Safety Research, and subsidised by the Dutch Ministry of Agriculture, Nature and Food Quality, in the context of Top Sector Agri-Food (project number LWV19070). 
WFBR Project number: 6224101800

Version: Final

Reviewer: Prof. Dr. J. Hugenholtz, Ir. E. Hamoen

Approved by: Dr. C.A.A. Claesen

Subsidized by: the Dutch Ministry of Agriculture, Nature and Food Quality in the context of Top Sector Agri-Food (project number LWV19070)

Confidentiality of the report: Public

Citation: A. M. López-Contreras, M. van der Geest, B. Deetman, S. W. K. van den Burg, G .M. H. Brust and G. J. de Vrije (2021) "Opportunities for valorisation of pelagic Sargassum in the Dutch Caribbean" WUR report 2137, DOI: $10.18174 / 543797$

The research that is documented in this report was conducted in an objective way by researchers who act impartial with respect to the client(s) and sponsor(s). This report can be downloaded for free at DOI https://doi.org/10.18174/543797 or at www.wur.eu/wfbr (under publications).

(C) 2021 Wageningen Food \& Biobased Research, institute within the legal entity Stichting Wageningen Research.

The client is entitled to disclose this report in full and make it available to third parties for review. Without prior written consent from Wageningen Food \& Biobased Research, it is not permitted to: a. use this report for the purposes of making claims, conducting legal procedures, for (negative) publicity, and for recruitment in a more general sense;

b. use the name of Wageningen Food \& Biobased Research in a different sense than as the author of this report.

PO box 17, 6700 AA Wageningen, The Netherlands, T + 31 (0)317 4800 84, E info.wfbr@wur.nl, www.wur.eu/wfbr.

All rights reserved. No part of this publication may be reproduced, stored in a retrieval system of any nature, or transmitted, in any form or by any means, electronic, mechanical, photocopying, recording or otherwise, without the prior permission of the publisher. The publisher does not accept any liability for inaccuracies in this report. 


\section{Contents}

Project details $\quad 5$

Summary 6

1 Introduction $\quad 8$

2 Research on biology, ecology, origin, distribution, causes, socio-ecological impact and management of pelagic Sargassum blooms and influxes: mapping the state-of-the-art

2.1 Biology and ecology of pelagic Sargassum 9

$\begin{array}{lll}2.2 & \text { Origin and distribution patterns of pelagic Sargassum } & 10\end{array}$

2.3 Causes of recent beaching events of pelagic Sargassum in the Caribbean 11

2.4 Ecological and socio-economic impacts of pelagic Sargassum influxes in the Caribbean 12

2.4.1 Ecological impacts 12

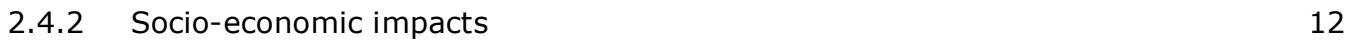

2.4.3 Impacts reported in the Dutch Caribbean 13

2.5 Management approaches to reduce socio-ecological impacts of pelagic Sargassum

influxes 13

2.5.1 Detection and prediction of pelagic Sargassum blooms and influxes 13

2.5.2 Collection of pelagic Sargassum at sea 15

2.5.3 Removal and disposal of beached Sargassum 17

$3 \quad$ Storage and valorisation of pelagic Sargassum biomass $\quad 18$

$\begin{array}{llr}3.1 & \text { Storage of pelagic Sargassum } & 18\end{array}$

3.2 Valorisation of pelagic Sargassum biomass $\quad 19$

3.2.1 Chemical composition and uses of biomass 19

3.2.2 Chemical analysis of Sargassum collected in 2020 in Bonaire, St. Maarten, Florida \& Mexico $\quad 25$

4 Economic, societal and environmental impact of pelagic Sargassum valorisation 30

$\begin{array}{lll}4.1 & \text { The cost and impact of non-action } & 30\end{array}$

4.2 The economic feasibility of harvesting and processing Sargassum 31

$\begin{array}{lll}4.3 & \text { Design of the value chains for harvesting and processing Sargassum } & 31\end{array}$

4.4 Environmental impacts of harvesting and processing Sargassum blooms 32

$5 \quad$ Value chains for valorisation of pelagic Sargassum biomass in the Dutch Caribbean 34

$\begin{array}{lll}5.1 & \text { Sustainable feedstock supply } & 35\end{array}$

$\begin{array}{llr}6 & \text { Policy challenges and advice } & 37\end{array}$

$\begin{array}{lll}6.1 & \text { Policy challenges and governance } & 37\end{array}$

6.2 Current policies for the exclusive economic zone of the Dutch Caribbean 38

6.3 Policy advice in relation to Sargassum management and financing aspects 39

$7 \quad$ Knowledge gaps and implementation plan $\quad 41$

$\begin{array}{lll}7.1 & \text { Knowledge gaps: harvesting, biology and ecology } & 41\end{array}$

$\begin{array}{lll}7.2 & \text { Knowledge gaps: storage, processing and conversion } & 43\end{array}$

$\begin{array}{lll}7.3 & \text { Knowledge gaps: application of products } & 44\end{array}$

$\begin{array}{lll}7.4 & \text { Knowledge gaps: socio-economic impacts } & 44\end{array}$ 
7.5.1 Implementation plan: Phase 1

7.5.2 Implementation plan: Phase 2

7.5.3 Implementation plan: Phase 3

10 Other studies on pelagic Sargassum management 52 


\section{Project details}

Project number

Project title

Coordinator

Project period
LWV19070

Identification of sustainable management and valorisation strategies of Sargassum influxes in the Dutch Caribbean: turning the brown tide into a golden opportunity

Wageningen Food \& Biobased Research

01-01-2020 to $31-12-2020$

Authors:

Ana M. López-Contreras (WFBR), Matthijs van der Geest (WMR), Bea Deetman (WEcR), Sander van den Burg (WEcR), Hanneke Brust (WFSR), Truus de Vrije (WFBR)

Contributions by:

Prof. dr. Linda Amaral-Zettler

Research Leader, Department of Marine Microbiology and Biogeochemistry

NIOZ Royal Netherlands Institute for Sea Research

J.W. (Jaap) van Hal, Ph.D.

Senior Consultant

Innovation manager biorefinery

TNO Energy Transition

K.M. (Karla) Dussan Rojas, PhD

Scientist Innovator

Biobased and Circular Technologies

TNO Energy Transition

Alyson Myers

President of Fearless Fund

www.FearlessFund.org

Ing. Peter Lindeman, MBA

Climate Cleanup

www.climatecleanup.org

Sabine Engel, MSc

Green Mangroves-Blue Carbon

Photo cover: Seaweed Sargassum close up in a hand, from Marine Larzilliere

Photos back: Fearless Fund and WFBR 


\section{Summary}

Since 2011, unprecedented beaching events of Sargassum seaweed have caused major environmental, health and economic problems in the Caribbean, Gulf of Mexico, northern Brazil and the western coast of Africa. Not only are Sargassum influxes threatening already fragile and often endangered coastal ecosystems, such as coral reefs, mangroves and seagrass beds, they also disrupt the livelihoods of communities, especially those associated with the tourism and fishing sectors. The aim of this study is to develop a plan to turn these "brown tides" into opportunities for sustainable, scalable and efficient harvesting and valorisation approaches that will deliver environmental and socioeconomic benefits to the Dutch Caribbean and other end-users in the region.

In this report we have reviewed the state-of-the-art of research on recent Sargassum blooms and influxes in the Caribbean with respect to biology, ecology, origin, distribution, socio-ecological impact and management options, in addition to existing valorisation chains and uses of Sargassum biomass, and environmental and socio-economic impacts of Sargassum valorisation. We conclude that value chains based on valorisation of nearshore Sargassum biomass into biofuel and agricultural products (i.e. fertilizer, animal feed supplement) seem the most promising for the Dutch Caribbean islands, since they will contribute to sustainable energy and food security, while reducing environmental impact of the energy and agricultural sector. Some of the identified management and valorisation strategies could also be applied to other areas that are affected by massive Sargassum influxes, such as the Gulf of Mexico.

During 2020 pelagic Sargassum samples have been collected in different locations in the Caribbean region (Bonaire, Mexico, St Maarten) and Florida. These samples have been analysed for major components (including sugars and ash) and for content in iodine and heavy metals. The values obtained in these analysis were compared to values reported in the literature. The results of these analysis are of importance for the definition of possible applications of the Sargassum biomass or its products as component in the food and feed value chains

Based on our literature review, a number of knowledge gaps have been identified that are related to the availability of pelagic Sargassum biomass, the environmental impacts of the harvesting, technological challenges, effects of Sargassum leachates to the environment (in case of agricultural uses) and on socio-economic impacts of the current and predicted actions (Chapter 7). These knowledge gaps need to be addressed before (commercial) harvesting and valorisation actions concerning pelagic Sargassum are taken. Therefore, we defined an implementation plan (Section 7.5 and Fig. 1), which addresses these knowledge gaps to set the first steps in the short term towards efficient and sustainable management and valorisation of pelagic Sargassum in the Dutch Caribbean. In the potential value chains defined, prevention of landings of Sargassum on the coasts is preferred to harvesting onshore. This is due to the negative ecological impact of harvesting onshore and the lower quality of beached Sargassum, that decays very rapidly. 


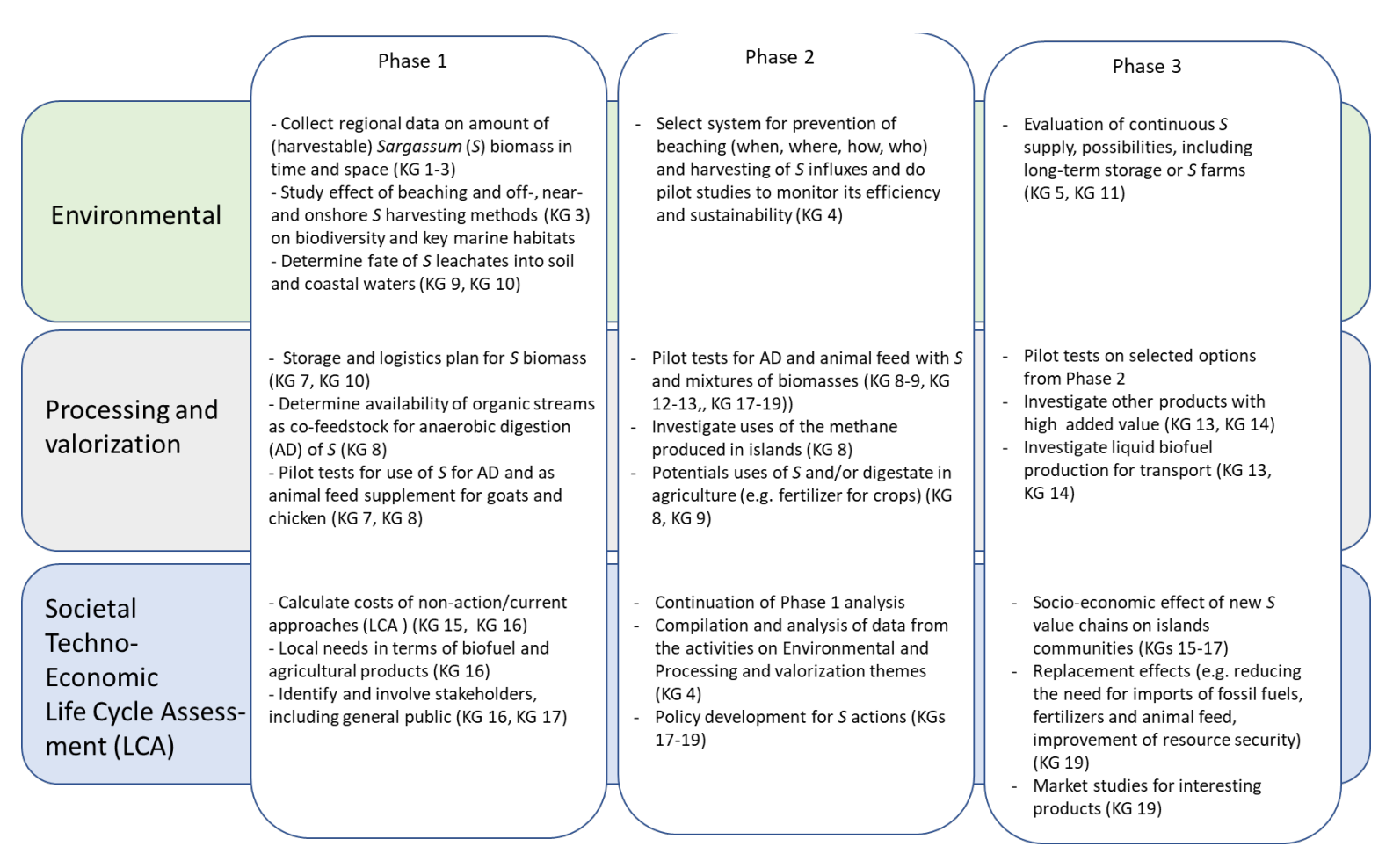

Figure 1 Suggested implementation plan for establishing pelagic Sargassum harvesting and valorisation value chains in the Dutch Caribbean

Moreover, we dedicated a chapter to policy challenges and advice regarding to management of the recent pelagic Sargassum influxes in the Caribbean, as good governance, both at a local and at a regional scale. In this report we have also compiled an extensive list of references to recent studies on the pelagic Sargassum blooms and influxes the Caribbean area. 


\section{Introduction}

Sargassum blooms are a persistent problem throughout the Caribbean, with negative impact on coastal ecosystems, fisheries and tourism. Since this is a relatively recent phenomenon, currently there are no standard management protocols for the Sargassum-related problems, as well as no wellestablished value chains for valorisation of this biomass. The Dutch Caribbean islands are affected by the Sargassum blooms, and currently Sargassum management plans are being developed to mitigate the negative effects of these blooms. There is a need to define strategies for management and investigate possible valorisation of the biomass towards products of interest for the islands, that fit in the current goals with respect to sustainable nature management and enhancing of the resilience of the island communities. This report has been elaborated during the TKI-Agrifood-financed project "Identification of sustainable management and valorization strategies of Sargassum influxes in the Dutch Caribbean: turning the brown tide into a golden opportunity".

In this report, a summary of the state-of-the-art of the different aspects related to the Sargassum influx events has been made in relation to (1) biology and ecology of pelagic Sargassum, (2) management options with regard to harvesting, storage and pre-processing, (3) valorisation chains and (4) environmental, market and societal impacts of Sargassum valorization. The chemical composition of the biomass is very important to evaluate applications. Therefore samples of Sargassum collected at different locations have been subjected to a detailed biochemical analysis on components relevant for different applications.

Based on the data collected, potential value chains and management strategies have been defined to help local authorities to reduce the negative impact of Sargassum blooms on coastal ecosystems and fisheries and support the local island economy. The knowledge gaps in these new chains have been identified and a three-phase plan has been proposed to address these gaps in order to realise implementation of the proposed strategies. The strategies defined in this report could be exported to other countries in the Caribbean (and elsewhere) that are affected by massive Sargassum influxes, although adapted to the characteristics and conditions of the specific area. Further application of the management approaches identified in this project, provides opportunities for the Dutch maritime, environmental and bio-based sectors and research institutes to play a leading role in managing the impact of Sargassum blooms.

Given the multidisciplinary character of the subject, our consortium consists of four Wageningen research institutes, namely Wageningen Food and Biobased Research (involved in valorisation studies), Wageningen Marine Research (involved in environmental impact studies, ecosystem services, and coastal management), Wageningen Economic Research (involved in environmental and economic assessment of valorisation chains), and Wageningen Food Safety Research (involved in analysis of biochemical elements). Local organizations in Bonaire (STINAPA, OLB), a US-based organisation (Fearless Funds) and the research institutions TNO and NIOZ have collaborated in this report by participating in discussions, sharing knowledge, performing analysis and/or supplying samples. 


\section{Research on biology, ecology, origin, distribution, causes, socio-ecological impact and management of pelagic Sargassum blooms and influxes: mapping the state-of-the-art}

\subsection{Biology and ecology of pelagic Sargassum}

Pelagic Sargassum is a free-floating brown macroalgae that is restricted to the tropical and subtropical Atlantic Ocean where it completes its full lifecycle at the ocean surface [1,2]. Pelagic Sargassum consists of two species, Sargassum fluitans and Sargassum natans, that reproduce by vegetative fragmentation, a type of asexual reproduction where a new thallus grows from a fragment of the parent thallus. These species are characterized by numerous blades, highly branched thallus (stem), and gas-filled bladders (pneumatocysts) that help the macroalgae float, which promotes photosynthesis as the plants receive more light when floating at the ocean surface. Yet, variation in blade size and shape, number of floats, and general branching and arrangement has led to the recognition of distinct morphological forms within each species of pelagic Sargassum [3], with S. natans I and S. flutians III being the most common forms, and S. natans VIII being a typically rare form (Fig. 2) until the last decade. These forms can also be distinguished at the mitochondrial level with stable polymorphisms [4].
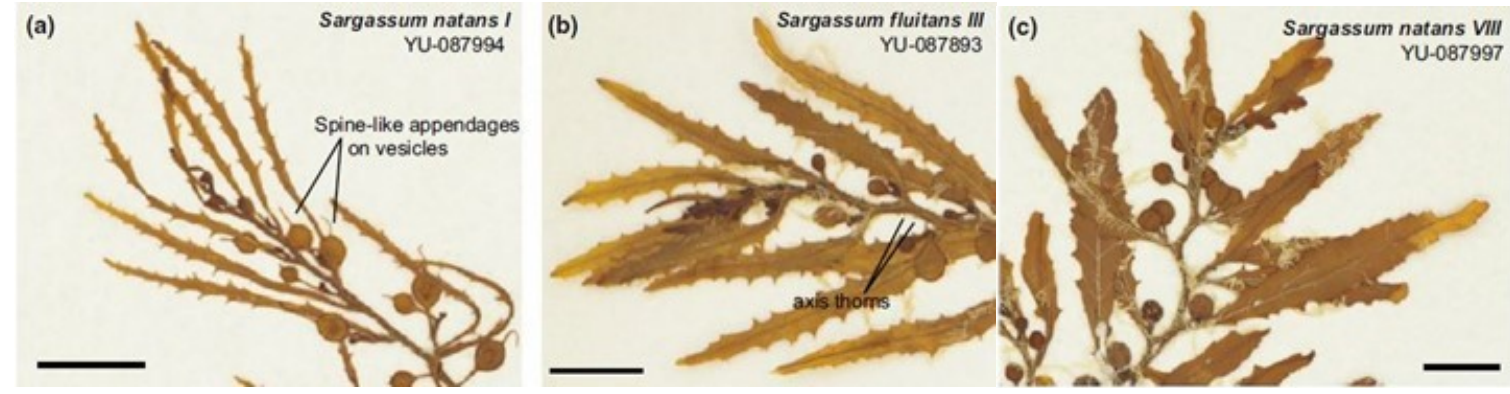

Figure 2 The most common forms of holopelagic Sargassum found in the Atlantic: (a) Sargassum natans I showing characteristic spine-like appendages on vesicles; (b) Sargassum fluitans III showing characteristic axis thorns; (c) S. natans VIII showing neither spine-like appendages nor thorns. Scale bars are $1 \mathrm{~cm}$. These are herbarium images from the Peabody Museum of Natural History, Yale University (YU), which are modified from Amaral-Zettler et al. [4]

When light, nutrient and temperature conditions are favourable, pelagic Sargassum can grow very fast, with a maximum doubling time of 9.3 days for $S$. fluitans and 13.8 days for $S$. natans [5], which can result in extensive aggregations of floating Sargassum that can travel long distances under the action of winds, currents and waves $[1,6]$. These floating rafts have been called the "golden floating rainforest of the Atlantic Ocean" as they provide essential habitats for a wide range of invertebrates, fishes, sea turtles, birds, and mammals, and serve as hotspots for biodiversity and productivity in otherwise substrate poor, low-nutrient open-ocean waters [7]. Pelagic Sargassum mats provide foraging grounds for over 145 species of marine invertebrates, 111 species of fish and 26 species of seabird [8,9]. In addition, pelagic Sargassum mats serve as a nursery habitat for many commercial and endangered species, including large pelagic fish (i.e. tuna, bill fish, mahi-mahi) and 4 species of sea turtles that use the rafts as a refuge to reduce predation risk during early life stages $[9,10]$. 
Because of its importance as spawning, nursery and foraging habitat for fish, commercial harvest of Sargassum within U.S. jurisdictional waters was banned in 2003 [11]. When pelagic Sargassum and the sea life it carries is washed ashore in small quantities, it can also benefit biodiversity by providing food and habitat for beach fauna, and by adding nutrients to the coastal soil, which promotes the growth of beach and dune plants [12]. Sargassum wrack also plays an important role in stabilizing shorelines, which helps reducing coastal erosion [13]. However, most of the pelagic Sargassum biomass ends up sinking to the deep sea, where it provides an important carbon resource to the benthic community $[14,15,16,17]$ and significantly contributes to the global ocean sequestration of carbon, which helps mitigation of climate change [18].

A number of mechanisms have been identified for the delivery of floating Sargassum to the deep sea. Wind-induced Langmuir circulation can cause down welling of Sargassum fragments at depths where pressure can collapse their gas vesicles, rendering the macroalgae negatively buoyant, after which they sink $[19,20]$. The growth of encrusting calcifiers on Sargassum surfaces can also add to their density and contribute to their subsequent sinking $[20,21]$. When buoyancy is lost, pelagic Sargassum sinks slowly to the bottom at a rate between 50 and $200 \mathrm{~m} \mathrm{~d}^{-1}$ [22]. Overall, biomass developments of pelagic Sargassum populations depends on growth rate and sinking rate.

From the above, it becomes clear that pelagic Sargassum provides vital ecosystem services in the ocean, on shore, and on the seafloor.

\subsection{Origin and distribution patterns of pelagic Sargassum}

In the $15^{\text {th }}$ century, Christopher Columbus was the first to report floating mats of Sargassum seaweed, which he encountered in an area in the North Atlantic Ocean, currently known as the Sargasso Sea. While at first it was believed that the mats of floating Sargassum were restricted to the Sargasso Sea [1], further surveys by Parr [3] revealed that they were also present in the Caribbean Sea and Gulf of Mexico. Attempts have been made in the past to estimate changes in the total biomass of pelagic Sargassum from surface net tows [3,23]. This led Stoner [23] to suggest decreasing Sargassum abundance from the early to the late $20^{\text {th }}$ century, although this claim has proven difficult to verify due to seasonality in the sparse observations used [24].

Gower and King [25] were the first to map the global distribution and movement of pelagic Sargassum, using time series of ocean colour satellite images provided by the Medium Resolution Imaging Spectrometer (MERIS) satellite (see also $[26,27]$ ). Their observations provided strong quantitative evidence that between 2002 and 2008 the largest populations of pelagic Sargassum were found in the Sargasso Sea and the Gulf of Mexico, a pattern that is consistent with historical surveys from ships. Their results showed a seasonal pattern, in which pelagic Sargassum originates in the north-western Gulf of Mexico each spring, after which it is advected into the Sargasso Sea where it accumulated in the summer months, and by winter ends up disappearing northeast of the Bahamas, presumably because aged thalli sink to the deep sea [20].

In the summer of 2011, massive unprecedented amounts of pelagic Sargassum, washed ashore on the beaches of the islands of the eastern Caribbean, well to the South of the previously defined latitude range of pelagic Sargassum, with severe local impacts on fishing, reef and benthic communities, mangroves, turtle hatchlings, and tourism [28]. Based on historical records, it was initially believed that this major influx of pelagic Sargassum must have originated in the Sargasso Sea or the Gulf of Mexico. However, using a numerical model Franks et al [28] found that the Caribbean Sargassum accumulations could be traced back to the tropical Atlantic, while they found no direct or indirect linkage to the Sargasso Sea. Analysis of satellite images by Gower et al [29] provided additional evidence that this 2011 "Sargassum event" had its origin in the tropical Atlantic, in an area north of the mouth of the Amazon not previously associated with Sargassum growth. Moreover, they found that this new source region formed the basis of a large population of pelagic Sargassum that by summer spanned the Atlantic basin from West Africa to northeast Brazil and the Caribbean Sea.

Recently, Wang et al. [6] extended satellite detections of pelagic Sargassum for the tropical Atlantic region over 2000-2018. They showed a recurrent and increasing Sargassum belt in the tropical Atlantic every year since 2011 except for 2013, a year when the Sargassum did not form these accumulations in the tropical Atlantic. Based on Lagrangian simulations over a climatological year, they concluded that ocean circulation largely explained the so called 'great Atlantic Sargassum belt' summer distribution, which often extended from West Africa to the Gulf of Mexico, accompanied 
by frequent beaching events that have caused serious environmental, ecological, and economic problems [30,31]. Understanding whether this new expanded geographic range of massive Sargassum blooms and associated beaching events will become the new norm, requires sustained monitoring and research.

\subsection{Causes of recent beaching events of pelagic Sargassum in the Caribbean}

As described in the chapter above, evidence accumulates that the western equatorial Atlantic is the new, unexpected source of floating Sargassum mats that strand in massive accumulations on Caribbean beaches $[6,28,29]$. Model simulations of pelagic Sargassum transport from the western equatorial Atlantic explain close to $90 \%$ of the annual variation in observed pelagic Sargassum entering the Caribbean Sea [32] but recent research on surface drifters highlight the need for improvements in assimilated hydrodynamic models in the Great Sargassum Belt [161] (Fig. 3). Because of the ecological and socioeconomic impacts of large mass strandings of pelagic Sargassum in the Caribbean, scientific efforts have been directed towards understanding the causes of the sudden, and now recurring, appearance of the Sargassum blooms in the western equatorial Atlantic.

In an attempt to

determine the origin of the sudden appearance of pelagic Sargassum in the tropical Atlantic Johns et al. [33] used a numerical particletracking system, wind and current reanalysis data, drifting buoys trajectories and satellite imagery. Their joint analysis suggested that during the winter 2009-2010, there was a large scale redistribution of pelagic

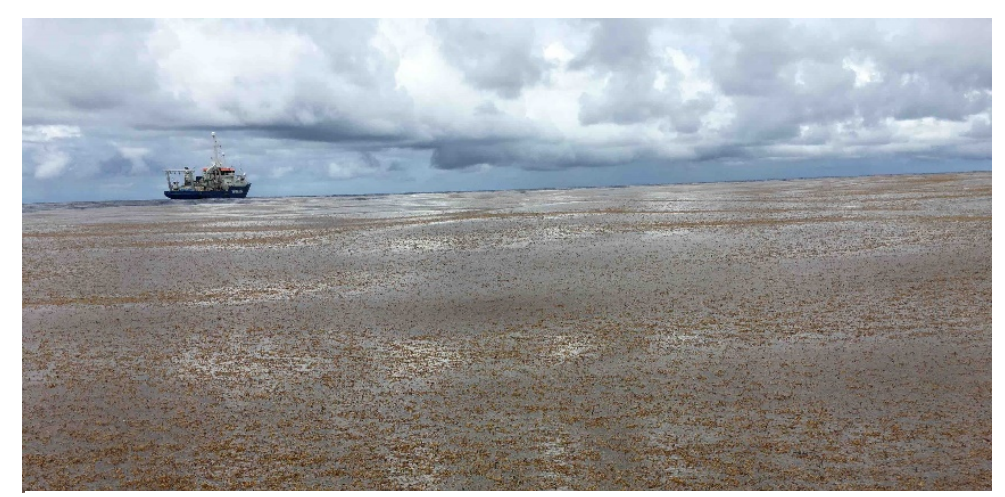

Figure 3 Great Sargassum Belt. Photo credit: Erik Zettler

Sargassum from the Sargasso Sea into the far eastern North Atlantic, that was driven by unusually strong and southward-shifted westerly winds. Moreover, Lagrangian analysis of the regional circulation suggested that (1) part of the Sargassum subsequently drifted to the southwest in the North Equatorial Current (NEC) and entered the central tropical Atlantic, arriving in the Caribbean by the spring of 2011, with (2) another portion continuing southward along the coast of Africa in the Canary Current, eventually joining the seasonally-varying system of tropical Atlantic currents and thereby delivering a large Sargassum population to the tropical Atlantic [33]. Overall, their work suggests that the Sargassum population in the Sargasso Sea may have been the source for the now recurring large blooms in the central tropical Atlantic, that in turn have led to the massive inundations that affect the coastal areas in Africa, the Caribbean and the Gulf of Mexico.

Although there is strong support that winds and currents advect Sargassum blooms into the Caribbean $[32,34]$, the drivers of these recent blooms in the tropical Atlantic and related beaching events are still not well understood. Several studies suggest that these recent Sargassum blooms in the tropical Atlantic are caused by altered nutrient conditions in the Atlantic Basin due to: (1) increased nutrient discharges of large rivers (Amazon, Orinoco, Congo) due to deforestation and other land-use changes upstream; (2) stronger upwelling off the coast of northwest Africa; (3) changes in open-ocean upwelling patterns; (4) changes in the amount or deposition patterns of Sahara dust containing iron and nutrients; (5) changes in the mixed layer depth resulting in higher replenishment of near-surface nutrient stocks; or by, (6) higher sea surface temperatures and associated storm intensity, or are the result of all of these causes combined [e.g., 6,33,35-39].

In general, Sargassum blooms should be considered a result of the combination of physicochemical seawater conditions (e.g. temperature, sunlight, nutrient availability), biophysical properties of Sargassum (e.g. depth, buoyancy, growth rates, sinking rates) and biological interactions. Yet, continued monitoring and multidisciplinary research is needed to provide a more comprehensive understanding of the dynamics of Sargassum throughout the Atlantic, and to improve predictions of its distribution and impacts. 


\subsection{Ecological and socio-economic impacts of pelagic Sargassum influxes in the Caribbean}

\subsubsection{Ecological impacts}

As described above, when floating at sea, pelagic Sargassum masses provide essential habitat for a wide range of organisms, including invertebrates, fish, sea turtles and sea birds [7]. As such, the increased presence of pelagic Sargassum in the Caribbean could have beneficial effects on biodiversity and productivity in otherwise substrate-poor, low-nutrient open-ocean waters. If these masses were to remain at sea, or if only small quantities were to arrive at the shore, ecological problems would be minor. Small quantities of Sargassum wrack on a beach are usually beneficial, stabilizing shorelines which reduces coastal erosion [13], providing food and habitat for small animals, and adding nutrients to the coastal soil, which promotes the growth of beach and dune plants [12]. However, at high concentrations, beached or near-shore accumulations of Sargassum can have major impacts on Caribbean coastal ecosystems and communities.

Close to the shoreline, the decomposition of the algal masses produces leachates and organic particles that create Sargassum Brown Tides (SBT), turning the water brown, reducing light penetration, oxygen levels, and the $\mathrm{pH}$, while increasing the temperature, sulphide levels, and organic matter and nutrient loads [40]. These SBT can stretch over $100 \mathrm{~m}$ from the coastline, while its impact on benthic communities can reach as far as 500 from the coastline [30,31]. Although it depends on the local environmental conditions, the degree of this impact on the benthos follows a general pattern. Reduced light penetration in the water column, causes a reduction in photosynthesis by benthic plants, which decreases oxygen levels. At the same time, the large influx of organic matter from decomposing Sargassum leads to rapid depletion of dissolved oxygen, followed by increased levels of toxic sulphide as a result of anaerobic decomposition of Sargassum detritus in the absence of oxygen, eventually resulting in hypoxia or anoxia $[30,31,40]$.

Reduced water quality and hypoxia events due to SBT seem to be the major causes of mortality in nearshore seagrasses and fauna (i.e. corals, fish, crustaceans, echinoderms, mollusks, polychaetes) and has also been held responsible for nearshore mangroves to shed their leaves $[30,31,40]$. Seagrass meadows both stabilise sediment and attenuate waves, providing effective coastal protection services for sandy beaches [41]. As such, the loss of nearshore seagrasses due to SBT will make beaches more vulnerable to the impact of storms and hurricanes. This would add to already enhanced beach erosion, as a result of massive Sargassum beaching $[30,40]$. SBT can also affect trophic dynamics in coastal communities, as was recently shown for the sea urchin Diadema antillarum that changed diet when the source of available organic matter was modified due to large inputs of decaying Sargassum [42]. In addition, SBT can alter animal behaviour, as was shown by Antonio-Martínez [43], who found effects that the swimming behaviour of coral larvae was modified by pelagic Sargassum leachate, which may reduce larval dispersion and genetic diversity.

Coastal accumulation of Sargassum is also known to interfere with marine turtle nesting, hatching and with the seaward journeys of the juvenile turtles that now will have to crawl over the Sargassum masses [44, 45]. The generally high content of metals in Sargassum is also of concern for coastal contamination, since these potentially toxic metals, including arsenic, may be released to the environment during decomposition of Sargassum [31]. Moreover, the negative impact of SBT on benthic communities is likely to interact with other threats. For example, it has been suggested that the deterioration in water quality due to SBT has contributed to the susceptibility of reef corals to diseases [46].

\subsubsection{Socio-economic impacts}

Mass invasions of Sargassum also have socio-economic impact, by disrupting livelihoods, especially those associated with the tourism and fishing sectors $[40,47,48]$. The unattractive visual impact of decaying Sargassum on the beach, the flies it attracts, and the foul odour it produces, has harmed the tourist industry, which is the main driver of the economy of many Caribbean countries [48]. In addition, the gases emitted by rotting Sargassum, such as hydrogen sulphide and ammonia, can reach concentrations that are known to cause health problems in humans (Dutch Caribbean Nature Alliance, 2019, [49]). Coastal residents have reported that the smell of these gasses is sometimes noticeable up to several hundred meters inland. The release of hydrogen sulphide $\left(\mathrm{H}_{2} \mathrm{~S}\right)$ gas is also known to 
cause corrosion of copper cables, electronic equipment and domestic appliances in nearshore dwellings [40]. Apart from causing loss of important fish nursery habitats, such as seagrass beds [30], nearshore accumulations of Sargassum also affect fisheries by clogging nets and impending the passage of small boats [50].

To stop further decline in tourism and to avoid a deterioration of coastal ecosystems, local governments, together with the tourism industry have spent much money to remove Sargassum from their beaches and coastal waters. For example, the Mexican government invested USD 17 million dollars in the removal of 522,226 tons of Sargassum in 2018, and USD 2.6 million dollars for the removal of 85,000 tons in 2019 [40]. For Cancun, Mexico, they estimated that the cleaning of each meter of coastline could be as high as a USD 1000 dollars [37]. Clearly, the costs and efforts related to these clean-up activities, posed severe socioeconomical impacts on the local society.

\subsubsection{Impacts reported in the Dutch Caribbean}

The current state of Sargassum influx related impacts in the Dutch Caribbean has been summarized in a recent report from the Dutch Caribbean Nature Alliance (Dutch Caribbean Nature Alliance, 2019). In this report it is described that in the case of Bonaire, the island has been hit hard by Sargassum beaching events, especially the East coast where seaweed mats washed in and coated the coastline, including sand/rubble beaches (Lagun, Washikemba and Lac Sorobon area) and mangrove lagoons (Lagun and Lac) (STINAPA Bonaire) (Fig. 4). During the March 2018 Sargassum invasion, the worst to date, the gases emitted by rotting Sargassum reached concentrations known to cause health problems for people. After several episodes of

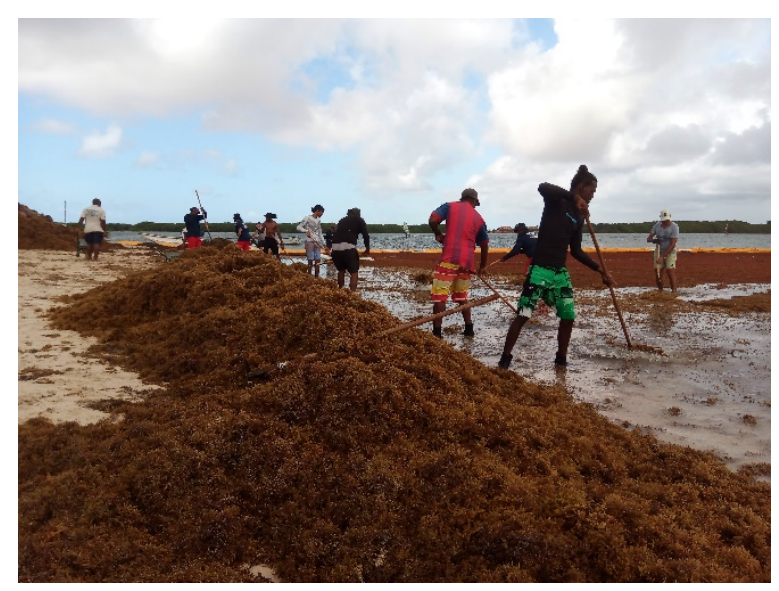

Figure 4 Cleaning of Sargassum on sand in Bonaire. Photo credit: Sabine Engel

Sargassum influx that year (Lac Bay, Lagun - March and July 2018) and for the past several years (Lagun - June 2015, December 2017), these areas have experienced direct die-offs (fish, seagrass) and damage (mangroves). In Lac Bay, the March 2018 Sargassum incident resulted in the death of thousands of fish, dead patches of seagrass, brown tide and large tracts of mangroves had their leaves turn yellow and fall off (STINAPA Bonaire).

\subsection{Management approaches to reduce socio-ecological impacts of pelagic Sargassum influxes}

\subsubsection{Detection and prediction of pelagic Sargassum blooms and influxes}

Early detection of Sargassum, risk assessment and alerts are strategic elements in the process of helping coastal communities to timely prepare for Sargassum blooms and subsequent beaching events. Therefore, recent scientific efforts were aimed at combining remote sensing techniques with drift models to locate and quantify Sargassum rafts and to predict their development and movement $[32,51,52,53,54]$. These scientific developments formed the basis of several Sargassum early warning systems, that monitor and track Sargassum in near-real time and provide predictions on which shorelines are at risk with regard to Sargassum influxes. Although these early warning systems will not prevent Sargassum from approaching the coast, they will allow coastal communities to prepare their Sargassum mitigation plan in time, which will help them to reduce the devastating effects of Sargassum strandings on their local economies.

Non-commercial Sargassum early warning systems include:

- Sargassum Early Advisory System (SEAS; [55]): using LANDSAT 7 \& 8 satellites with 30 m resolution to track Sargassum rafts in the northwestern Gulf of Mexico. The forecast only predicts 
out to 8 days. Because of the relatively large resolution for Landsat, SEAS is only suitable to detect and predict moderate to large landings of Sargassum.

- Sargassum Watch System (SaWS; [56]): using satellite data from four sensors (MODIS/Terra, MODIS/Aqua, VIIRS, Landsat $8 \mathrm{OLI}$ ) and numerical models to provide a general outlook of current Sargassum bloom condition and future bloom probability for the Caribbean Sea. These outlooks are made available online through monthly outlook bulletins. Although SaWS cannot be used for predicting bloom conditions for a specific location or beach, it does provide at least two months of lead time to respond to beaching events.

- CERMES Sargassum Outlook Bulletin [57]: provides medium-range (3-monthly) island-scale forecasts of sargassum influxes to the Eastern Caribbean, based on a validated Sargassum transport model from the new source region in the equatorial Atlantic. This bulletin is released every 2 months and also provides comment on sector-specific implications for tourism and fisheries stakeholders and provides summaries and links to the latest Sargassum papers and innovations.

Commercial Sargassum early warning systems include:

- I-Sea and Hydro-cote Sargassum tracking on the Lesser Antilles: using satellite data from medium (300-1000 m resolution; MODIS/VIIRS/Sentinal-3) to high-resolution (10-60 m resolution; Sentinal2) to allow for daily monitoring and weekly reports of Sargassum rafts at sea. They provide 4-day stranding forecasts for the islands and publish stranding bulletins. In case a risk is detected, an alert is issued and notified directly to the customers smartphone to allow for fast an adequate decisions.

- SAMtool [58]: Key operational tool developed by a consortium consisting of Collecte Localisation Satellites (CLS), Météo France, I-Sea, Nova Blue Environment (NBE) and the European Space Agency (ESA). Sargassum rafts are detected daily using a unique combination of 6 Earth Observation ocean color satellite instruments (MODIS-Aqua, Sentinel 3A \& 3B at 300m resolution, Sentinel 2A \& 2B, Landsat-8 - 20m resolution). An example of a prediction is shown in Figure 5 . Sargassum drifts are forecasted up to 5 days based on a Lagrangian advection model that combines surface current and wind models with Sargassum detections and uses a probabilistic approach to predict where landings are likely to occur. An online interface provides access to the satellite detection products, drift results, as well as weather \& oceanographic conditions. An export function makes it possible to create PDF situation bulletins. Situation \& forecast bulletins prepared by their expert analysts and tailored to the end-user's specific needs are available upon request. Moreover, over 50 end-users representing the Caribbean basin including Aruba, Bonaire, Curaçao, and St. Maarten have received credentials to test the SAMtool web platform for free from March 2020 up to the end of 2020. Currently STINAPA is using a trial version of the SAMtool. The costs are USD 2.000 per month which could be shared between the $A B C$ Islands. In order to efficiently use resources, it would be advisable to cooperate with the authorities on Curaçao and possibly on Aruba in utilizing the SAMtool.

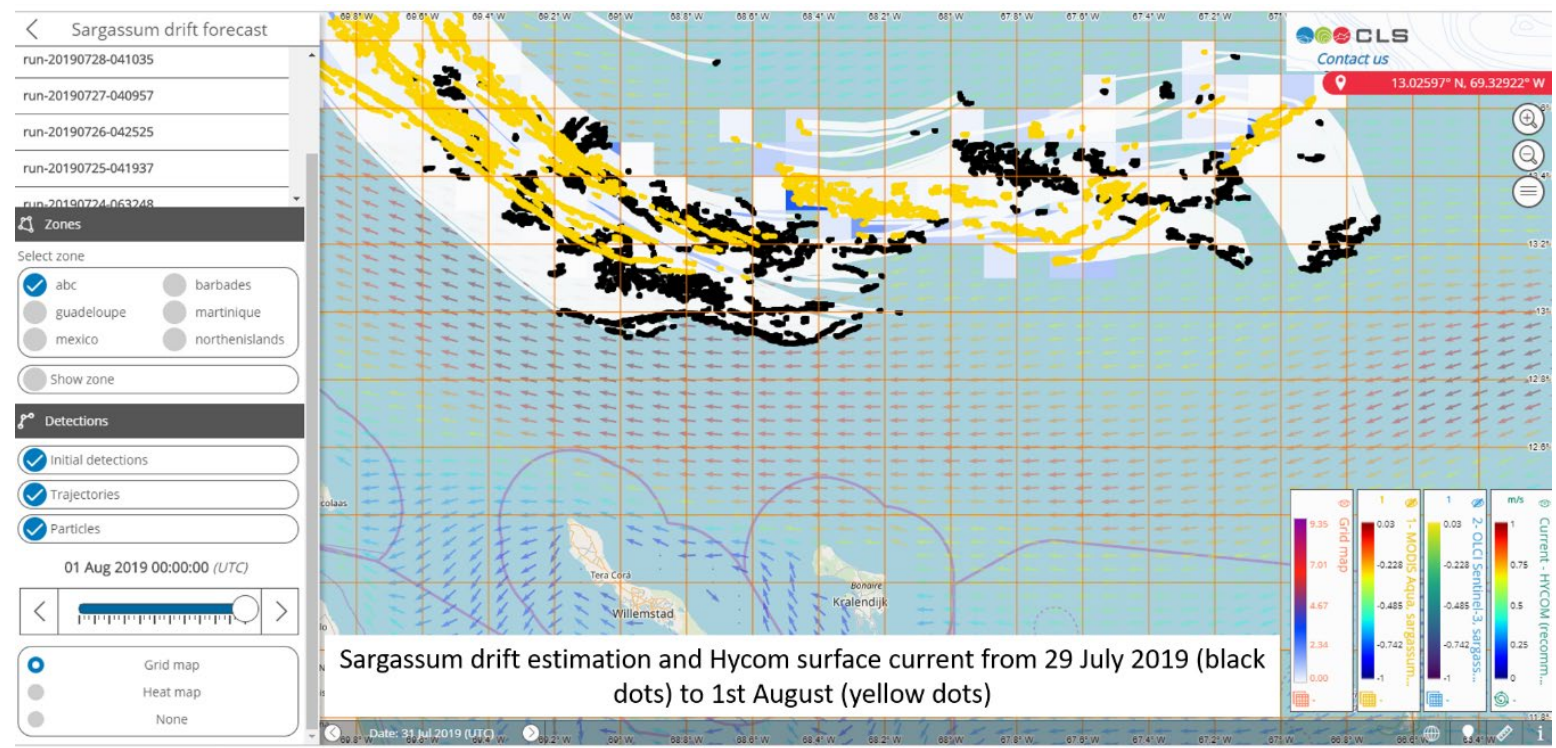

Figure 5 SAMtool Sargassum drift prediction from 29 July 2019 (black dots) to 1 August 2019 (yellow dots) prepared for STINAPA park, Bonaire. () SAMtool, CLS, 2020, with permission 
Tjiong (2020) [59] investigated the effectiveness and limitations of using the freely available Sentinel2 satellite platform with up to $10 \mathrm{~m}$ spatial resolution and five days revisit time, to map Sargassum on the open sea, the shallow coastal waters and the east coast of Bonaire. Whereas the Sentinel-2 platform was capable of effectively mapping Sargassum in the open ocean and in shallow coastal waters, Sargassum on land could not be classified with high accuracy, due to various degree in organic decomposition and water content of the Sargassum leading to a larger variation in spectral reflectance and subsequent ambiguity in the training samples and possibly also due to mixed pixels [59].

\subsubsection{Collection of pelagic Sargassum at sea}

As pelagic Sargassum rafts provide essential habitats for a wide range of organisms and serve as hotspots for biodiversity and productivity in otherwise substrate-poor, low-nutrient open-ocean waters, it is preferred to harvest Sargassum rafts that are nearshore. First because nearshore Sargassum rafts are more likely to strand on the coast when not harvested, so that associated fauna would be lost anyway, and secondly because nearshore harvesting of Sargassum increases the chances of preventing Sargassum biomass to beach on the nearby shore, thus minimizing environmental impact on critical coastal habitats. The current state of the art for harvesting floating Sargassum consists of small-scale dredging and mowing equipment (water bulldozer) which removes the floating seaweed from the surface of the water with the help of catch arms and conveyor belts (Fig. 6). Examples of these small vessels are the "Ocean cleaner" ships [60]. The drained seaweed is then dumped in a floating transport container. Such containers have a capacity to harvest 10 to 20 $\mathrm{m}^{3}$. These containers are then unloaded ashore using a crane or conveyor belt. If the Sargassum is harvested close to the shore/disposal area, a production rate up to $1.000 \mathrm{~m}^{3} /$ day may be achieved. This equipment is not suitable to operate under rough open water conditions, but is very handy under calm sea conditions close to the shore [61]. This type of ship has been used in Mexico for many years to collect Sargassum from area's impacted coastal areas.
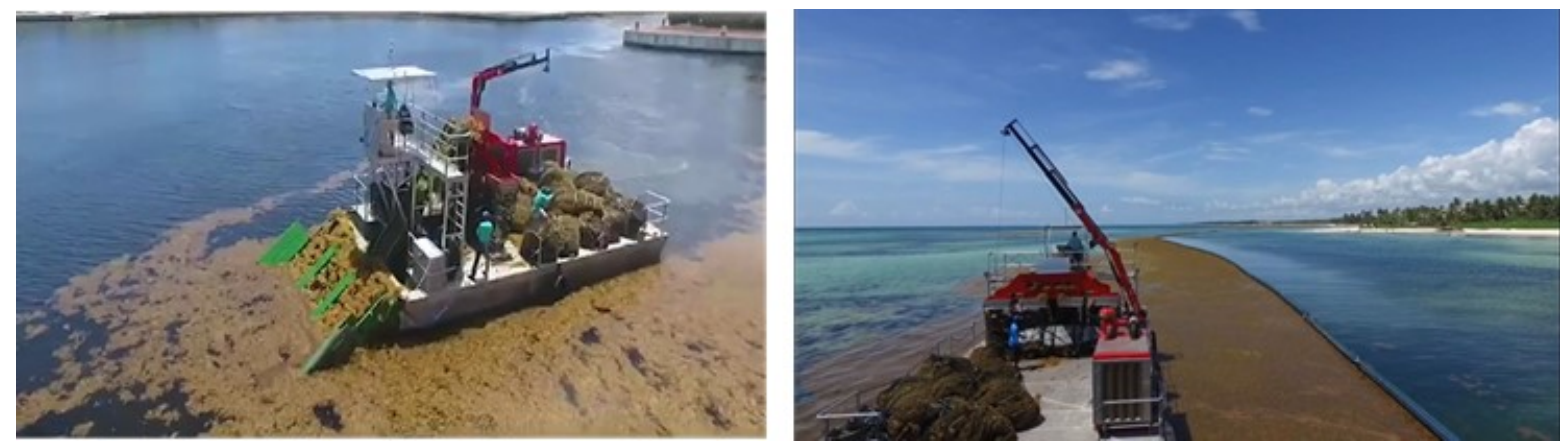

Figure 6 Sargassum harvesting at Punta Cana (Dominican Republic). The Sargassum is kept behind barriers near the coast, and collected by dedicated ships. The ship in the picture collects up to 100 tons (fresh weight) of biomass per day. Source: www. algeanova.com

For large scale harvesting in open waters, bigger ships with stabilizers are needed that can navigate offshore and perform on board pre-processing of Sargassum biomass. Due to the large water content of seaweeds (up to $85 \%$ of the weight), it is important to (partially) dry the biomass to avoid decay and unwanted transport of large amounts of water on shipboard. As an example, the Dutch shipping company Damen Shipyards has recently announced a joint venture with the biotechnology company Van Maris to develop a prototype ship for Sargassum harvesting and processing (Fig. 7). Damen will develop a dedicated solution based on a custom MultiCat for harvesting, pre-processing, and transportation of Sargassum. Maris brings experience in scalable pre-processing and anaerobic conversion technology. With this, the consortium is assessing the viability of turning the Sargassum into methane for energy purposes. The solution proposed is based on the harvesting of the biomass and directly ensile the biomass so it can be stored. Once on shore, the Sargassum could be used for anaerobic digestion using technology developed by Van Maris. This approach is being studied in the French Caribbean. 


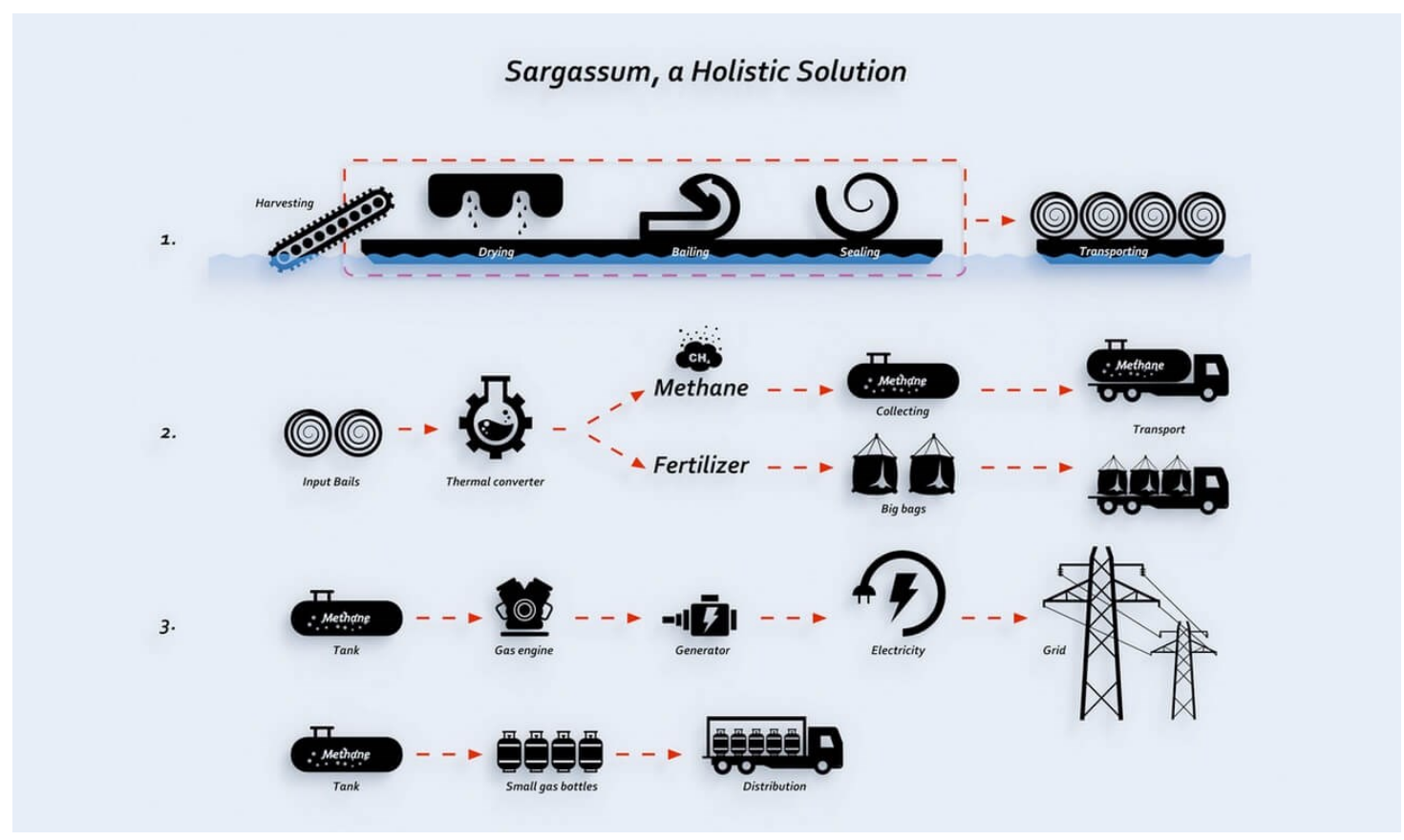

Figure 7 Description of the Damen/Van Maris value chain for Sargassum harvesting, processing and valorisation [62]. Source: Damen Shipyards

On Bonaire, there is a need for easily-deployed, cleanable, robust booms to prevent Sargassum from floating above critical habitats (i.e. seagrass beds, coral reefs) (Fig. 8) and to direct Sargassum towards suitable sites for harvest. Moreover, there is need for a MultiCat that can harvest and process Sargassum nearshore in bays, lagoons, and shallow coastal zones, the coastal areas most severely impacted by Sargassum influxes.

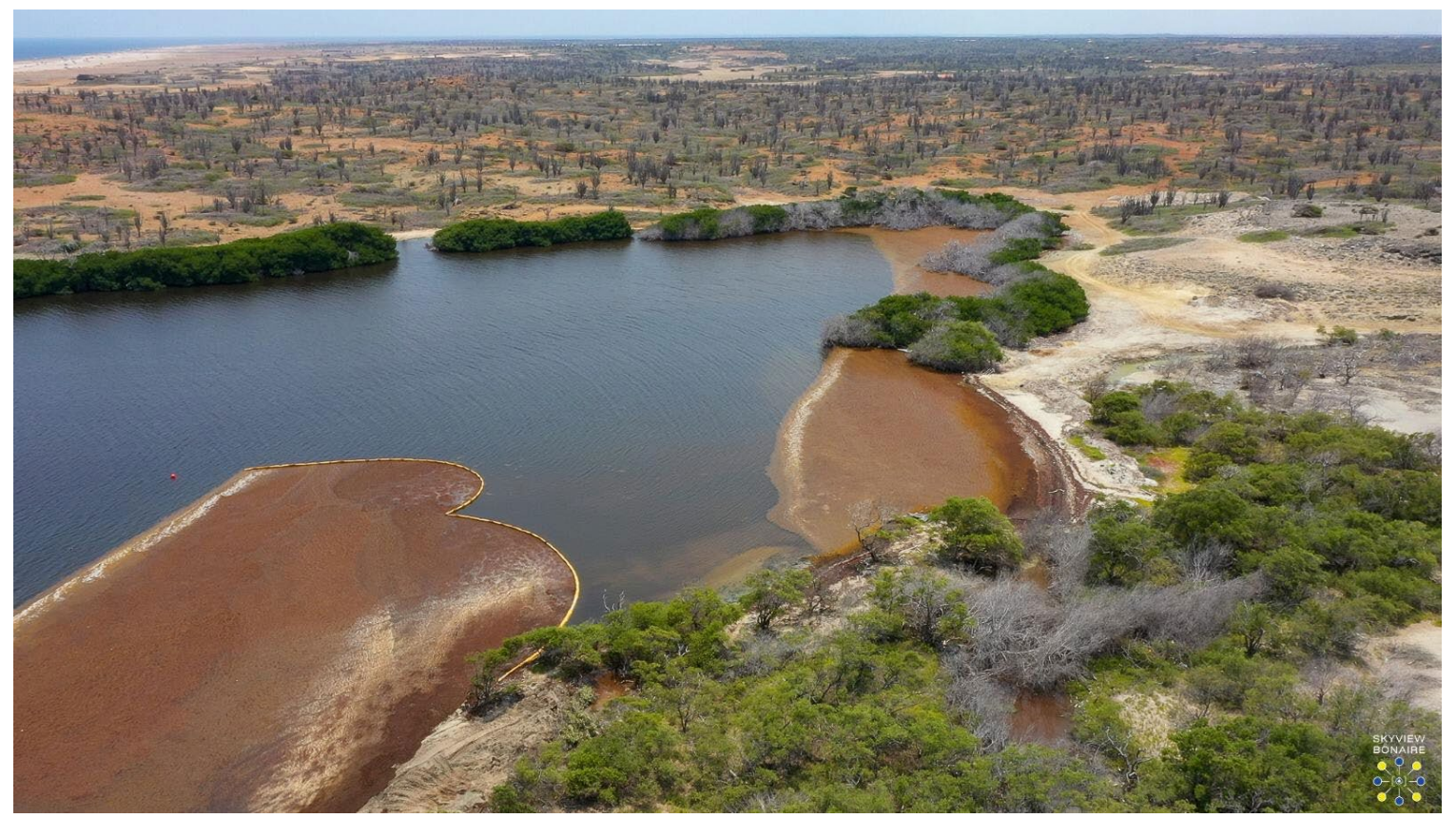

Figure 8 Picture of a boom collecting Sargassum at Lagun, Bonaire (Photo credit: Skyview Bonaire)

In Mexico there are developments also being made towards Sargassum harvesting. Because of the huge negative impact of the Sargassum landings on the tourism in areas of the Caribbean, the Mexican government has invested in Sargassum-harvesting ships, that are operated by the navy [63]. These new ships are $15 \mathrm{~m}$ long and have a capacity of 20 tons per day of biomass (it is not mentioned if it is dry or wet weight). There are currently three of these new ships in operation in different parts of the Mexican Caribbean coast and more are being constructed, according to the local press. These 
bigger ships are an addition to the small "water bulldozers" that are also active in the area for harvesting close to the shore.

\subsubsection{Removal and disposal of beached Sargassum}

STINAPA Bonaire has organized massive clean-ups of Lac Bay with the help of volunteers and is currently experimenting with booms. In 2018 a draft for a Civil Service Checklist (Ambtelijk Bestuurlijke Checklist (ABC Card)) has been made for emergency services (fire department, police, Area Health Authority and Public Entity): a detailed work plan on how to assist STINAPA Bonaire during a Sargassum disaster including responsibilities and contact details. However, criteria on when a massive Sargassum influx is qualified as a disaster and becomes the responsibility of the Public entity are not clear, yet urgently needed. Other missing information is an inventory of heavy equipment on island (type, name contractor) and identifying whether suitable or not and identifying Sargassum disposal sites. As a result, representatives of DRO OLB and STINAPA, are in the process of developing a Sargassum Response Plan, to arrive at an adequate and structural approach aimed at efficiently and effectively removing and responsibly disposing of Sargassum on Bonaire. This should be done with care for habitats and biodiversity, facilitating sustainable use of local ecosystems by various stakeholders, and ensuring public health is not threatened. Crucial for this plan to succeed is the commitment of a party that is to be responsible for when, where, how and on what scale to intervene. 


\section{Storage and valorisation of pelagic Sargassum biomass}

\subsection{Storage of pelagic Sargassum}

The methods used for stabilisation and storage of the Sargassum biomass will have an impact on the further processing into products. As seaweed biomasses contain a high amount of water (up to $85 \%$ of the fresh weight), the first steps on the valorisation process may include a de-watering methodology. The water content in the biomass can be reduced by drying using hot air, sunlight or pressing using mechanical methods. Dried Sargassum can be stored in cool, dark conditions for some time. However, dewatering and drying techniques have a considerable energy demand. The removal of water from the algal biomass by evaporation is very energy-intensive, requiring an energy input of $\sim 2.6 \mathrm{MJ} \cdot \mathrm{kg}^{-1}$ to heat water from 20 to $100{ }^{\circ} \mathrm{C}$ and evaporate it at atmospheric pressure [64]. Dewatering (the mechanical removal of water) generally uses less energy than evaporation, and thus it would appear preferable to minimise the water content of the harvested algae prior to drying. Although coal-fired driers have been used in Ireland for the production of seaweed-meal products [65], the use of fossil fuels to dry seaweed will be costly, have a negative energy balance, and produce unwanted greenhouse gases $[66,67]$. However, the cost of conventional drying could be reduced if 'waste' heat is available from power generation or large-scale refrigeration plant.

Sun-drying is the main method for drying seaweed $[68,69,70]$. Clearly this approach does not require fossil fuel energy but is both weather- and volume-dependent. Sun-drying in tropical locations may take 2-3 days in sunny weather but could take up to seven days during rainy seasons [70]. Despite these limitations, solar methods are the least expensive drying option [71], but large areas are required as only around $100 \mathrm{~g}$ of dry matter can be produced from each square metre of surface [72]. Solar drying can cause considerable denaturisation of organic compounds in seaweed $[73,74,75,76]$. Freeze drying tends to cause less damage to organic materials, but is more expensive than solar or conventional drying, and is typically used for products such as premium instant coffee to give better flavour $[77,78]$. Freeze drying has been used for algae, particularly microalgae, such as Dunaliella, but is considered too expensive for the large-scale commercial recovery of algae, and its use is confined primarily to research and some high-value seaweed products $[75,76,79,80]$.

To store Sargassum for a longer period, ensiling can be used with low energy costs and low energy losses in the biomass. Ensiling is a procedure commonly used to store agricultural products (such as grasses) during the winter seasons, and it can be used for seaweed storage as well. During ensiling wet biomass is stored under anaerobic conditions where lactic acid fermentation of watersoluble carbohydrates in the biomass occurs, causing a reduction in $\mathrm{pH}$ that preservers the wet biomass. Due to the special characteristics of the seaweed biomass, several challenges have been identified that impact the effectiveness seaweed silage. These challenges have been summarized by Milledge and Manee [81] in a recent review publication, and consist of:

- High moisture content (water activity of seaweed: 0.974-0.979)

- High ash content

- High buffering capacity potential due to high anion content, that makes the pH drop to be more difficult to reach

- Varied cell wall structure that can be very different from terrestrial vascular plants

- Composition of seaweed can be very different from fodder crops, with different carbohydrates (alginates, laminarin, etc.) and compounds that are rarely found, or found in much lower concentrations, in terrestrial vascular plants, such as phloroglucinol, fucans (sulphated carbohydrates), and highly unsaturated long-chain fatty acids.

Because seaweeds are compositionally diverse, specific strategies for ensiling of each type of them need to be determined. In the case of Sargassum species, successful ensiling with reusable plastic bags or barrels has been reported in literature. As an example, S. muticum silage has been described by Milledge and Harvey [82]. In their study, the Sargassum biomass was ensiled in vacuum-sealed composite bags and stored at $20^{\circ} \mathrm{C}$ for 60 days. The major effect that was observed on the biomass 
was a significant reduction of salt in the ensiled biomass with a lower reduction when the biomass was chopped before ensiling. This loss of salts could be beneficial for the application of the ensiled material for anaerobic digestion, as high salt concentrations inhibit the anaerobic digestion processes. The ensiled biomass did not show reduced properties during anaerobic digestion tests compared to the fresh biomass, resulting in $0.06-0.11 \mathrm{~L} \mathrm{CH}_{4} / \mathrm{g}$ volatile solids (VS). This is a relatively low yield of methane, but typical for brown seaweeds. In the next chapter, more information of anaerobic digestion of seaweeds is presented.

\subsection{Valorisation of pelagic Sargassum biomass}

\subsubsection{Chemical composition and uses of biomass}

Seaweeds are currently seen as interesting feedstock for production of fuels and chemicals by biological or chemical conversion of sugars or other components in the biomass, or as a source of components with a high economic value, such as antibiotics or anti-inflammatory agents. Brown seaweeds are usually rich in carbohydrates (30-60\% of the dry matter) and contain a relatively low amount of protein (5-20\% of the dry matter) compared to other types of seaweed $[83,84]$, which make them less interesting for direct applications in food, and more suitable as a feedstock for fermentation, anaerobic digestion or chemical conversions. Typical composition of Sargassum biomass is shown in Table 1.

Table 1 Chemical composition of Sargassum from different parts of the world. Adapted

\begin{tabular}{|c|c|c|c|c|}
\hline \multicolumn{5}{|c|}{ omponent ( $\%$ of dry weight) } \\
\hline & Total carbohydrates & Lipids & Crude protein/amino acids & Ash \\
\hline S. muticum (UK) [86] & $35.1 *$ & - & 3 & \\
\hline S. muticum (Philippines) [87] & $51.1^{* *}$ & 0.7 & 10.2 & 26.2 \\
\hline S. wightii (India) [88] & $74-88^{* * *}$ & $2-5$ & $4-6$ & $25-32$ \\
\hline S. vulgare (Brazil) & 67.8 & 0.5 & 15.8 & 14.2 \\
\hline $\begin{array}{l}\text { S. platycarpum (Virgin island \& } \\
\text { Puerto Rico) }\end{array}$ & 48.7 & 0.4 & 6.9 & 36.8 \\
\hline S. mangarevense (Tahiti) & $42.8 \#$ & 3.4 & 13.2 & 30.6 \\
\hline
\end{tabular}

*Includes $16.9 \%$ of alginic acid, $7.7 \%$ mannitol, $8 \%$ fucans; ** Includes $5 \%$ of mannitol; ***Includes $24-33 \%$ alginic acid; \#Total fibre.

The diverse chemical composition of seaweeds, and of Sargassum, make them a very versatile feedstock. For example, carbohydrate polymers like alginates can be used as a food ingredient, but also components of biomaterials. There are many applications described for seaweeds over the years. A very detailed overview of the uses of Sargassum in current applications has been reported recently by Desrochers and colleagues in their "Sargassum uses guide" [89]. This guide is very complete, and we have used it as a reference in several sections of this report. A scheme of possible value chains for Sargassum harvesting and valorisation is show in Figure 9. Examples of products being commercialized from Sargassum harvested in Mexico and Barbados are shown in Figure 10. 


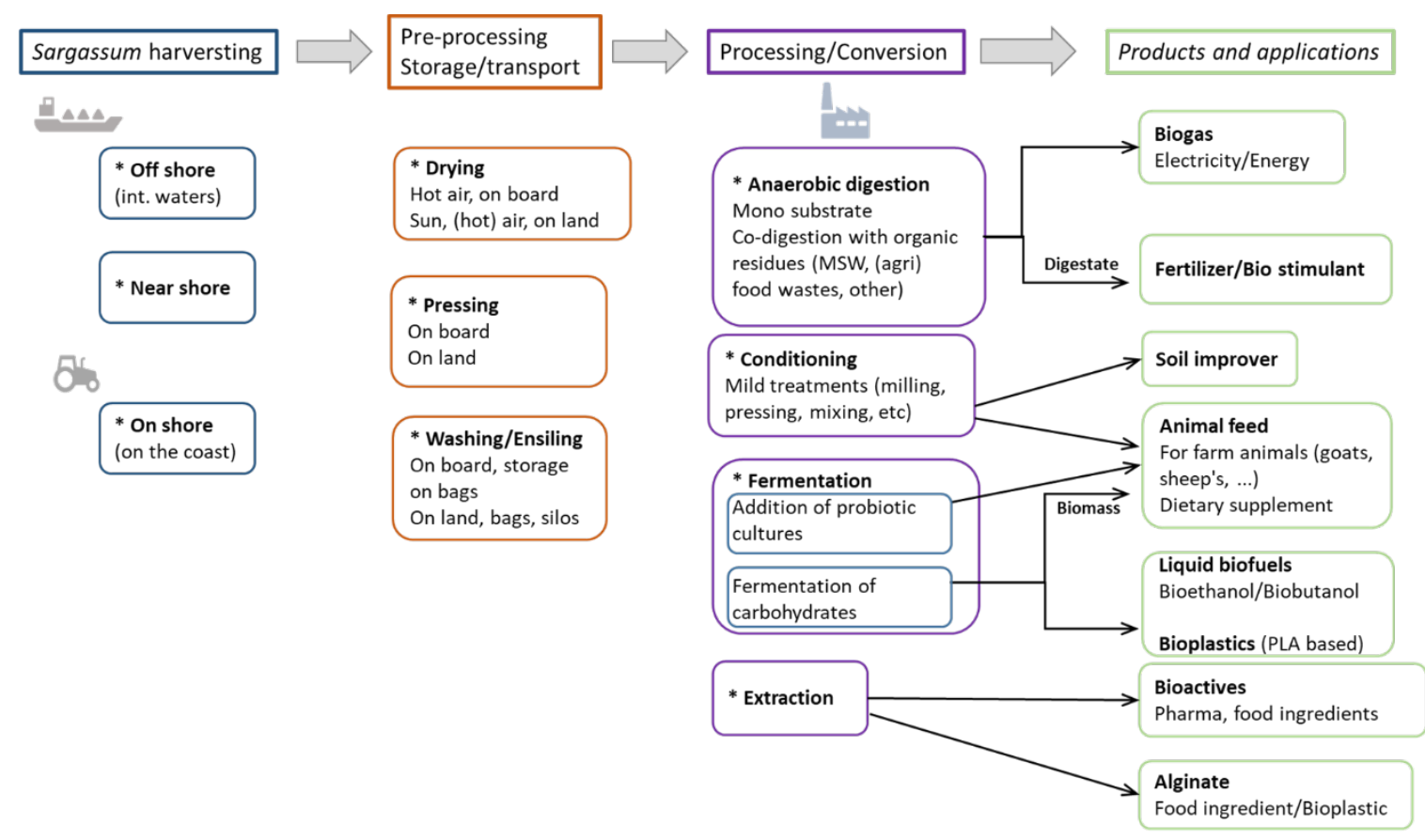

Figure 9 Scheme of value chains for Sargassum valorisation

The uses of seaweeds for the production of energy, in the form of liquid fuels (bioethanol, biobutanol) or of biogas by anaerobic digestion (AD) are currently being studied by many research groups in the world $[90,91]$. Brown seaweeds, that include Sargassum species, appear to be the most appropriate type of seaweeds for these applications. They can contain up to $60 \%$ dry weight content of fermentable sugars in their biomass, mostly in the form of laminarin, a glucose polymer that can be extracted from the biomass using mild conditions, or as the soluble sugar mannitol. Many examples are found in literature on the use of brown seaweeds or of Sargassum in particular for fermentative production of bioethanol $[92,93]$ or biobutanol $[94,95]$. Brown seaweeds are, in general, possible feedstocks for anaerobic digestion, alone [96] or in combination with other substrates [97].

In the context of valorisation of Sargassum biomass in the Caribbean islands and Mexico, the most studied options concern uses as feedstock for anaerobic digestion or as fertilizer, sometimes in combined processes. Most islands are dependent on imports for supply of energy and fertilizers. In most cases, the electricity generation in the islands rely on diesel-based generators. As an example, In the developments towards a more sustainable and circular economy in the islands, generation of energy and production of fertilizers could play a significant role.

\section{Anaerobic digestion}

Anaerobic digestion (AD) is a biological process in which anaerobic microorganisms transform organic biomasses into biomethane through several steps. Methane and power produced in an AD plant can be used to replace energy derived from fossil fuels, therefore reducing greenhouse gas (GHG) emissions. The energy generated from AD plants using (animal) wastes, energy crops, or sewage as feedstocks is renewable, and can be used in the islands, reducing imports of fossil fuels, enhancing waste management and generating new income for farmers or the community.

There are many studies on anaerobic digestion of seaweeds. Brown seaweeds are considered a good substrate for anaerobic digestion, as they usually have high content of fermentable components, like carbohydrates. For the specific case of Sargassum from the Caribbean there are few reports that show data on experimental tests on anaerobic digestion, and the studies found refer to laboratory scale experiments. Because of the composition of the seaweeds in general, and Sargassum in particular, there are important aspects to take into account for their use as substrate for biological conversion processes, including anaerobic digestion, that have been described by several authors $[85,98]$ :

- Harvesting and variation in chemical composition. The harvesting conditions will determine the content of other organic and inorganic compounds in the biomass. Attention needs to be paid with respect to marine organisms, plastics, sand, or other pollutants, that require procedures to remove 
them prior to further processing. The Sargassum blooms are seasonal, appearing at difficult to predict times and quantities. This makes it necessary to develop tailor-made valorisation chains that take into account the local aspects of Sargassum influxes. In addition, the chemical composition of the biomass might show variations from season to season, or location of harvesting. For anaerobic digestion processes, these variations are not a big problem as the most components of the biomass are used. But for other processes based on specific components (for example, fermentation of sugars, extraction of alginates, etc.), this needs to be taken into account.

- High content of cations, sulphur and salts. In Sargassum, high metal ion content, sulphur and salt has been reported, which is reflected in the high content in ash (Table 3.1). Accumulation of salts in the $A D$ process, especially cationic elements such as $\mathrm{Mg}, \mathrm{Ca}, \mathrm{Fe}, \mathrm{Na}, \mathrm{K}$ and $\mathrm{Al}$, could inhibit microbial cultures, reducing the methane yields, and result in fouling of the reactor. A similar effect is observed for sulphur, that is present in relatively high concentrations in Sargassum. This component, at high levels, can inhibit microbial growth, causing reduction of product yields and also could be converted into hydrogen sulphide, that is a toxic and corrosive gas. High salt concentrations, above $10 \mathrm{~g} / \mathrm{L}$, have been reported to inhibit anaerobic digestion of several seaweed species. Ensiling and pre-treatment methods to de-salt the biomass could remediate, at least partially, the drawbacks generated by these components.

- Low C:N ratio. For a successful AD to methane, optimal carbon to nitrogen ( $\mathrm{C}: \mathrm{N})$ ratios in the feedstock range from 20-30:1. At C:N ratios below 20:1, the product profile is shifted towards volatile fatty acids, and excess nitrogen promotes ammonia formation and toxicity. The C: $\mathrm{N}$ ratio of Sargassum spp. varies from 8 to 22 , due to the rich elemental composition of $12-40 \%$ carbon and 0.6-2.0\% nitrogen. To amend the $\mathrm{C}: \mathrm{N}$ ratio to 20-30:1 for optimum bioconversion efficiency and biogas output, co-digestion of Sargassum with another feedstock has been explored successfully (see Table 2).

- Insoluble fibres. Brown seaweeds are rich in insoluble fibres, such as alginates, which reduce the concentration of available substrates for the AD process. This results in this group of seaweeds showing lower biomethane production yields (120-190 mL/g VS), when compared to other species such as Gracilaria spp. (280-400 mL/g VS) [99] and P. palmata (279 mL/g VS). Low methanation yields of S. muticum were also reported by Milledge and Harvey [82] who recovered the maximum methane yield of $110 \mathrm{~mL} / \mathrm{g}$ VS or $25 \%$ of the theoretical methane potential (TMP).

- Aromatic compounds. The content in aromatic components, mostly polyphenols, in seaweeds is relatively high. These components show antioxidant and antimicrobial activities and constitute important potential products to be extracted and commercialised. However, these compounds show inhibitory effect on the growth of the AD organisms. For S. muticum, $19 \mathrm{~g}$ polyphenols/kg total solids have been reported.

To mitigate the negative effects of the above-mentioned factors, several strategies have been described, including adjustment of the storage or pre-treatment methods to reduce the content in salts or other potentially toxic components. The pre-treatments can be mechanical/physical (including chopping, pressing, ball milling, maceration), thermal (autoclaving, hydrothermal treatments), thermochemical (acid- or alkali-based treatments) or biological (by addition of fungi or enzymes to the biomass).

The co-digestion of the seaweed biomass with other organic wastes has a good potential to be used for increasing the $\mathrm{C}: \mathrm{N}$ ratio in the feedstock and reducing the concentration of toxic components in the mixed feedstock, increasing the yields of methane. Examples of results available in the literature on $A D$ yields are shown in Table 2. A recent study of valorisation routes for pelagic Sargassum in Grenada includes small scale tests on anaerobic digestion of seaweed samples to evaluate the biogas potential and use of residue as fertilizer [99]. 
Table 2 Examples of production of methane from brown seaweeds by anaerobic digestion alone or mixed with wastes. Modified from [85]. VS: volatile solids.

\begin{tabular}{|c|c|c|c|c|}
\hline Seaweed & Co-substrate & C:N-ratio & $\mathrm{CH}_{4}$ yield & Summary \\
\hline $\begin{array}{l}\text { Sargassum sp. from } \\
\text { Mexican Caribbean }\end{array}$ & - & $20: 5$ & $81-104 \mathrm{~mL} / \mathrm{g}$ VS & $\begin{array}{l}\text { - Pre-treatment using fungi gave highest } \\
\text { yields }\end{array}$ \\
\hline $\begin{array}{l}\text { Sargassum sp. } \\
{[100]}\end{array}$ & - & - & $541 \mathrm{~mL} / \mathrm{g}$ VS & $\begin{array}{l}\text { - Hythane process with } 2.5 \mathrm{~g} / \mathrm{L} \text { biomass } \\
\text { - Pre-treatment was autoclaving } 121^{\circ} \mathrm{C} \\
\text { and } 1 \text { bar for } 15 \mathrm{~min}, \text { which is not } \\
\text { standard }\end{array}$ \\
\hline Sargassum sp. & $\begin{array}{l}\text { Glycerol / waste } \\
\text { frying oil }\end{array}$ & - & $\begin{array}{l}157-283 \mathrm{~mL} / \mathrm{g} \\
\text { COD }\end{array}$ & $\begin{array}{l}\text { - Mono-digestion of Sargassum reached } \\
181 \mathrm{~mL} / \mathrm{g} \text { COD ( } 52 \% \text { of TMP) } \\
\text { - Co-substrates show high C:N ratio }\end{array}$ \\
\hline $\begin{array}{l}\text { Saccharina latissima } \\
\text { / Laminaria digitata }\end{array}$ & Dairy slurry & $15.7-23.4$ & $232-252 \mathrm{~mL} / \mathrm{g}$ VS & $\begin{array}{l}\text { - Dairy slurry reduced the C:N ratio of } \\
\text { the seaweed } \\
\text { - Feedstock ratio of } 66: 33 \text { seaweed to } \\
\text { slurry exhibited highest yield }\end{array}$ \\
\hline Laminaria digitata & Green peas & - & $275-375 \mathrm{~mL} / \mathrm{g}$ VS & $\begin{array}{l}\text { - Addition of seaweed decreased the } \\
\text { yields of methane compared to mono- } \\
\text { digestion of peas } \\
\text { - Low OLR support AD of a mixed } \\
\text { feedstock with } 35 \% \text { of seaweed }\end{array}$ \\
\hline
\end{tabular}

\section{Uses in agriculture}

In the recent report "Sargassum Uses Guide: A resource for Caribbean researchers, entrepreneurs and policy makers" published by the Centre for Resource Management and Environmental Studies (CERMES), University of the West Indies, Barbados [89], a very complete overview is given on the uses of Sargassum.

The applications in agriculture for improving crop production are very wide, including uses as fertilizers, compost, bio-stimulants, bio-elicitors, soil conditioners or soil amendments, mulch, biopesticides and as growth substrate for plants. Seaweeds have been traditionally used is in agriculture in coastal areas or in areas with infertile soils since long time [101,102]. The current interest in the uses of seaweeds in agriculture is related to the growing interest in organic farming and agriculture, where the aim is to produce high quality food or feed while respecting the environment and maintaining soil fertility through optimal use of resources. Organic agriculture promotes the recycling of nutrients to minimize the quantity of nutrients imported to the farm. If any product is to be used to maintain soil fertility it should be of biological origin, as organic matter is a key for maintaining fertility in the soil-plant system. The demand for organic products in local and global markets is growing and is likely to gain significance in the future. However, organic fertilizer of sufficient quality to be used in this type of production is currently quite expensive, in spite of the increase in organic livestock farming. In coastal areas the seaweed that reaches the coast by the action of tides and wind washes up on beaches has been used for centuries as natural fertilizer. In the case of the Caribbean islands, where the soils require addition of fertilizer and that suffer from erosion, the uses of locally produced or harvested seaweed is particularly relevant, and applications in agriculture represent a potential use for the Sargassum biomass or for the digestate resulting from its anaerobic digestion.

There are many publications and reports on the positive effects of seaweeds on improving soil structure and providing it with trace elements and growth activators, and seaweed-based fertilizers, bio-stimulants, bio-elicitors and soil conditioners are being commercialized by companies all over the world $[89,102,103,104]$. Examples of beneficial effects of Sargassum extracts on cultivation of crops are numerous, and include rice [105], wheat [106] and chickpea [107]. In areas where seaweed becomes a waste product due to eutrophication, such as is the case of the Sargassum in the Caribbean region or the green tides in Brittany (composed of Ulva sp.), initiatives have been carried out to add value to it by looking to composting, alone or in combination with other wastes, such as fish waste or agricultural by-products, as an economically and environmentally viable biotechnology solution. This would reduce the volume of seaweed on beaches and take advantage of its rich nutritive 
elements, particularly potassium, calcium and magnesium. Recent publications from the Texas State University describe field trials on the use of Sargassum for composting with organic wastes such as cafeteria food waste, locally produced wood chips and fish waste $[108,109]$. From these trials, the final compost products were of equal or higher quality compared to current compost standards. As such, these studies show that the composting and waste management industries can use Sargassum as a feedstock to create a desirable compost product that could be used in the horticulture and agriculture industries, while helping to manage this invasive species.

The digestate resulting from anaerobic digestion of seaweeds has been studied for uses as fertilizer. In a recent report, Thompson et al. studied the possibilities of using digestate from AD of Sargassum biomass in Barbados [85]. The utilisation of the nutrient-rich solid digestate after anaerobic digestion of Sargassum could contribute to supplying the island with fertilizers, which are currently imported. A similar study has been published for the evaluation of Sargassum uses in Grenada [99], where the imports of fertilizers have been reported to be 349 tons during 2016.

\section{Uses in animal feed}

Seaweeds, as such, or in the form of seaweed meals, have been used as feed or feed supplement for livestock and aquaculture for a long time in coastal areas. In these areas, sheep, cattle and horses graze seaweed on the shore as dietary supplement. Seaweeds and seaweed meals are usually mixed with the diet of the animals at certain percentages, depending on the type of seaweed and the nutrient requirements of the type of livestock. There are many reports on the use of seaweed meals from tropical species as Sargassum, Macrocystis or Enteromorpha in feed for goats, chicken and sheep in Mexico with beneficial effects compared to control diets without seaweed [112]. Supplementation of the diets with seaweeds or seaweed meals have been reported to have significant positive effects on the health of many types of animals, although there are limits to the quantity of seaweed to be used in the diets. These limitations are related to the high content in salt, metals and on undigestible fibres in seaweeds. In Table 3, an overview of reported uses of seaweeds in feed is given.

Table 3 Recommended maximum seaweed amounts in the diet of animals to achieve beneficial results. Values are in \% dry weight (DW) of total feed intake. Data are based on several different species of seaweed. Modified from Desrochers et al. [89]

\begin{tabular}{lc}
$\begin{array}{lc}\text { Animal } \\
\text { Cattle }\end{array}$ & $\begin{array}{c}\text { Seaweed amount } \\
\text { (\% DW in total feed) }\end{array}$ \\
\hline Sheep*, Goats & $2-5$ \\
\hline Pigs & $1-2$ \\
\hline Chicken & $1-5$ \\
\hline Ducks & $12-15$ \\
\hline Fish** & $5-10$ \\
\hline Shrimps & $2-5$ \\
\hline Molluscs*** & $10-30$ (\% of body weight) \\
*Studies using Sargassum in Mexico [113] & \\
**Fish: $5 \%$ Sargassum spp. fed to supplement sex-reversed tilapia diet; $10 \%$ Ulva rigida fed to Senegalese sole diets. 5-10\% seaweed meal was \\
also reported for different fish species by Rajauria [114]. \\
***Molluscs: fresh seaweed is a preferred feed of molluscs during a period of their life cycle
\end{tabular}

For all uses of pelagic Sargassum (or any other seaweed) related to the food chain, there are important considerations to be made with regard to food safety issues. It is important to be aware of:

- Potentially high levels of toxins (such as inorganic arsenic, other heavy metals, pollutants and certain compounds found in high concentrations).

- The high concentration of salts, including Na or K.

For food safety reason, in the next section, compound analysis have been performed by TNO and by WFSR on different Sargassum samples collected in 2020. In particular heavy metals and (inorganic) 
arsenic have potential toxic effects and their content in the biomass may limit the applications due to regulations regarding the maximum levels of these. The analysis have been carried out using state-ofthe-art methods, and the difference between total and inorganic arsenic could be determined.
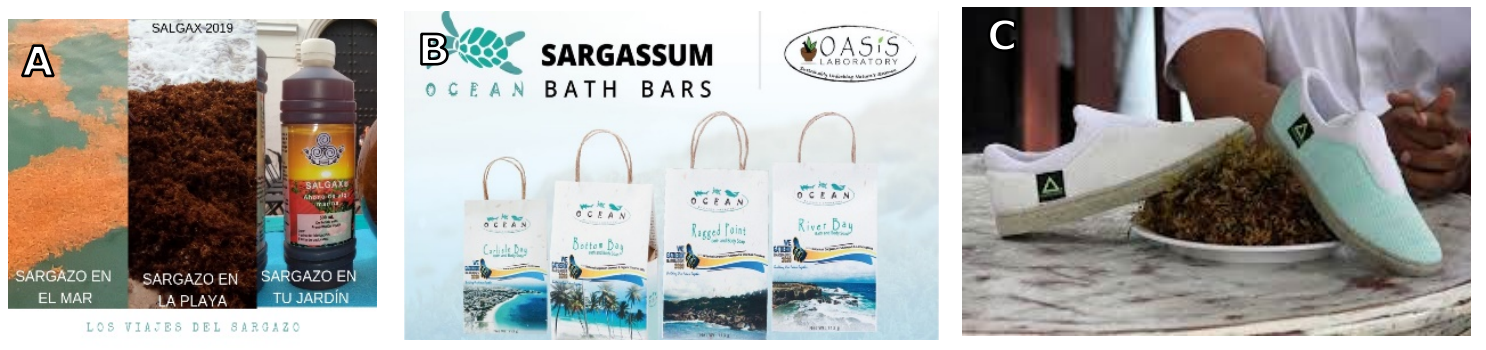

\section{Figure 10 Sargassum can be used in many different types of products. Examples of products from Sargassum that are being commercialised. A, Fertilizer (Salgax, Mexico [115]); B, Soaps (Oceans by Oasis, Barbados); C, Shoes (Renovare, Mexico [116])}

\section{Other uses}

The carbohydrate fraction of Sargassum biomass, as that of most brown seaweeds, is composed mainly of: (1) mannitol (0-10\% DW), an alcohol-sugar that is free in the cell and serves as an storage compound, (2) laminarin, a $\beta$-glucan polymer that is high soluble in water, cellulose as a part of cellwall, (3) fucoidan (8-9\% DW), a polysaccharide that contains sulphated fucose, and (4) alginate (or alginic acid) (17-45\% DW), a polymer of mannuronic and guluronic acids at different ratios. The total content in carbohydrates and the ratio between them is very variable, and depends on species, cultivation conditions and time of harvest. In this study we show literature data on chemical composition of Sargassum in Table 1 and data from analysis carried out by TNO and WFSR in Tables 5-7.

Various ingredients can be extracted from the organic fractions of seaweeds which find uses in the pharma- and nutraceuticals sectors, and biotechnology. The carbohydrate constituents, as mentioned above, include alginic acid and fucoidan, as well as other carbohydrates (laminarin, a starch-like molecule, and mannitol). Alginic acid is extensively used in the food industry as additive due to its gel-forming ability and behaviour in dispersions and emulsions [117]. Due to its properties, alginate can also be used in high-value applications (pharma and biotech), including cell immobilization and encapsulation [118]. Fucoidan has a wide range of applications (cosmetics, food additive, human and animal dietary supplement) thanks to both its bioactive and hydrocolloid properties [119]. The bioactivity of fucoidans includes antioxidant and anticoagulant uses, and varies with the technology used for its extraction [120].

Other bioactive components, such as polyphenolics and lipids, can also be found in brown seaweeds and are active as antimicrobial and antioxidant agents [121]. Extracts from Sargassum sp. have been found to have comparable therapeutic potency as synthetic chemical antibiotics to treat human microbial pathogens, e.g. Staphylococcus sp., Bacillus sp., E. coli, Salmonella sp.[122]. Interestingly, in the microbiome associated to Sargassum biomass collected at the coast of Barbados, microorganisms producing potential plastic-degrading enzymes have been reported recently [123].

\section{Uses in materials and for bioplastic production}

The high content in sugars and polymers make macroalgae potential feedstocks for production of biodegradable plastics by using two different routes:

- Extraction of the polysaccharides in the biomass and use them in materials or films. As an example, during the EU SEABIOPLAS project (2012-2015), films were produced from Ulva and Gracilaria biomasses by extracting the polymers using microwave technology. In the Caribbean region there are several initiatives by local and European industries that produce a range of products already. Examples are French Algopack [124] that commercialise granules to make materials based on brown 
seaweeds. Although Algopack focuses on cultivated brown seaweeds as feedstock, they are also active in the Caribbean region and utilize Sargassum as well. Other initiative is AlgaeNova [125], in the Dominican Republic, that is investigating the production of materials using mixed seaweeds with other materials. In Mexico, Abaplas [126] is a company already producing materials from recycled plastics, such as construction bricks and other materials for infrastructures, that include Sargassum as a component.

- Production of precursors for bioplastics by fermentation. The production of lactic acid, as precursor of the polymer polylactic acid (PLA), by fermentation of seaweed sugars has been achieved in the EU SEABIOPLAS project [127], and it is reported by some authors in literature. The production of polyhydroxyalkanoates (PHA) or polyhydroxybutyrate (PHB) from Sargassum biomass using fermentation at laboratory scale has also been described [128]. The fermentation of seaweed fractions in general needs to be studied in relation of the effect of the seaweed components such as salts or phenolics on the fermentation by microorganisms. It is expected that salts or other components could have a negative effect on the fermentation and detoxification steps would be needed.

\section{Thermochemical treatment for methane, oil or hydrochar}

SCW (Supercritical Water) gasification and its variations, such as HTL (hydro-thermal liquefaction) has been suggested as means to valorise seaweed. The technique relies on converting seaweed as wet feedstock to either gas (methane or hydrogen, depending on the conditions) or an oil. At supercritical condition, the water becomes very acidic and non-polar thus greatly accelerating reactions. As the reaction is in water, all forms of wet seaweed, ensiled or not, could be used in this process. However, the reaction is difficult to perform continuous and only sparse reports have been published for continuous operation $[146,157]$.

TNO is project partner in a new EFRO project aiming at SCW conversion of seaweed and seaweed residues. This project will start in the near future. Seaweed plagues such as Sargassum are considered as raw materials. The advantage of SCW is that is can be done on a stranded asses at sea, thus alleviating the transport logistics to land. Existing natural gas infrastructure can also be used. Another option is the milder form of this technology to produce hydrochar [159]. It is a soil supplement and or peat replacement and can also use the wet seaweed in all forms to be processed. The application of this technology for Sargassum biomass has not been reported yet.

\section{Other uses}

Uses of Sargassum for diverse products are described in the CERMES report (2020) [89]. Interesting uses of seaweed polymers (especially alginates and related polymers) in textile production are being developed all over the world with the goal to produce biodegradable and green clothing. Shoes using Sargassum in the soles are being commercialized by the Mexican company Renovare [116] (Fig. 10).

\subsubsection{Chemical analysis of Sargassum collected in 2020 in Bonaire, St. Maarten, Florida \& Mexico}

Seaweeds are known to accumulate heavy metals, notably cadmium and arsenic [129], and iodine. Element concentrations in Sargassum have shown to vary with time and location of harvest [130]. The heavy metal levels in Sargassum are a concern when defining processing routes for valorisation of the Sargassum biomass.

Seaweeds have been used as fertilizer since ancient times. Next to providing macro and micronutrients, seaweeds enhance the soil moisture holding capacity, improves microbial life [131], improves structure of clay soils [132] and is reported to help recover nutrient depleted soils [133]. Seaweed's main constituent is a hydrocolloid polysaccharide which account for the moisture retaining capacity. Seaweeds in general have high levels of macro elements such as $\mathrm{P}, \mathrm{K}, \mathrm{Ca}$, Fe and I, next to a range of micronutrients/trace elements. High levels of metals in seaweed used as fertilizer may however lead to accumulation of metals in agricultural soils and even in crops [134]. For seaweed as fertiliser, the general regulations for fertilizers apply. Limit values for arsenic, cadmium, mercury, lead and other elements in fertilizers are listed in EU regulation 2019/1009. In literature and previous reports, a high concentration of arsenic has been detected in biomass harvested at the French islands, which could limit its uses as fertilizer [135]. 
Metals from seaweed-based fertilizers may be transferred to crops and affect food safety, however seaweed is nowadays also used in feed and food products, because it can be a sustainable source of protein, vitamins and minerals. The main food and feed safety hazard related to the use of seaweed is the high amounts of iodine and heavy metals such as arsenic, cadmium, mercury and lead. Arsenic in seaweed exists in different species, being organic or inorganic. Inorganic arsenic is more toxic than organic arsenic species. Levels of both total arsenic and inorganic arsenic depend on the seaweed species, with brown seaweeds, including Sargassum, generally containing higher levels than red and green species [136]. For feed, maximum limits for arsenic, cadmium, mercury in lead are listed in EC Directive 2002/32, with a separate limit for inorganic arsenic in seaweed-based feed materials. Regulation for heavy metals in seaweed-based food products is limited to maximum residue levels (MRLs) for mercury in algae and prokaryotic organisms (EC 296/2005) and for cadmium, lead and mercury in food supplements (EC 1881/2006). To be able to assess whether additional MRLs for seaweed-based feed and food products are necessary, the European Commission has requested the monitoring of arsenic, cadmium, mercury, lead and iodine in seaweed products (EU 2018/464).

Samples of Sargassum have been collected in 2020 at Bonaire by Sabine Engel and at the coast of Florida by Fearless Funds. In addition, we have received Sargassum samples from the coast of St. Maarten that were collected by Climate Cleanup for a parallel project under the MMIP018. Analysis has been carried out on all these samples (Table 4) in order to generate recent datasets on the composition of the biomasses with respect to the major biochemical components and those critical for the application of Sargassum in the food chain. The general biochemical characterisation of the samples was performed by TNO at their Seaweed Lab and total arsenic, and inorganic arsenic, cadmium, lead, iodine and mercury levels (Table 7) were determined by WFSR.

\begin{tabular}{|c|c|c|c|}
\hline Table 4 & \multicolumn{3}{|c|}{$\begin{array}{l}\text { List of Sargassum samples supplied in } 2020 \text { by different parties for analysis of } \\
\text { sugars, uronic acids, protein, ash, heavy metals and other elements. }\end{array}$} \\
\hline Sample \# & Harvest location and date & Treatment & Contact \\
\hline 1 & $\begin{array}{l}\text { Bonaire, Lagun, close to shore, } \\
\text { May } 282020\end{array}$ & $\begin{array}{l}\text { rinsed couple of times with clean seawater, air } \\
\text { dried in the shade }\end{array}$ & $\begin{array}{l}\text { Sabine Engel, } \\
\text { Bonaire }\end{array}$ \\
\hline 2 & $\begin{array}{l}\text { Bonaire, Lac Bay, off shore, } \\
\text { June } 162020\end{array}$ & $\begin{array}{l}\text { rinsed couple of times with clean seawater, air } \\
\text { dried in the shade }\end{array}$ & $\begin{array}{l}\text { Sabine Engel, } \\
\text { Bonaire }\end{array}$ \\
\hline 3 & $\begin{array}{l}\text { Collected off Florida's coast, } \\
\text { July } 2020\end{array}$ & forced air-dried & $\begin{array}{l}\text { Alyson Myers, } \\
\text { Fearless Fund }\end{array}$ \\
\hline 4 & $\begin{array}{l}\text { St. Maarten, open sea, } \\
\text { September } 12020\end{array}$ & $\begin{array}{l}\text { air dried in the sun for } 8 \mathrm{~h} \text { on black weed } \\
\text { block }\end{array}$ & $\begin{array}{l}\text { Peter Lindeman, Climate } \\
\text { Cleanup }\end{array}$ \\
\hline 5 & $\begin{array}{l}\text { St. Maarten, open sea, } \\
\text { September } 32020\end{array}$ & $\begin{array}{l}\text { air dried in the sun for } 8 \mathrm{~h} \text { on black weed } \\
\text { block }\end{array}$ & $\begin{array}{l}\text { Peter Lindeman, Climate } \\
\text { Cleanup }\end{array}$ \\
\hline 6 & St. Maarten, Point Blanche bay & $\begin{array}{l}\text { sample from a wet compost heap } \\
\text { (uncontrolled conditions) }\end{array}$ & $\begin{array}{l}\text { Peter Lindeman, Climate } \\
\text { Cleanup }\end{array}$ \\
\hline 7 & St. Maarten, Guana Bay & charcoaled Sargassum, dried on the beach & $\begin{array}{l}\text { Peter Lindeman, Climate } \\
\text { Cleanup }\end{array}$ \\
\hline 8 & $\begin{array}{l}\text { Cancún, Mexico, } \\
\text { July } 2020\end{array}$ & dried at $40^{\circ} \mathrm{C}$ & $\begin{array}{l}\text { Brigitta van Tussenbroek, } \\
\text { UNAM, Mexico City }\end{array}$ \\
\hline
\end{tabular}

In general, the results on the composition of the different samples show a wide variation in content on the different components of the samples. This is a characteristic for many seaweeds. The composition observed for each sample depends on location, time of harvest, environmental conditions as well as the methods used for harvesting and storage.

In Table 5, the composition in sugars and uronic acids is shown. In the samples from Bonaire, the major sugar is glucose, and mannitol is present at very low levels. In the sample from Florida, mannitol is the major sugar $(8.7 \% \mathrm{DW})$, followed by glucose $(6.7 \% \mathrm{DW})$. The levels of total uronic acids were similar in the samples, in most of the samples varying from $10.2-15.5 \% \mathrm{DW}$, except for two of the St. Maarten samples that showed very low levels ( $2.2-2.8 \% \mathrm{DW})$, maybe due to degradation by composting or drying method. Mannuronic and guluronic acids are components of alginate-type polymers that, after extraction, could be of interest for applications in the food industry (as gelling agent, for example) or as polymer component for packaging applications. Alginate polymers from Sargassum need to be characterized for chemical properties before an application is 
chosen. Several studies on extraction of sodium alginate from Caribbean waste Sargassum show that this product has potential for uses as gelling agent $[162,163]$. The maximum content in alginates reported for Sargassum species (approx. $15 \%$ DW) is significantly lower that the content in commercial seaweed species used as alginate source (approx. $40 \% \mathrm{DW}$ ), that could limit its potential as a feedstock for this product [138]. Both sugars and uronic acids can be used as fermentation substrates in anaerobic digestion by mixed cultures or by pure cultures of microbial strains for production of liquid fuels or other bioproducts.

The content in ash was high in all samples (Table 6), as it is typical for brown seaweeds. In the samples from Bonaire, the ash content was $42.4 \%$ DW for the sample taken on the Lagun, and $47.5 \%$ DW for the sample taken by the Lac Bay. Samples 6 and 7, collected in St. Maarten, show the highest ash content, 67 and $48 \%$ DW, respectively. These samples correspond to composted and charcoaled Sargassum, and these treatments could probably explain this high content in ash, as the sugars and uronic acids levels are low, indicating degradation by the treatment.

Table 5 Sargassum sugar and uronic acid content as percentage of dry weight (\% DW).

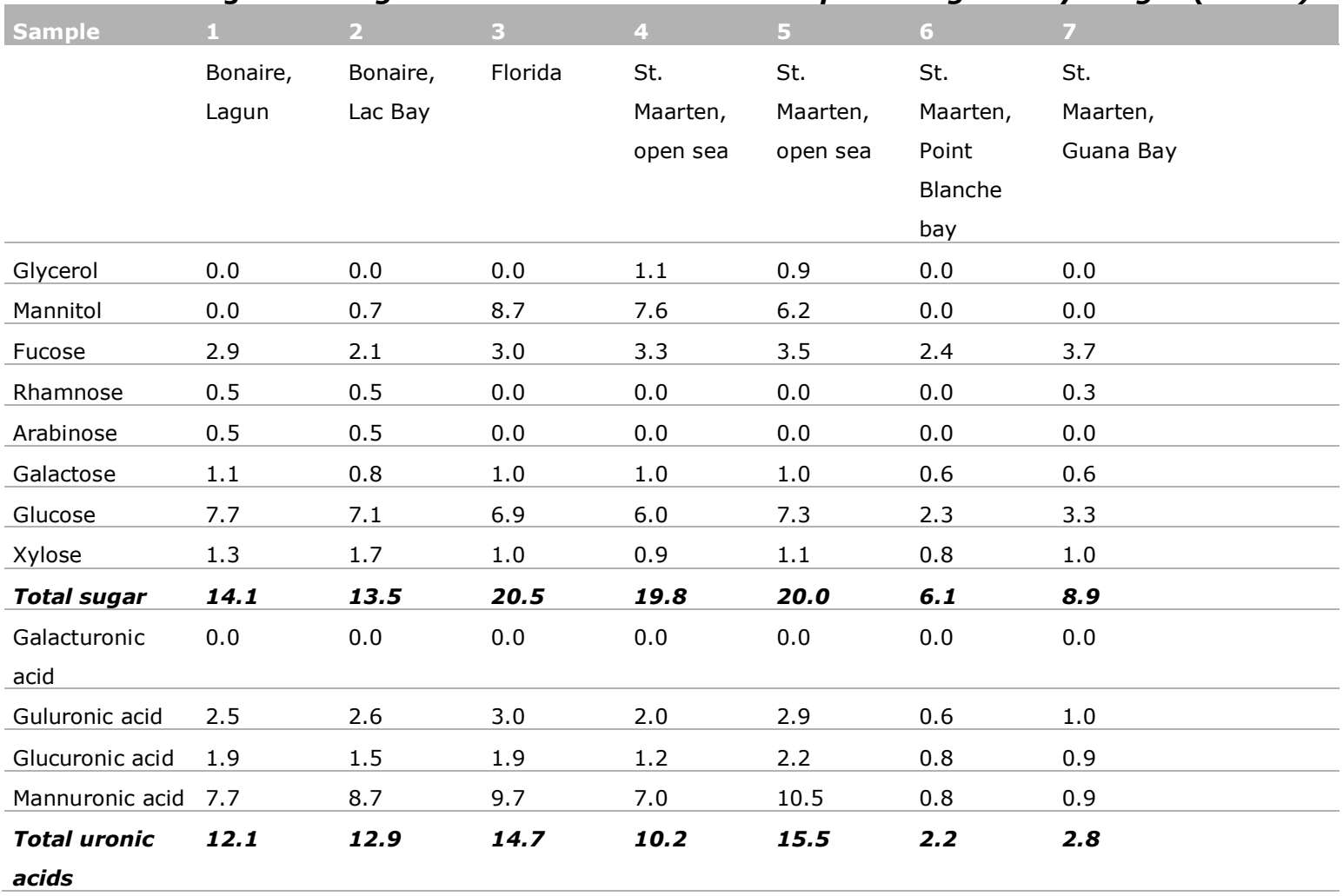

Table 6 Sargassum content of elements, ash and protein (5 times the $\mathbf{N}$ content). Total characterised is the sum of sugars and uronic acids (Table 5), protein and ash. SD is not determined.

\begin{tabular}{|c|c|c|c|c|c|c|c|c|}
\hline & & & & & & & Blanche bay & \\
\hline $\mathrm{C}$ & $\% \mathrm{DW}$ & 27.0 & 24.2 & & 27.9 & 29.8 & 21.6 & 21.9 \\
\hline $\mathrm{N}$ & $\% D W$ & 1.2 & 1.2 & & 0.8 & 0.9 & 0.7 & 1.3 \\
\hline $\mathrm{Ca}$ & $\mathrm{g} / \mathrm{kg}$ & 50.4 & 56.0 & & & & & \\
\hline $\mathrm{K}$ & $\mathrm{g} / \mathrm{kg}$ & 60.8 & 62.9 & & & & & \\
\hline $\mathrm{Mg}$ & $\mathrm{g} / \mathrm{kg}$ & 10.9 & 12.0 & & & & & \\
\hline Protein & $\% D W$ & 6.2 & 5.8 & & 3.8 & 4.5 & 3.4 & 6.5 \\
\hline Total & $\% D W$ & 74.9 & 79.8 & 71.9 & 69.1 & 76.1 & 79.4 & 66.8 \\
\hline
\end{tabular}


The content in protein in the samples varied between 6.5 and 3.4\% DW (Table 6). These levels are in agreement with other studies, and show that proteins are a minor component in the Sargassum biomass. Other types of seaweeds, such as the green specie Ulva, show higher content of proteins, approximately $30 \%$ DW, making them more interesting for some applications as animal or human feed. The applications of brown seaweeds in feed are usually related to mineral supplement, rather than as protein source.

Table 7 Element concentrations in Sargassum from the Caribbean and Florida obtained in this project (first seven samples) and values from literature [130,137-

142,144]. Concentrations are in ppm, given for cadmium (Cd), mercury (Hg), lead (Pb), total arsenic (tAs), inorganic arsenic (iAs) and iodine (I). For samples marked with an asterix $(*)$ the concentrations are expressed on dry weight. Other literature results are expressed 'as is', although in all cases dried samples were analysed.

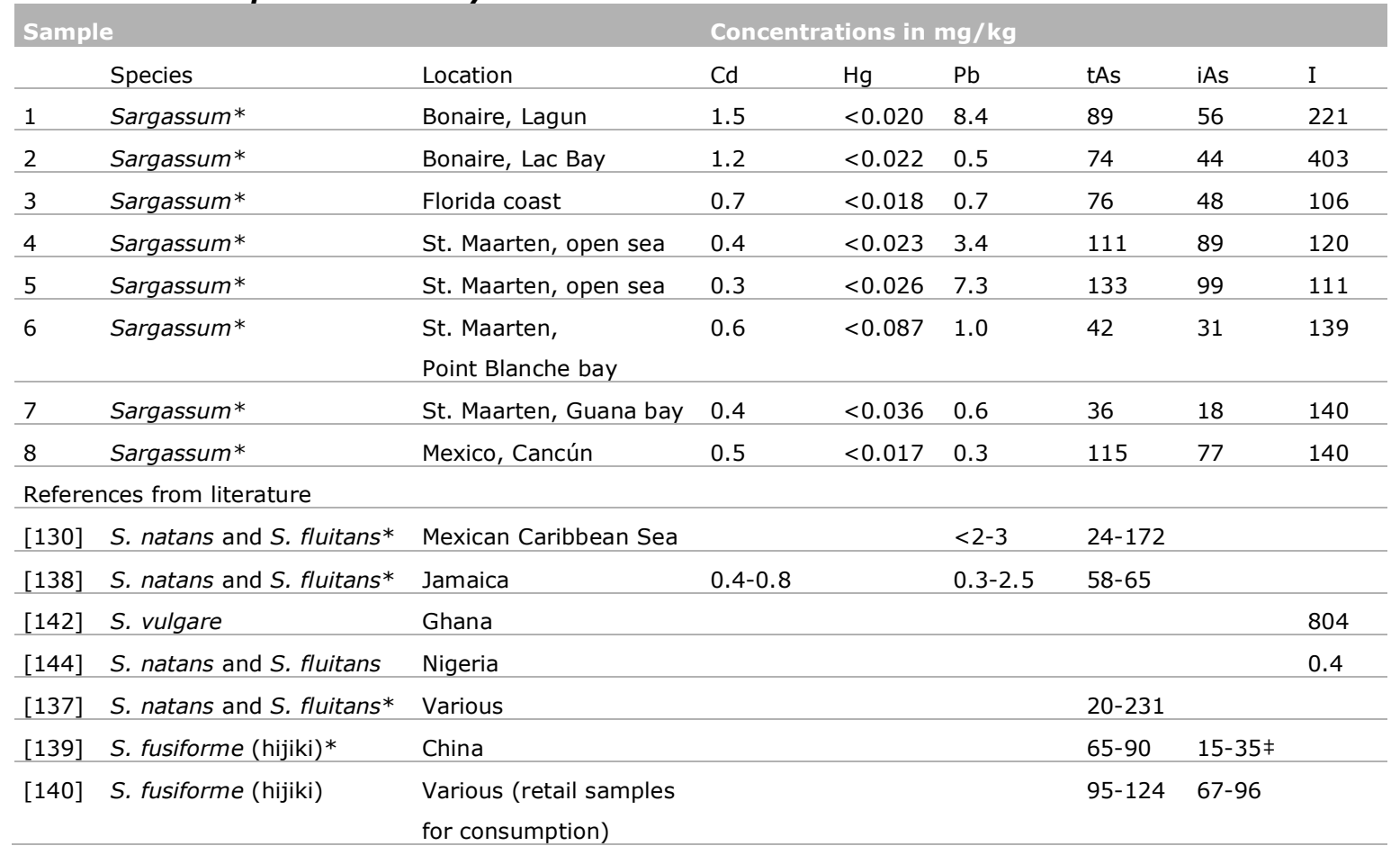

Sargassum samples from the project were analysed for heavy metals and iodine by WFSR using ICP-MS. The inorganic arsenic content was determined using HPLC-ICP-MS. * Concentrations reported on dry weight (DW); ₹ Only arsenate (As(V)).

As described previously, brown seaweeds generally contain relatively high levels of both total arsenic and inorganic arsenic [137]. This is also observed for the Sargassum samples from this project (Table 7). Total arsenic concentrations in most samples as well as inorganic arsenic concentrations in all samples are exceeding the maximum limits for seaweed-based feed material (2002/32/EC; 40 $\mathrm{mg} / \mathrm{kg}$ (12\% moisture) for total As and $2 \mathrm{mg} / \mathrm{kg}$ (12\% moisture) for inorganic As). In addition the cadmium levels in the two samples from Bonaire are above the maximum limit for cadmium in feed materials ( $1 \mathrm{mg} / \mathrm{kg}$ (12\% moisture); 2002/32/EC). The use of feed materials exceeding the maximum limits by mixing with other products to dilute contaminant levels is prohibited (2002/32/EC), eliminating the direct use of Sargassum as animal feed as long as the maximum levels are exceeded. The maximum limit for inorganic arsenic in organic fertilisers (40 mg/kg DW; EU 2019/1009) is exceeded in most samples, except for the Sargassum samples collected from Point Blanch Bay and Guana Bay at St. Maarten. The maximum limit for inorganic arsenic in organic fertilisers $(40 \mathrm{mg} / \mathrm{kg}$ DW; EU 2019/1009) is exceeded in most samples, except for the Sargassum samples collected from Point Blanch Bay and Guana Bay at St. Maarten. However, the arsenic concentrations are similar to reported values in literature [130,137-140]. The inorganic arsenic in the Sargassum samples from this project was between 50 and $60 \%$ of the total arsenic content, compared to $70-80 \%$ reported in literature $[139,141]$. Although the remaining (organic) arsenic content cannot be identified with the HPLC-ICP-MS method used in this study, a significant part of the organic arsenic in seaweed is known 
to be present as arsenosugars. Arsenosugars are considered to be of low toxicity to humans, but when seaweed is applied as fertiliser arsenosugars may degrade to inorganic arsenic in the soil [160].

For the other elements (cadmium, mercury, lead and iodine), fewer data has been reported. The cadmium levels of the Sargassum collected from two locations near Bonaire are slightly higher compared to the Sargassum sample collected near Florida, St. Maarten and Mexico and to reported values from Sargassum near Jamaica [138]. Lead levels in the Sargassum samples are varying between 0.35 and $8.4 \mathrm{mg} / \mathrm{kg}$ DW. Sargassum samples collected from Lagun, Bonaire and from St. Maarten (open sea) are higher than the other samples and reported values in Sargassum obtained near Mexico and Jamaica [138,142]. A possible explanation for the elevated lead levels may be residual sand in the samples from drying the Sargassum on the beach.

The iodine content in the Sargassum samples from this project vary by a factor of 4 (106 $403 \mathrm{mg} / \mathrm{kg} \mathrm{DW}$ ). Although limited data is already available on iodine in Sargassum, brown seaweeds are known to accumulate iodine from seawater. Iodine concentrations in other brown seaweed species may vary depending on species and sampling location. Iodine concentrations have been reported for example for Palmaria (72-293 mg/kg DW), Alaria (181-1070 mg/kg DW) and Saccharina (1556-7208 $\mathrm{mg} / \mathrm{kg} \mathrm{DW}$ ) [143]. Currently, maximum levels for iodine in seaweeds (or other types of food and feed) have not been established in the legislation in EU. For humans an upper tolerable level (UL) at 600 $\mu \mathrm{g} /$ day has been established (SCF, 2003), hence consumption of as low as $100 \mathrm{mg}$ of certain seaweeds would lead to exceeding of this guideline value. For the Sargassum samples from this project with an average iodine content of $173 \pm 100 \mathrm{mg} / \mathrm{kg} \mathrm{DW}$, the UL would be exceeded when consuming ca $3.5 \mathrm{~g}$ of dried Sargassum. There is a need for a better documentation of the iodine levels in seaweeds and further knowledge.

The relatively high arsenic and iodine concentrations limits potential of direct applications of the Sargassum in human and animal nutrition and fertilisers. In case of products derived from this biomasses, such as extracts, the content in these components need to be determined.

Several methods have been described for the treatment of brown seaweeds, mostly in Alaria and Saccharina species, to remove iodine, arsenic, cadmium or other components that can represent a health risk for food or feed applications $[164,165]$. Most of the methods are based on water extraction by washing, boiling or soaking at different temperatures, different $\mathrm{pH}$ values and/or incubation times. These are relatively simple treatments that can result in significant reduction of these components, however, they also affect the content in other components of interest, such as bioactives or carbohydrates. As an example, for $S$. fusiforme treated by washing and soaking, a reduction of 30 to $60 \%$ in the arsenic content has been reported [166]. On the market there are currently Sargassum extracts that claim to have low content in arsenic and heavy metals and can be used as growth stimulant for crops, such as the products from Algas Organics from St Lucia. 


\section{$4 \quad$ Economic, societal and environmental impact of pelagic Sargassum valorisation}

The harvesting and processing of Sargassum, whether for conversion into useful materials or for carbon sequestration can be evaluated from an economic, societal and environmental perspective. Below we outline how the proposed options for valorisation are, or can be, evaluated from divers perspectives.

The research gaps below, as well as proposed tasks, are based on a literature review conducted in the period June-August 2020. Based on this literature search, 24 publications were retrieved. These were analysed and the economic and social aspects studied in these publications were recorded in an Excel file. This enabled us to identify the main topics studied, as well as gaps in research.

Quantitative data on the economic impacts of Sargassum blooms, or of the economic feasibility of harvesting and processing is very scarce. For the future development of Sargassum value chains, it is necessary to get good insight in to the costs of Sargassum blooms and of existing solutions (i.e. harvesting). Viable processing options should be evaluated from economic perspective. Techno-economic modelling can be used to evaluate the economic feasibility of the envisioned harvesting and processing process. Little attention is paid to the social impact of Sargassum harvesting and processing. This impact can take different shapes (1) the local population can play a role in harvesting of Sargassum, either on shore or offshore and (2) there are benefits of processing in terms of employment and income generation.

Before harvesting and processing on a larger scale is promoted, more knowledge is needed about its environmental impact. This includes knowledge on ecosystem impact (see Chapter 2) and knowledge on the comparative performance of Sargassum based products vis-à-vis alternative products. The Life Cycle Assessment (LCA) methodology can be used for these kind of analyses.

\subsection{The cost and impact of non-action}

Research into the potential usage of Sargassum often starts from the assumption that algal blooms have a negative impact. The short term effect is that these Sargassum blooms pollute the beaches and make an unsightly appearance which directly harms tourism. In a long term continued massive influx of Sargassum may have a deleterious impact on coral reefs and can lead to eutrophication of coastal waters. It is posed that it will take decades to recover. Tourism can disappear and this affects the local community on the long term.

However, in the literature review no studies were found that explicitly quantified the economic and social impacts of Sargassum blooms. Some predictions are made (e.g. 120 million euro for the entire Caribbean, but scientific justification for these number could be not be found). A study of the social and economic impacts of Sargassum blooms, and not taking action to harvest these blooms, would shed light on the economic impacts now. This makes it visible who bears the current costs of Sargassum blooms and enables comparison with the economics and harvesting and processing (see chapter 4.2) This analysis can be conducted independent of the other activities outlined in this implementation plan.

To understand the social and economic impact, the following activities could be conducted:

- Stakeholder analysis: to get an overview of local, regional and international stakeholders, relevant for Sargassum harvesting and processing. The analysis should point out how stakeholders benefit from, and are negatively impacted by, the proposed harvesting and processing options.

- Analysis of direct economic impact: to know the costs currently made for cleaning up the Sargassum blooms and disposal of the biomass. This analysis should take into account that beach cleaning might also provide revenues and income. 
- Analysis of indirect economic impacts: to understand if Sargassum blooms have a negative impact on the economy of the Caribbean islands, in particular with a focus on tourism and fisheries.

To carry out this research a mix of methods is available. The lack of reports and publications on this topic means that data collection through other methods is needed, for example through interviews or surveys. Data retrieved can be incorporated in an economic model to assess costs and benefits.

\subsection{The economic feasibility of harvesting and processing Sargassum}

In the literature various applications of Sargassum are studied, including biofuel and fertilizer. Thompson et al (2020) [85] argue that Sargassum shows biofuel potential but hitherto, methane recovery is low due to a carbon to nitrogen ratio below $20: 1$, the restricted bioavailability of structurally complex carbohydrates for degradation and high insoluble fibre, salt, polyphenol and sulphur content [146] consider pelagic Sargassum inundation of coastlines across the North Atlantic Ocean an ongoing challenge which poses a great threat to economic productivity. This study evaluated the valorisation of these invasive seaweeds into biogas and fertiliser using hydrothermal pretreatment and anaerobic digestion technologies. Another option is the production of fertilizer, reportedly done in the Philippines [147]. No studies were found that provide quantitative data on the economics of Sargassum harvesting and processing.

To understand the economic feasibility of harvesting and processing the blooms before washing ashore, the following activities could be conducted:

- To evaluate the economic effects of the Sargassum based innovations, a simulation model can be constructed, using the output from other research activities. The input variables on costs and revenues can be varied and effects on profitability and the underlying cost- and revenue items can be calculated. The model will provide the economic cost-benefit analysis of the innovations compared to current value chain, categorized by the discerned fractions in the value chain.

- As described in chapters 2.5 and 3.1, harvesting the Sargassum nearby the shore before it arrives to the beaches and ensiling the biomass seems to be the best option for the harvesting and storage. This method isn't researched in the Dutch Caribbean yet and potential costs and profits need to be calculated as part of the research.

- Seaweeds provide macro and micronutrients, enhance the soil moisture holding capacity, improves microbial life, improves structure of clay soils and is reported to help recover nutrient depleted soils. It's important to be aware of potential high levels of heavy metals and other pollutants. Blending Sargassum with other fertilizers is mandatory before selling it for agricultural applications. Possibilities for these mixtures, including costs and profits, in the Dutch Caribbean could be researched.

\subsection{Design of the value chains for harvesting and processing Sargassum}

In addition to questions on the economic profitability of harvesting and processing Sargassum it is needed to understand and, where necessary support development of, the value chain. Recent investigations into seaweed value chain have highlighted the importance of non-financial issues in value chain analysis, i.e. a proper understanding of value chain requires one to look into relations between actors, information sharing, patent protection and more [148],

The value chain faces a number of challenges. A few examples are:

- Once ashore, the Sargassum starts rotting. It is therefore sometimes suggested to store Sargassum near the coast in a shielded part of the ocean to prevent rotting.

- How to prevent the Sargassum to come ashore seems a challenge because the start of the influx is still hard to predict. 
- Because of these unpredicted landings of Sargassum it is hard to make harvesting and further processing viable.

- Besides the need to store Sargassum after a massive influx another suggestion was done to combine harvesting Sargassum with harvesting other seaweed and blue-green algae form the sea. As far as the literature tells, tools are designed. The lessons learned were not presented.

Most of the ideas to deal with the brown tides are only researched on a small scale. There is a call from the government of the Netherlands Antilles that all countries with Sargassum influxes exchange ideas, share costs and solve the problem together. This is, due to other priorities, not yet put into practice.

To attain a Sargassum value chain, the following activities could be conducted:

- Given these observations, a Task dedicated to the design of a Sargassum value chain is proposed. This must address technological, social, environmental and economic challenges, drawing upon results from the other Tasks. Furthermore, the analysis can include an analysis of patents and the organisation and relative power of different actors in the value-chain.

- The CERMES report [89] gives a good insight of potential uses of Sargassum biomass. Given the fact that the influx is on small islands in the Caribbean a research for the opportunities of potential products of Sargassum for the coastal communities is proposed.

To carry out this research the Value Chain Analysis according the FAO method could be used. Supplementary local data collection is needed to get interaction with local stakeholders and get a good insight in the local context.

\subsection{Environmental impacts of harvesting and processing Sargassum blooms}

Floating Sargassum is designated as an essential fish habitat as well as a protected habitat for juvenile turtles. Unregulated Sargassum harvesting can do harm and has to be restricted. The United States' South Atlantic Fishery Management Council implemented the Fishery Management Plant for Pelagic Sargassum Habitat in the South Atlantic Region in 2003 which created restrictions on commercial harvesting [149]. These topics are addressed in Chapter 2.

If Sargassum blooms are harvested for processing into (various) products, comparative assessment of the environmental impacts should be conducted. For example, the environmental impact of Sargassum-based fertilizer should be compared to the impact of conventional fertilizer. Life Cycle Assessment (LCA) provides detailed insights in environmental impacts needed before making decisions on where to harvest (i.e. off-, near- or onshore). LCA is an international recognized method used for systematic comparison of impacts of processes on the environment (ISO14040: 2006). In this case, suggested research activities are:

- An analysis of the environmental impacts of Sargassum blooms, and the environmental impacts of harvesting and processing provides insight into the pros and cons of proposed valorisation routes. Such an analysis should be connected to the biological research reviewed in Chapter 2 and has a clear relationship to the economic analysis.

- LCA of the Sargassum products: Harvesting and processing of the Sargassum has various potential environmental impacts, positive and negative. To be able to choose the optimal solution to Sargassum blooms from an environmental perspective, an integrated environmental assessment is needed, combining local environmental impacts, the impacts of harvesting and processing and the (positive) effects of Sargassum products, including replacement effects (e.g. reducing the need for artificial fertilizer).

\section{Role of Sargassum in the carbon cycle: carbon balance}

The world's oceans sequester large quantities of carbon dioxide from the atmosphere by a combination of physico/chemical processes moving dissolved inorganic carbon from the surface into deeper water via current movements, and by biological processes of photosynthetic fixation of carbon dioxide into 
particulate matter. This particulate matter ultimately sinks to the deep ocean, a process known as the biological pump. These processes are major factors in controlling the concentration of carbon dioxide in the lower atmosphere and thus impact the global climate system. Sargassum seaweed plays a major role in the natural Carbon Cycle. The seaweed that naturally sinks in the Sargasso sea accounted for no less than $7 \%$ of the world's biological ocean carbon-pump during the years 19922006 [150]. The concept of Blue Carbon refers to initiatives to quantify carbon sequestration and attach an economic value to the amount sequestrated. Economic values can be monetized through legal or voluntary carbon offset schemes. Whether this biological $\mathrm{CO}_{2}$-pump can play a role in the Sargassum management in the Caribbean needs to be determined, as many aspects need to be taken into account when managing the Sargassum mats at open sea. The Sargassum constitutes an important nutrient source and nursery area for (commercial) fish species and other aquatic life in the Sargasso sea and beyond. As rafts of Sargassum drift with the currents in the Caribbean Sea, the Gulf of Mexico, through the Florida Straits and up the east coast of the United States by way of the Gulf Stream, they provide critical habitat for species of fish that are important for the recreational and commercial fishing industries. The importance of Sargassum as an essential fish habitat was recognized by the South Atlantic Fishery Management Council in 2002 when they developed a Fishery Management Plan to protect and conserve Sargassum in a portion of the EEZ of the United States (South Atlantic Fishery Management Council 2002) [149].

Some studies propose the use of Sargassum as a carbon sink in the ocean by mechanically facilitating large scale sinking of Sargassum biomass to the bottom of the sea. These studies are in early stage currently, and the ecological impact of sinking off of pelagic Sargassum rafts which are considered hot-spots of biodiversity, still need to be investigated. However, by quantifying the carbon balance of the different actions identified for harvesting and/or sinking of Sargassum, we can get an indication of the impact of $\mathrm{CO}_{2}$ sequestration on these processes. 


\section{$5 \quad$ Value chains for valorisation of pelagic Sargassum biomass in the Dutch Caribbean}

The quality (physical characteristics, homogeneity, presence of impurities) of the Sargassum biomass that can be harvested may vary in time and space and depends on the harvesting method and the eventual pre-processing on board and the storage conditions prior to being subjected to conversion technologies. In case of collection of biomass onshore, most probably there would be a considerable amount of sand in the biomass, that would require extensive washing before other treatment, while water is relatively expensive on the islands in the Dutch Caribbean [156]. In addition, as soon as Sargassum is washed ashore, it piles up and starts decaying, which results in the release of toxic gases that can affect human health, and which reduces the quality of the Sargassum that can be harvested from the beach compared to Sargassum that can be harvested at sea. Moreover, when heavy machinery is used to harvest Sargassum from the beach, this can have negative impacts on the coastal environment through increased beach erosion and compaction, or the damage inflicted to sea turtle nesting beaches [152]. Therefore, there is a preference for at sea harvesting of Sargassum biomass. Moreover, as pelagic Sargassum rafts provide essential habitats for a wide range of organisms and serve as hotspots for biodiversity and productivity in otherwise substrate poor, low-nutrient open-ocean waters, it is preferred to only harvest Sargassum rafts that are nearshore. First of all because nearshore Sargassum rafts are more likely to hit the coast when not harvested so that associated fauna would be lost anyway, and second because nearshore harvesting of Sargassum increases the chance to prevent Sargassum biomass to beach on the nearby shore, thus minimizing environmental impact on critical coastal habitats.

The Sargassum biomass contains up to $85 \%$ of water, thus transporting the Sargassum biomass as such would mean to transport a considerable amount of water to the shore, with the corresponding high costs and energy use. In addition, when out of the water, the compacted Sargassum biomass decays very fast (depending on storage conditions) releasing gases containing hydrogen sulphide $\left(\mathrm{H}_{2} \mathrm{~S}\right)$, that may reach levels that are toxic when inhaled. For this reasons, the processing of the biomass on board to dewater and stabilise the material is required, which means that specific boats for the harvesting and processing need to be developed (see chapter 2.1).

In Figure 11, a scheme is shown that reflects the steps involved in the valorisation of Sargassum biomass collected near shore towards several types of products with applications as biofuel and in agriculture, that are relevant for the Dutch Caribbean. In the value chain, after the biomass has been stabilised, technologies for conversion of the biomass can be applied, depending on the final product of interest.

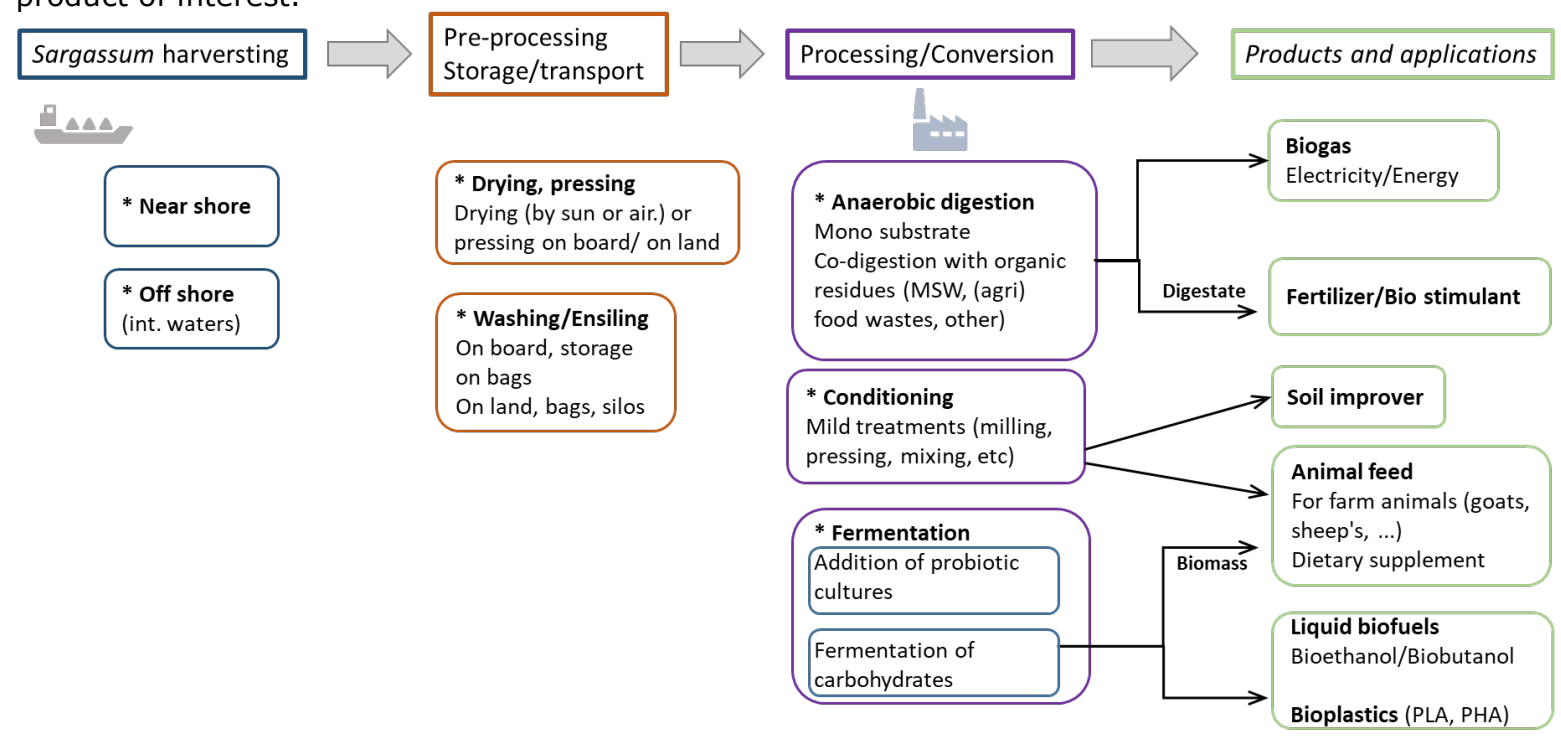

Figure 11 Scheme of potential value chains for valorisation of Sargassum in the Dutch Caribbean 


\section{$5.1 \quad$ Sustainable feedstock supply}

Although the large blooms of Sargassum have been appearing almost every year since 2011, these blooms cannot be predicted in time or in abundance on the long term. These are important factors that hamper the establishment of services or industries related to the Sargassum chain in the affected areas. It is important to develop strategies to cope with the issues of a discontinuous and/or irregular supply of feedstock, in order to create solid value chains that are likely to result in stable economic and social benefits for the communities. From discussions with stakeholders some strategies have been identified, and are described below:

- Use multifunctional harvesting/storage technologies. Due to the seasonal character of the blooms, it is likely that the harvesting activities would be taking place only some months per year. To reduce the cost of the fleet of ships for harvesting, it is an approach to develop multifunctional vessels that can be used for other tasks outside the harvesting season. The storage of the biomass needs to be adapted to the needs of the processing methods for further valorisation.

- Establish seaweed farms for Sargassum, alone or in combination with other seaweeds of interest, to create a predictable supply of feedstock, adequate to the needs for the industries. This approach is followed by our partner Fearless Funds, whose activities have been focused on developing Sargassum farms for stable supply for further applications of the biomass for biofuels or other applications (Fig. 12).

- Co-processing of Sargassum with other organic streams available on a regular basis. This approach is particularly interesting for valorisation using biological or chemical processes to products such as biogas, liquid fuels and animal feed. When value chains are established for processing of local organic biomasses, the Sargassum biomass harvested when blooms occur can be co-processed. This approach requires processes that are flexible on type of feedstock and on volumes to be processed. Modular facilities where the volumes of the feedstocks to process can be adjusted to the needs at different time points are preferred.
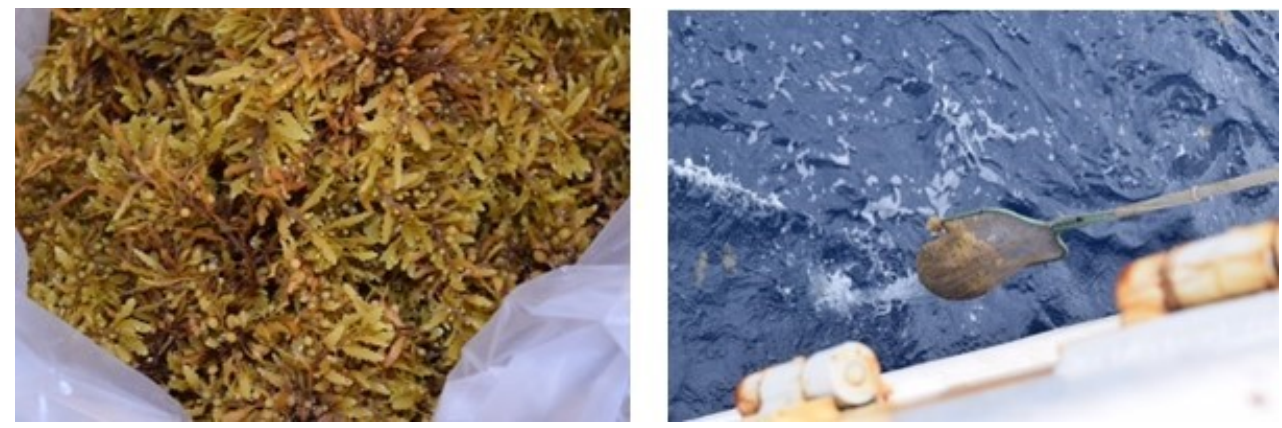

Figure 12 Sargassum collection by Fearless Fund at the coast of Florida. Due to the Covid situation it was not possible to harvest Sargassum from own farms in 2020. Source: Fearlessfund.org

The applications of the Sargassum will depend on the specific conditions (infrastructures, markets, ...) and needs in the geographical area where it will be processed. In this study, we concentrate on two main areas: the Dutch Caribbean islands (Bonaire, St Eustatius, Saba) and Mexico. The choice for a solution to prevent the Sargassum landings, with their negative environmental effects, and the value chain to valorise the biomass will not only depend on the technologies to be used, but also on the governmental policies of the respective area's and on the interest of industries to establish new chains and commercialization activities.

In the Dutch Caribbean there is a need for reinforcing the agriculture sector and energy networks in a sustainable, integrated and nature-inclusive way to contribute to food, ecosystem, water and energy security $[151,156]$. Therefore, Sargassum-based products that can fit in these needs would be preferred to other products that have other applications. As local harvesting of Sargassum will reduce impact of Sargassum influxes on coastal habitats, fisheries, tourism, and can be converted to biofuel and agricultural products (e.g. fertilizers, animal feed supplements) these Sargassum value chains can contribute to the ambition of local authorities in the Dutch Caribbean to reduce greenhouse gas emissions and to invest in a more sustainable and upscaled agricultural sector [151, 156]. 
In view of the urgency of the Sargassum problem in the area, solutions that can be applied in the short term are preferred, as a first step towards setting up efficient prevention or remediation measures, and to establish value chains to benefit the economy and environment of the islands in a sustainable way. In Figure 6 (chapter 3.2), a scheme of a value chain based on valorising the Sargassum biomass into biogas, electricity and fertilizer is shown. The fermentation processes are indicated as potential steps in a second phase for implementation, as their technology readiness level (TRL) is lower than the anaerobic digestion or technologies for agricultural uses.

In the Mexican situation, the options for valorisation of Sargassum and other seaweeds appear to be wider, given that there are more infrastructures and businesses that can address national or international markets. Currently there are many companies that are using Sargassum as a starting material for products with uses in agriculture, in the materials sector (in composites, for example) or as a component in shoes. Applications for uses in energy generation are not established yet, being the low price of electricity an important factor that hampers the implementation of new technologies for energy generation. 


\section{$6 \quad$ Policy challenges and advice}

The massive Sargassum influxes in the Caribbean region affect a number of communities, belonging to different countries and continents. Whether the Sargassum influxes are a result of human activities or is a natural phenomenon needs to be determined, but it is clear that solutions for the negative effects of these influxes need to be found in the short term at the level of the communities affected. That these massive blooms started recently, in 2011, and that they are unpredictable, as described in the previous chapters, make the finding of adequate management and governance approaches very challenging.

\subsection{Policy challenges and governance}

Governance aspects are very important in the context of dealing with the Sargassum issues, due to the large environmental and economic impacts in the areas where the influxes land. Efficient wide spread policies for the management of the impacts are lacking currently, and each region copes with these impacts in its own way. Several approaches can be defined to help developing efficient strategies for management of the impacts, that are currently lacking:

- Establish a guiding framework that is specific for the Sargassum influxes. In this framework, attention needs to be given to treating the blooms not only as a nuisance or a polluting agent, but look into a wider perspective of applications.

- For the issues related to harvesting of the Sargassum biomass, there are factors that are important, such as where and when to harvest and the impact of the harvesting on the environment and the establishment of logistic and storage chains adapted to the region. Policies for issuing of permits for harvesting and uses of the Sargassum need to be defined yet to ensure good practices and sustainability.

Because of the international character of the blooms, legal and diplomatic aspects are involved. The question on "ownership" of the biomass when floating on international waters remains open, and it is difficult to address.

In 2003, after private companies began unregulated Sargassum harvesting, the United States' South Atlantic Fishery Management Council implemented the Fishery Management Plant for Pelagic Sargassum Habitat in the South Atlantic Region, which created strict restrictions on commercial harvesting (SAFMC, 2002) [149]. Sargassum was designated as an essential fish habitat for commercially important species as well as a protected habitat for juvenile turtles [152]. Harvest, using allowed methods, was restricted to less than 5.000 pounds per year, collected from offshore regions during certain times of the year.

Sargassum is a natural resource and for the exploitation of natural resources in the world's oceans and seas rules governing al uses are laid down in the United Nations Convention on the Law of the sea (UNCLOS). According to this Convention Coastal States exercise sovereignty over their territorial sea which they have the right to establish its breadth up to a limit not to exceed 12 nautical miles. When harvested in territorial waters, within 12 nautical miles from the coast, it's possible to make a bilateral agreement between one government and a specific company for a specific use of Sargassum. Agreements between different countries might be an option for the longer term. Regional policies and statements that support the valorisation and commercialization of Sargassum include: the United Nations Environment Programme-Caribbean Environment Programme's white paper 'Sargassum Outbreak in the Caribbean: Challenges, Opportunities and Regional Situation' (UNEP 2018); and the 2019 Final declaration of the International Conference on Sargassum in Guadeloupe 'Caribbean Programme for Sargassum'. 


\subsection{Current policies for the exclusive economic zone of the Dutch Caribbean}

In this section, laws are described that are of importance for local policy development regarding harvesting of pelagic Sargassum in Dutch Caribbean waters.

\section{https://wetten.overheid.nl/BWBR0010480/2010-04-28}

The definition of exclusive economic zone you can find in the "Rijkswet instelling exclusieve economische zone".

The exclusive economic zone of the Kingdom is the area beyond and adjacent to the territorial sea of the Kingdom that extends not more than two hundred nautical miles from the baselines from which the breadth of the territorial sea is measured.

The Kingdom of the Netherlands has, subject to the boundaries set by international law, in the exclusive economic zone:

- sovereign rights for the purposes of the exploration, exploitation, conservation and management of the living and non-living natural resources of the waters above the seabed and of the seabed and its subsoil, and in relation to other economic activities exploitation and exploration of the zone, such as the generation of energy from the water, the currents and the wind;

- jurisdiction over the construction and use of artificial islands, installations and establishments, marine scientific research and the protection and preservation of the marine environment.

Examples of exploiting natural resources are fishing, drilling and extraction of oil and natural gas, and the generation of energy by, for example, wind turbines.

\section{https://wetten.overheid.nl/BWBR0003749/2010-10-10}

The definition of the territorial sea you can find in the "Rijkswet uitbreiding territoriale zee van het Koninkrijk".

The territorial sea of the Kingdom in Aruba, Curaçao, Sint Maarten and in the public entities Bonaire, Sint Eustatius and Saba will be extended to twelve nautical miles, taking into account rules to be laid down by order in council.

The coastguard is responsible for control and enforcement on the sea.

https://wetten.overheid.nl/BWBR0023731/2010-10-10

The 'Rijkswet Kustwacht voor Aruba, Curaçao en Sint Maarten alsmede voor de openbare lichamen Bonaire, Sint Eustatius en Saba' describes the authorizations of the coastguard.

The supervisory and investigative tasks are, among other tasks, surveillance of the environment and fisheries.

The Coast Guard performs its duties in the following waters and airspace above:

- the inland waters of Aruba, Curaçao and Sint Maarten as well as of the public bodies Bonaire, Sint Eustatius and Saba,

- the territorial sea of Aruba, Curaçao and Sint Maarten, as well as of the public entities Bonaire, Sint Eustatius and Saba, and

- the contiguous zone and the other sea area in the Caribbean Sea, subject to the provisions of Article 11.

From a control and management point of view Sargassum should be harvested in the territorial sea. From an economic perspective harvesting the Sargassum nearby the shore before it arrives to the beaches and ensiling the biomass seems also to be the best option for the harvesting and storage.

https://wetten.overheid.nl/BWBV0003172/1996-07-28

United Nations Convention on the Law of the Sea.

Important articles: Article 2 (in connection with the territorial sea), Articles 33 and 303, second paragraph (in connection with the contiguous zone) and Articles 55 and following (in connection with the exclusive economic zone) of the 10 United Nations Convention on the Law of the Sea (Treaty Series 1983, 83) concluded in Montego Bay in December 1982. 


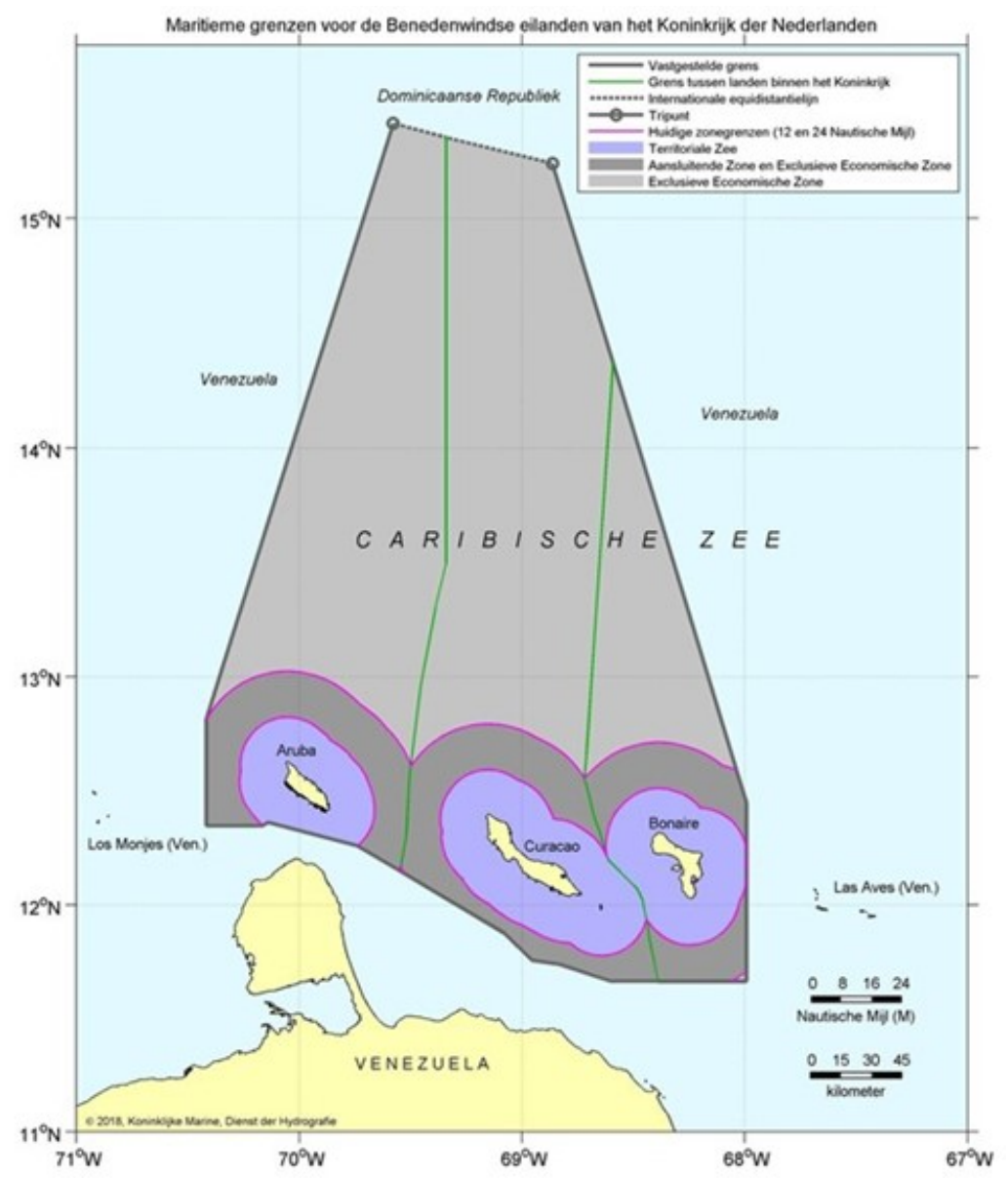

Figure 13 Sea borders of the Dutch Caribbean islands. Source:

https://www.defensie.nl/onderwerpen/hydrografie/maritieme-zones-en-zeegrenzen/zeegrenzencaribisch-deel-van-het-koninkrijk

\subsection{Policy advice in relation to Sargassum management and financing aspects}

One of the important aspects for Sargassum management is the current lack of standards for management or for products that are derived from this biomass. Therefore, to develop standards and protocols for safe harvest, handling of the biomass and the properties of the products is a need in this sector. These standards need to be defined to ensure that the environmental and health risks of harvesting and handling are minimized. Also, standards on products requirements for the uses on the food chain, for example, will help to develop an industry that is complying with safety regulations. The establishment of management measures for the harvesting and valorisation of Sargassum is expected to result in a reduction of the current problems caused by the beaching events. When products are made that can contribute to renewable energy generation or to uses that would help to reduce costs in the agriculture sector, valorisation strategies for Sargassum will also contribute to a more sustainable island society.

At the local level, support for development of a value chain for Sargassum in the islands can be realised through different ways:

- Financing of research and education programs to improve the knowledge on the blooms in the areas of ecology, monitoring, mitigation and education. These programs can be at local and at international level, to create networks of stakeholders contributing to a better awareness and understanding of the situation and find solutions that are widely accepted.

- Invest on local initiatives for creating infrastructures and businesses based on Sargassum by small and medium enterprises. By supporting local entrepreneurs and services, using different measures, such a subsidies, tax reduction or other, jobs can be created while helping the environment. 
Programs can be focused on supporting innovation research, marketing, commercialization or knowledge development and formation of staff.

- Integrate the Sargassum value chain with other goals of the area, including nature conservation, sustainability, resilience and societal changes. An example of this can be the contribution of renewable energy products from Sargassum and/or other organic sources to the energy resilience of the islands [154]. Stimulate or make obligatory the use of the Sargassum products in the islands, by defining benefits of creating policies. The creation of a specific "Sargassum tax" has been suggested [89] to generate income for the Sargassum programs.

The vision of integrating nature conservation goals with public and private sector policy and decision making programs is referred to as a "Nature inclusive" approach of policy development. This approach has been defined for the island of Bonaire for policy development towards 2050, and is presented in a recent report [151]. The integration of solutions for the Sargassum issues, that involve many stakeholders and has many different implications, could be one of the examples of such as nature inclusive approach to follow to enhance resilience and sustainability. In The Netherlands there are several stakeholders that show interest in contributing to the sustainable management of the Sargassum blooms. The interests of some of these stakeholders are described in this report (Chapter 9).

As already discussed, the negative effects of the Sargassum blooms represent a global environmental and economic problem, and international collaboration is essential to find a solution for it. Many efforts are being made worldwide to discover the causes of the blooms and to find mitigation actions for these effects. In the Caribbean area and the Gulf of Mexico there are many programs dedicated to Sargassum research at different levels, from fundamental research on the origins of the blooms to application of Sargassum products. The community of stakeholders involved in these studies and projects is very diverse. There is a willingness for collaboration between these stakeholders to mitigate the negative effects of the massive landings of pelagic Sargassum and to contribute to the sustainability of the impacted coastal communities. As an example, the UN, within the UN development program (UNDP), is supporting projects through the UNDP's Actions that are concerned with Sargassum mitigation. These projects include UNDP Accelerator Labs that concern Barbados and the Eastern Caribbean, where specific innovators test the use of pelagic Sargassum for bioplastics and energy, the Jamaican Climate Action Innovation that aims to convert pelagic Sargassum to a goat feed that is cheaper than those on the market, and interventions related to removal and utilization of Sargassum from the east coast of Saint Lucia to create organic compost for the farming industry, which are financed by the Small Grant Program. The specific value chain to be built in a specific area will depend on the characteristics of the area and on the needs where the Sargassum can contribute.

For financing of Sargassum related research and mitigation actions, besides national and local programs, the establishment of international funds for collaboration and development is needed. Especially in areas where multinational collaboration is needed, establishment of dedicated programs is essential to realize the efforts needed. By joining the existing international initiatives, like the one described above of the UN, or creating new ones with involved countries and organizations, new consortia can be made for collaboration. European research funds could be available through the European countries present in the area, and by establishing programs for research and development with the needed associated countries. 


\section{$7 \quad$ Knowledge gaps and implementation plan}

In order to implement a sustainable Sargassum harvesting and valorisation chain in the Dutch Caribbean a possibility is to select technologies that are currently at a high technology readiness level (i.e. anaerobic digestion, fertilizer production, or animal feed supplement) so the implementation can take place in short term. In the longer term, other valorisation processes can be developed that could generate more value or address specific needs in the area. Although there is often knowledge on the technologies to be used for a specific value chain (i.e. for anaerobic digestion or the preparation of animal feed meals) implementation of one of the value chains described in chapter 5 requires that identified knowledge gaps (KG) need to be addressed. A summary of the KG is shown in Figure 14, where each $K G$ is linked to the step in the value chain where it is related to.

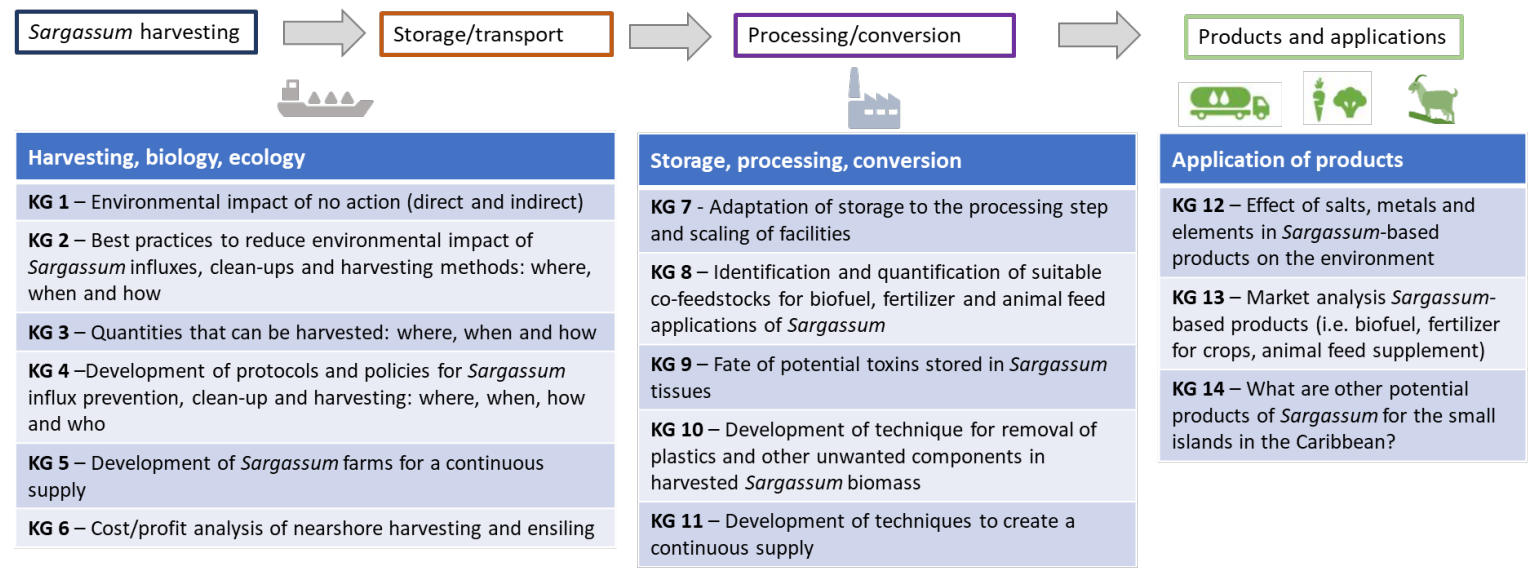

\section{Socio-economic impacts}

KG 15 - Socio-economic costs of no action (direct and indirect)

KG 16 - Identification of stakeholders relevant for Sargassum harvesting, processing and commercialization of products

KG 17 - Socio-economic effects of the Sargassum based innovations: employment, infrastructures, etc

KG 18-Supplementary local data to optimize the Value Chain Analysis

KG 19-Replacement effects (e.g. reducing the need for imports of fossil fuels, fertilizers and animal feed, improvement of resource security)

Figure 14 Summary of knowledge gaps (KG) to implement value chains for Sargassum harvesting and valorisation to products for uses in energy and agriculture

\subsection{Knowledge gaps: harvesting, biology and ecology}

KG 1 - Environmental impact of no action (direct and indirect)

To be able to quantify the environmental gains of activities to prevent pelagic Sargassum from beaching on the Dutch Caribbean shorelines, it is important to quantify the environmental impacts of no action on critical coastal habitats, such as coral reefs, seagrass beds and mangroves. Direct environmental impact include loss of these critical coastal habitats, while indirect environmental impact includes how loss of these critical habitats may affect animal populations (e.g. fish, birds) that depend on these critical habitats and coastal protection, and how organic loading of coastal systems with pelagic Sargassum may affect water quality in the long term. 
KG 2 - Best practices to reduce environmental impact of Sargassum influxes, cleanups and harvesting methods: where, when and how

As described in chapter 2.1, pelagic Sargassum rafts are considered the "golden floating rainforest of the Atlantic Ocean" as they provide essential habitats for a wide range of organisms and serve as hotspots for biodiversity and productivity in otherwise substrate poor, low-nutrient open-ocean waters. As such, (large-scale) offshore harvesting of pelagic Sargassum for commercial purpose, will a have a negative effect on biodiversity. However, in case these massive Sargassum rafts hit the shore, they will have severe impact on coastal habitats, and as such will reduce biodiversity and coastal ecosystem resilience. As such, there is a trade-off on whether or not to harvest Sargassum to reduce environmental impact, which depends on the likelihood of the harvested Sargassum to reach the shore, when not harvested. This trade-off thus depends on where and when the Sargassum is harvested and needs to be studied in detail to develop best practices with regard to Sargassum influx management and control with lowest environmental impact. Moreover, harvesting techniques need to be developed that minimize by-catch of fauna associated to Sargassum rafts (e.g. fish, turtles). In addition, the environmental impact of using specific barriers to prevent Sargassum from beaching and of the use of specific techniques to harvest Sargassum that concentrates behind the barriers, needs to be assessed. For example, location and type of barriers used to concentrate pelagic Sargassum should not interfere with migration of marine fauna.

KG 3 - Quantities that can be harvested: where, when and how

Not knowing when, how much or where Sargassum influxes will occur is a major challenge that hinders investment to protect critical coastal habitats from Sargassum influxes, to develop uses for Sargassum, and to scale-up existing small or medium enterprises into major commercial ventures [89]. As such, KG 3 refers to challenges regarding the prediction of when, how much and where Sargassum influxes will occur in the Dutch Caribbean waters. These amounts need to be estimated as accurate as possible, as they represent the real amount of biomass that would be possible to harvest or to process for the value chain. State-of-the-art satellite monitoring systems are needed for this estimation. There are currently several companies and institutions offering technologies for monitoring and prediction of Sargassum blooms in the Caribbean region (summarized in chapter 2.5.1), which can also can be hired to map and predict (harvestable) Sargassum biomass in the Dutch Caribbean waters.

KG 4 - Development of protocols and policies for Sargassum influx prevention, cleanup and harvesting: where, when how and who

Based on the results of studies addressing KG1 to KG3, the practices with minimal environmental impact need to be translated into protocols and policies for good practices on Sargassum management and control (i.e. preventing Sargassum from beaching, coastal clean-ups, and (nearshore)

harvesting). Policies for sustainable Sargassum harvesting need to be de developed before a company can start harvesting. One approach could be to make a bilateral agreement between a local government and a specific company for a specific use of Sargassum that is harvested in territorial waters, within 12 nautical miles from the coast. A licence system seems appropriate, but should be developed in consultation with the local government. In chapter 7, more in-depth advice on Sargassum policy development is described.

\section{KG 5 - Development of Sargassum farms for a continuous supply}

Due to the large unpredictability in the natural availability of Sargassum, Sargassum farms, alone or in combination with other seaweeds of interest, need to be developed to safeguard the continuous supply of Sargassum biomass to the value chain. This approach is followed by Fearless Funds, but isn't researched for the Dutch Caribbean.

\section{KG 6 - Cost/profit analysis of nearshore harvesting and ensiling}

There are no economic data available of the costs of the harvesting and storage. New infrastructures and logistic systems are needed to integrate the harvesting and storage into the current functions of 
harbours, warehouse and transportation networks. A simulation model can be constructed, using the output from other research activities and estimates from involved companies.

\subsection{Knowledge gaps: storage, processing and conversion}

\section{KG 7 - Adaptation of storage to the processing step and scaling of facilities}

The availability of Sargassum biomass will influence the size of the facilities for storage and processing. Because of the variability of the blooms, it is important to have a flexible system for storage and processing. Anaerobic digestion is a technology that can be run in modules, and the volumes of the process can be adapted to the availability of the feedstocks. Several methods for storage have been defined, but need to be adapted to the conditions of the islands and the requirements of the processing afterwards. Ensiling seems to be the most adequate solution for storage for short and mid-term (up to months).

KG 8 - Identification and quantification of suitable co-feedstocks for bio-fuel, fertilizer, and animal feed applications of Sargassum

The digestibility of Sargassum during anaerobic digestion has been reported to be relatively poor compared to other organic materials due to the content in salts and other elements (see chapter 3 ) and low content in free carbohydrates. Therefore, Co-digestion of Sargassum with a rich organic feedstock, such as food waste, agricultural rest streams or the organic fraction of municipal solid waste (MSW) is required. Availability and composition of organic feedstocks in the area need to be determined, in order to explore the best suitability. It might be possible that new procedures for waste collection for these feedstock's need to be put in place in the area. Processes for anaerobic digestion, fermentation, extraction or other need to be developed adapted to the specific feedstocks and the products of interest.

\section{KG 9 - Fate of potential toxins stored in Sargassum tissues}

The Sargassum biomass has a high content in salts and heavy metals. During decay of the biomass (Sargassum landfills or dumps) or during processing of the biomass these elements may leach into the environment or in the process streams. To determine how and where these potential toxic compounds accumulate is very important to evaluate potential risks and define good practices.

\section{KG 10 - Removal of plastics or other components in the biomass}

This knowledge gap addresses the practical issues related to harvesting and removing unwanted components in the biomass. In the Sargassum mats there is plastics present, as well as wild life. These need to be separated during harvesting or directly afterwards to avoid problems in the processing or effects on biodiversity.

\section{KG 11 - Development of techniques to create a continuous supply}

This knowledge gap is related to KG 7, but addresses the establishment of a continuous supply of the biomass. In case this is desirable for a certain application, new methods have to be found for long term storage (from several months on). In a mid-term, development of Sargassum farms that can supply the biomass at a regular basis could be considered (see section 5.1). 


\subsection{Knowledge gaps: application of products}

KG 12 - Effect of salts, metals and elements in Sargassum-based products on the environment

The effect on soil and groundwater properties when using Sargassum or Sargassum-based products for agricultural purpose need to be determined, due to the high concentration of salt and potentially high levels of other toxins (e.g. arsenic, other heavy metals, pollutants) in Sargassum. How the soil would absorb these components, and how they are potentially absorbed by vegetation needs to be determined to prevent possible negative effects, and determine the maximum dosage to be used.

KG 13 - Market analysis Sargassum-based products (i.e. biofuel, fertilizer for crops, animal feed supplement)

The market needs and the possibilities to integrate Sargassum-based products in the local situations need to be addressed. When Sargassum can be converted to biofuel, fertilizer, soil additive, or animal feed supplement, the island economies will become less dependent on import of these products, which will increase their resilience. The possibility for the use of Sargassum-based biogas in the electricity network needs to be assessed. Cost and profit analysis is needed for each application. Export of the products locally or internationally needs to be assessed in view of availability of the feedstock, and the specific product.

KG 14 - What are other potential products of Sargassum for the small islands in the Caribbean?

Local initiatives to use Sargassum in products like soaps or cosmetics are already in place in Barbados (section 3.2.1), for example. These type of applications require less volumes of the biomass and help the development of small businesses. The possibilities for such initiatives in the Dutch Caribbean should be explored.

\subsection{Knowledge gaps: socio-economic impacts}

KG 15 - Costs of no action (direct and indirect)

A study of the social and economic impacts of Sargassum blooms, and not taking action to harvest these blooms, would shed light on the economic impacts now. This makes it visible who bears the current costs of Sargassum blooms and enables comparison with the economics and harvesting and processing.

KG 16 - Identification of stakeholders relevant for Sargassum harvesting, processing and commercialization of products

KG 17 - Socio-economic effects of the Sargassum based innovations: employment, infrastructures, etc.

This KG addresses the need to understand the economic feasibility of harvesting and processing the blooms before washing ashore, and evaluate the economic effects of the Sargassum based innovations. Based on these insights, different valorization routes can be prioritized.

\section{KG 18 - Supplementary local data to optimize the Value Chain Analysis}

Recent investigations into seaweed value chain have highlighted the importance of non-financial issues in value chain analysis, i.e. a proper understanding of value chain requires one to look into relations between actors, information sharing, patent protection and more. This knowledge is not available yet for the potential Sargassum value chains. 
KG 19 -Replacement effects (e.g. reducing the need for imports of fossil fuels, fertilizers and animal feed, improvement of resource security)

If Sargassum blooms are harvested for processing into (various) products comparative assessment of the environmental impacts should be conducted. Life Cycle Assessment (LCA) is a well-established method. It can include analysis of the Carbon Footprint of various potential Sargassum applications.

\subsection{Implementation plan}

Based on the current knowledge around the massive Sargassum blooms of the last years and their negative effects on the environment and the economy of the affected areas, it is clear that actions are required on several fronts to relief these effects and prevent new landings on the coasts. Any action related to pelagic Sargassum harvesting and processing needs to be defined after environmental, techno-economic and societal issues are taken into account and integrated in the wide policy of nature conservation in the areas.

A total of 19 knowledge gaps (KG) are identified that hamper the sustainable implementation of value chains for harvesting and processing of the Sargassum biomass into energy and agricultural products that are of interest for the islands. These KG are partially related to each other - some can only be addressed when others are solved. A stepwise approach, scheduled in three phases, to tackling the KG is proposed below (Fig. 15). In the following text, for each of the three phases, activities are described to fill the KG that we have identified. It is important to mention that KG are interrelated, and that the results of each activity would be of importance for several KG. This implementation plan is indicative and a specific plan needs to be defined depending on the geographical location of implementation, the partners involved, legislation aspects and the products of interest.

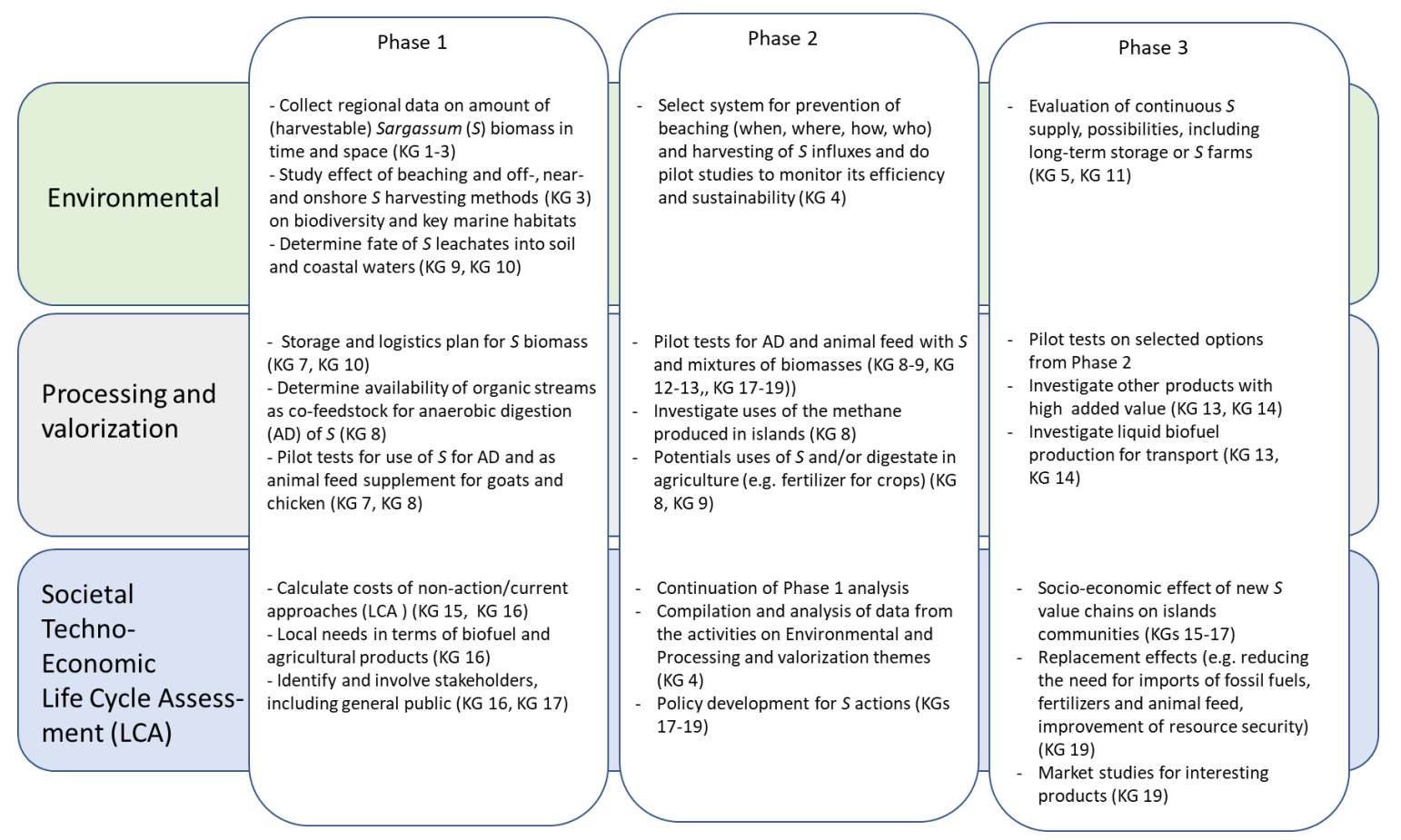

Figure 15 Implementation plan including tasks for a 3-phase Action plan to establish sustainable value chains for Sargassum (S) management and valorisation. The main KGs that relate to the activities are shown in brackets 


\subsubsection{Implementation plan: Phase 1}

First tasks are focused on determination of the environmental impacts, including impact on biodiversity, of different methods for pelagic Sargassum harvesting through pilot studies. Based on the results of these pilot studies the most sustainable harvesting method will be selected for use in practice, thus filling KG 1 and KG 2. Using monitoring systems and prediction tools, the amount of pelagic Sargassum that is available for harvest within defined time periods in the Dutch Caribbean region will be identified (KG 3 ).

An essential aspect for the applications and the ecological impact of valorisation of Sargassum biomass is related to its chemical composition, and in particular on its content of heavy metals (i.e. arsenic and iodine), which greatly vary in space and time. The chemical composition of Sargassum samples needs to be monitored using state-of-the-art analytical techniques, as those used by WFSR in the analysis done in this project. Specific attention will be given to the fate of heavy metals, arsenic and iodine of Sargassum leaching into the environment during the decay or processing of the biomass (KG 9), by analysing Sargassum biomass and environmental samples such as soil and water. The environmental impact of leachates of Sargassum needs to be determined in an early stage of the plan, to define best practices regarding storage of the Sargassum biomass, and on its use in different products (KG 9, KG 12). In addition, biomass storage, conditioning and logistics options will be studied to develop the value chain (KG 7, KG 10). To know the potential co-processing biomasses for Sargassum, the availability of organic biomass sources in the area (municipal solid waste, food waste, agricultural residues) will be studied (KG 8). Firsts studies and tests of suitability of the biomass for applications in anaerobic digestion or as feed will be started (KG 7, 8). Also, when processing the Sargassum for valorisation purposes, the different processing streams need to be analysed to explore potential applications of the processed Sargassum. The effect of Sargassum-based fertilisers on soil, groundwater and vegetation will be studied by determining the content of heavy metals, arsenic and iodine in both the fertilisers and environmental samples, contributing to filling KG 12 . With respect to the socio-economic impacts, priority lies in tackling "KG 15 - Costs of no action (direct and indirect)" and "KG 16 - Identification of stakeholders relevant for Sargassum harvesting, processing and commercialization of products". Both provide insight into the current situation and are the basis of evaluating any valorisation options. The KGs "KG 17 - Socio-economic effects of the Sargassum based innovations: employment, infrastructures, etc.", "KG 18 - Supplementary local data to optimize the Value Chain Analysis" and "KG 19 -Replacement effects (e.g. reducing the need for imports of fossil fuels, fertilizers and animal feed, improvement of resource security)" are to tackled in an iterative development process together with the KGs 3, 7, 8, 13 and 14 which focus on the development of Sargassum based markets.

\subsubsection{Implementation plan: Phase 2}

Upon selection of a method for prevention of beaching of the Sargassum biomass and harvesting, first experimental trials are envisaged on Sargassum hotspots or other locations for the harvesting (selected for their suitability) and storage. These activities contribute to filling KG 4 "Development of protocols and policies for Sargassum influx prevention, clean-up and harvesting".

The pelagic Sargassum harvesting and storage techniques and valorisation chains that are selected based on best practices during phase 1, will be upscaled to produce samples for testing. The different processes and applications will be tested at small scale, to generate results to characterize the products and generate data for techno-economical or environmental analysis, filling KG 8, 9, 12 and 13 related to the processing and applications and KG 6 and 17-19 related to the process costs estimation and societal, techno-economic LCA.

Based on the results on the activities on the societal, techno-economic LCA on phase 1 , policy advices and protocols will be developed, filling KG 4 (Development of protocols and policies for Sargassum influx prevention, clean-up and harvesting: where, when, how and how). 


\subsubsection{Implementation plan: Phase 3}

For a sustainable supply of Sargassum biomass there are some options (section 5.1). In this third phase of the plan, the potential for development of dedicated Sargassum farms or farms for other types of seaweeds will be investigated (KG 5). In addition, as Sargassum is a seasonal feedstock, long-term storage methods for Sargassum biomass will be investigated to be able to use it over a longer period of time (KG 11).

The applications of Sargassum as energy or in agriculture or animal feed, although of high importance for islands, are relatively of low economic value. Other processes for more advanced fuels (liquid fuels) or other types of products, with applications in cosmetics, food or pharma, for example, will be evaluated in phase 3. The results of these evaluations would fill KG 13 and 14 .

The new processes and value chains will be evaluated in detail, including market analysis, social acceptance, and carbon foot prints. During these evaluations, data will be collected from all relevant sources and stakeholders (project partners, industry, policy makers, general public, etc.). These evaluations contribute to filling KG 17-19, and will be based on most of the results obtained in the different activities of the implementation plan. 


\section{$8 \quad$ General conclusions}

This report highlights the complexity of the management and valorisation of massive pelagic Sargassum blooms. We conclude that value chains based on valorisation of nearshore Sargassum biomass into biofuel and agricultural products (i.e. fertilizer, animal feed supplement) seem the most promising for the Dutch Caribbean islands, since they will contribute to energy and food security, while reducing environmental impact of the energy and agricultural sector, which are both in agreement with current policies. However, a total of 19 knowledge gaps are identified that currently hamper the sustainable implementation of these value chains. These knowledge gaps need to be filled before (commercial) harvesting and valorisation actions concerning pelagic Sargassum can be taken.

In addition, some general conclusions can be made:

- Pelagic Sargassum provides vital ecosystem services in the ocean, on shore, and on the seafloor, which include provisioning of spawning, nursery and foraging habitat for many organisms, coastal protection, and carbon sequestration. However, at high concentrations, beached or near-shore accumulations of pelagic Sargassum have major ecological and socio-economic impacts on coastal communities.

- The causes of the recent massive Sargassum blooms and influxes, whether they are a natural phenomenon, a result of human activities, or a combination of both, is still not clear. However, these blooms seem likely to persist in the future.

- Recent pelagic Sargassum influxes have already impacted a large number of coastal communities in the Caribbean, the Gulf of Mexico and parts of West Africa, and thus represent a global problem. As such, international collaboration is crucial to get a better understanding of the causes of these blooms, and to develop effective actions to mitigate these blooms in the long term.

- The prevention of massive landings of Sargassum on the coasts is a first step to reduce the negative environmental effects. Prevention of landings of Sargassum on the coasts is preferred to harvesting onshore because of the negative ecological impact of harvesting onshore and the lower quality of beached Sargassum, that decays very rapidly. However, the environmental effects of potential prevention systems (such as barriers) and harvesting methodologies to be used, need to be studied to determine the most effective and sustainable practices. Where possible, the selected Sargassum prevention system and harvesting methodology should be integrated with the development of the most suitable Sargassum value chain for the area.

- From an ecological point of view, harvesting of Sargassum rafts that are nearshore $(<1 \mathrm{~km}$ from the shore) seems the most appropriate. First, because nearshore Sargassum rafts are more likely to strand on the coast when not harvested, so that associated fauna would be lost anyway, and secondly because nearshore harvesting of Sargassum increases the chances of preventing Sargassum biomass to beach on the nearby shore, thus minimizing environmental impact on critical coastal habitats.

- Sargassum management actions should be included in the general management of natural resources on the Dutch Caribbean islands, while specific policies will need to be developed for Sargassum management and valorisation activities.

- The amount of harvestable Sargassum biomass in the Dutch Caribbean waters needs to be quantified in time and space, so that an appropriate business plan can be developed for Sargassumbased valorization chains.

- The supply of Sargassum biomass, in terms of quantities and time of appearance, is uncertain and unpredictable in the long term, which complicates the establishment of Sargassum-based value chains based on anaerobic digestion. This could be solved by development of a more general organic biomass processing value chain that depends on organic biomass with a more predictable supply (e.g. food waste, agricultural waste, and/or municipal solid waste) to which Sargassum biomass can be co-processed when available. This would require an assessment of the availability and suitability of alternative biomass sources in the area, as potential co-processing biomasses for Sargassum.

- There is a wide range of products that can be made from Sargassum. The specific products of interest will depend on the local conditions and legislation. In the case of the Dutch islands, applications as substrate for energy generation (biogas, biofuels) or as soil enhancer or fertilizer would be examples of products that contribute to energy and agricultural resilience. The chemical 
composition of the biomass plays an important role in the applications, and the fate of the components in the environment needs to be monitored.

- Pelagic Sargassum has a high content in salts and heavy metals. The relatively high arsenic and iodine concentrations limit potential of direct applications of the Sargassum in human and animal nutrition and fertilisers. During decay of the biomass (Sargassum landfills or dumps) or during processing of the biomass these elements may leach into the environment or in the process streams. To determine how and where these potential toxic compounds may accumulate, it is very important to evaluate potential risks and define good practices.

- Besides the environmental and techno-economic aspects of the Sargassum management, social aspects (job creation, etc.) and how the new value chains affect the communities involved need to be determined as well. 


\section{Stakeholder analysis along the value chain}

The pelagic Sargassum blooms in the Caribbean, the Sargasso sea and the Gulf of Mexico are not an isolated event, but constitute an environmental problem affecting all communities in these areas. Whether the blooms are natural events or they are a result of the human action on the planet is not known yet. Also, the question regarding the "property" of the Sargassum needs to be answered. However, the direct negative environmental effects of these blooms on Nature, and the resulting negative effects on the tourism and economies of the affected areas is clear and require to take actions at all levels of society.

For future developments of Sargassum solutions and valorisation chains many stakeholders are involved. These stakeholders are diverse, belong to different fields and have different contributions to the chains, starting with Governmental institutions. In this chapter, stakeholders that have been identified are described.

An important network is the one realised by the Delta Team from the Netherlands Water Partnership (NWP), that is focused on the Mexico situation and stakeholders. NWP has organised in 2020 one physical and two online brainstorm and networking sessions, where approx. 50 participants have attended. This NWP team includes also members from RVO and are dedicated to find solutions to the Sargassum problem in Mexico and have active support from the Dutch embassy in Mexico.

Table 8 National and international consortia that are involved in Sargassum management or valorisation activities.

\begin{tabular}{|c|c|}
\hline National consortia & Area of work \\
\hline OLB & Policy \\
\hline $\mathrm{RCN}$ & Policy \\
\hline LNV & Policy \\
\hline RWS/I\&W & Policy \\
\hline DCNA & Nature Conservation \\
\hline STINAPA & Nature Conservation \\
\hline $\begin{array}{l}\text { Damen Shipyards Group / Maris } \\
\text { Projects }\end{array}$ & $\begin{array}{l}\text { Harvesting } \\
\text { Valorisation to biogas } \\
\text { https://www.damen.com/en/news/2019/10/ } \\
\text { damen_partners with maris to consider seaweed solution }\end{array}$ \\
\hline $\begin{array}{l}\text { WUR } \\
\text { MMIP-WUR }\end{array}$ & $\begin{array}{l}\text { Wageningen International, WMR, WFBR, WEcR, WFSR } \\
\text { Seaweed valorisation programs }\end{array}$ \\
\hline MMIP-18 & $\begin{array}{l}\text { Consortium coordinated by Climate Clean Up. Works on uses of } \\
\text { Sargassum as carbon sink url: https://climatecleanup.org/sargassum/ }\end{array}$ \\
\hline \multicolumn{2}{|l|}{$\begin{array}{l}\text { Netherlands Water Partnership } \\
\text { (NWP) }\end{array}$} \\
\hline International consortia & Area of work \\
\hline France & ANR program 2019, several research projects on Sargassum \\
\hline UK & $\begin{array}{l}\text { The UK seaweed biorefinery program is being developed. The University } \\
\text { of Nottingham is involved. }\end{array}$ \\
\hline Mexico- Different initiatives & $\begin{array}{l}\text { Mitigation of the effects of the blooms at Quintana Roo, Cancun. } \\
\text { Consortia including UNAM and other Mexican Universities and Institutes } \\
\text { are active on several topics. }\end{array}$ \\
\hline US- Fearless Funds DOE & Sargassum farming in the Caribbean and US coasts \\
\hline The Climate Foundation & Policy \\
\hline ARPA-E US program & Research and innovation funding for seaweed research \\
\hline Sargassum sea Commission & $\begin{array}{l}\text { Policy, communication } \\
\text { http://www.sargassoseacommission.org/about-the-sargasso-sea }\end{array}$ \\
\hline
\end{tabular}


Table 9 National and international parties (industry, research institutions, NGOs, besides those included already as partners).

\begin{tabular}{|c|c|}
\hline Dutch parties & Area of work \\
\hline All Optimal BV & Anaerobic digestion of agri-food streams \\
\hline Deltares & Consulting. Knowledge of Sargassum from projects in Mexico \\
\hline $\begin{array}{l}\text { Damen Shipyards Group, Royal } \\
\text { Boskalis Westminster NV }\end{array}$ & Large dredging and shipping companies \\
\hline Radboud University Nijmegen & Research on impact of Sargassum influx on coastal systems Bonaire \\
\hline BlueO2 (SME) & Uses of seaweed as fertilizer \\
\hline Companies on animal feed & Examples of companies: Agrifirm, Nutrition Science \\
\hline Climate Cleanup & Sargassum collection, blue carbon \\
\hline NIOZ & Sargassum metagenomics and population genetics \\
\hline $\begin{array}{l}\text { International parties and } \\
\text { projects }\end{array}$ & Area of work \\
\hline CLS (France, company) & Sargassum forecast tools \\
\hline Nova Blue Environment & Sargassum forecast tools \\
\hline $\begin{array}{l}\text { EU MacroFuels, EU } \\
\text { Macrocascade (EU funded } \\
\text { projects) }\end{array}$ & Production of fuels and value added products from cultivated seaweed \\
\hline $\begin{array}{l}\text { ANR (France, Research) } \\
\text { IFREMER }\end{array}$ & $\begin{array}{l}\text { All areas related to Sargassum. A list of projects funded in the } 2019 \\
\text { call: } \text { https://anr.fr/en/funded-projects-and-impact/funded- } \\
\text { projects/?q=Sargassum\&id=1781\&L=1 }\end{array}$ \\
\hline Enzyme producers & Examples: Dupont, Novozymes, DSM \\
\hline Producers of hydrocolloids & Examples: Dupont (FMC-alginate), Cargill, Algaia \\
\hline Olmix & Cultivation and uses of seaweed for fertilizer \\
\hline University of Barbados & Sargassum valorisation \\
\hline WNF Bonaire (NGO) & World Nature Conservation Fund \\
\hline Ocean2050 (NGO) & NGO that enables networking for Ocean related projects \\
\hline $\begin{array}{l}\text { Tourism councils in the } \\
\text { Caribbean }\end{array}$ & Associations of parties involved in tourism \\
\hline Phycomex & Sargassum to fertiliser \\
\hline
\end{tabular}




\section{Other studies on pelagic Sargassum management}

The Sargassum blooms have been the subject of a large number of studies, from fundamental science to practical guides and policy studies. Below, a list of relevant reports on different fields and by different authors is shown.

1. "Sargassum Uses Guide: A resource for Caribbean researchers, entrepreneurs and policy makers" published by the Centre for Resource Management and Environmental Studies (CERMES), University of the West Indies, Cave Hill Campus, Barbados, authored by Desrochers et al. (2020) [89].

This excellent recent study gives a very complete overview on the uses of Sargassum, and includes lists and descriptions of stakeholders, policy advices and other interesting information.

2. "The feasibility of using macroalgae from anaerobic digestion as fertilizer in Grenada: A literature study of the potential use of residue as fertilizer in Grenada, and a complementary laboratory study to evaluate the biogas potential" Published by the KTH University in Sweden with authors Sterley and Thörnkvist (2020) [99].

Study on the possibilities for using Sargassum as a feedstock for biogas and fertilizer production in the island of Grenada. The benefits of this approach are studied in the context of environmental benefits and reducing imports of fertilizer.

3. "The protection and management of the Sargasso Sea: The golden floating rainforest of the Atlantic Ocean. Summary Science and Supporting Evidence Case" Published by the Sargasso Sea Alliance, with authors Laffoley et al. (2011) [150].

This report provides a summary of the scientific and other supporting evidence for the importance of the Sargasso Sea and is intended to develop international recognition of this; to start the process of establishing appropriate management and precautionary regimes within existing agreements; and to stimulate a wider debate on appropriate management and protection for the High Seas. The reasons for the importance of this sea and of Sargassum are described, and real and potential risks due to human activities, such as over-fishing, are described, and advices are gives for actions to protect this area.

4. "Sustainable energy, transportation, and resilience in the Caribbean: a White paper for the Caribbean Forum on Sustainable Energy, Transportation and Resilience". Report of The Caribbean Forum on Energy, Transport and Resilience congress (Bay Gardens Hotel, Rodney Bay, Saint Lucia, June 26-27, 2019). Published by Organization of American States, Department of Sustainable Development. Authored by Curtis Boodoo [154].

The Caribbean Forum on Energy, Transport, and Resilience in 2019 was hosted by the Organization of American States (OAS) and the Government of Saint Lucia, with support from the Organisation of Eastern Caribbean States (OECS) Commission. With the objective of exploring new technologies and combining them with existing regional experiences in sustainable urban development, the event had an overall goal to design a roadmap for the Caribbean smart cities of the future. The forum sought to further public-private exchanges among governments, energy and transportation experts, and the private sector. It addressed multiple aspects, such as technology innovation, policy and regulation, infrastructure resilience, and financing and brought together utilities, policy makers, physical planners, multilateral institutions, universities, and the private sector from across the Caribbean to build a blueprint for resilient energy and transportation infrastructure, and to exchange ideas, best practices, and technologies. 
5. "Quintana Roo, recommendations on how to deal with urgent challenges posted by coastal erosion and sargassum". Final report from the Delta Cooperation Program Mexico - The Netherlands, and the workshop on 25 October 2018. Published by RvO, with authors Arent van Wassenaer and Roberto Hernández Garcia [155, Summary].

Relevant reports for Dutch Caribbean:

6. Verweij et al. (2020). A nature inclusive vision for Bonaire in 2050 [151].

In this study a vision for Bonaire is portrayed, in which nature and natural processes play a key role in all development activities.

7. Prevention and clean-up of Sargassum in the Dutch Caribbean (2019) DCNA letter [153].

This management brief focuses on the immediate problem of clean-up after mass strandings of pelagic Sargassum in the Dutch Caribbean, helping coastal communities find effective solutions for the collection and use of Sargassum.

8. van der Geest et al. (2019). Nexus interventions for small tropical islands: case study Bonaire [156].

Using the Caribbean island of Bonaire as a case study, this study explores how a holistic "NEXUS approach" that considers the inter-connections between water, food, and energy sectors in relation to the ecosystems on which these sectors depend, can aid resource and ecosystem security in SIDS.

\section{Acknowledgements}

This work was financed by the Dutch Ministry of Agriculture, Nature and Food Quality through the TKIAgrifood program (project nr LWV19070). Besides the collaborators mentioned already, the authors wish to thank Ria Hulsman (Wageningen International) and Erik Plaisier and the team of the Agriculture section of the Dutch Embassy in Mexico for useful discussions. 


\section{Literature}

1. Winge, O. 1923. The Sargasso Sea, its boundaries and vegetation. Carlsberg Physiological Laboratory, Copenhagen, Denmark.

2. Butler, J. N., B. F. Morris, J. CaDWallader, and A. W. Stoner. 1983. Studies of Sargassum and the Sargassum community. Bermuda Biological Station.

3. Parr, A. D. 1939. Quantitative observations on the pelagic Sargassum vegetation of the western North Atlantic. Bulletin of the Bingham Oceanograpic Collection, Yale Univ. 6 (7):1-94.

4. Amaral-Zettler, L. A., N. B. Dragone, J. Schell, B. Slikas, L. G. Murphy, C. E. Morrall, and E. R. Zettler. 2017. Comparative mitochondrial and chloroplast genomics of a genetically distinct form of Sargassum contributing to recent "Golden Tides" in the Western Atlantic. Ecology and Evolution 7:516-525.

5. Hanisak, M. D. and M. A. Samuel. 1987. Growth rates in culture of several species of Sargassum from Florida, USA. Hydrobiologia 151, 399-404. Springer Netherlands.

6. Wang, M., C. Hu, B. B. Barnes, G. Mitchum, B. Lapointe, and J. P. Montoya. 2019. The great Atlantic Sargassum belt. Science (New York, N.Y.) 365:83-87.

7. Laffoley, D. d. A., H. S. J. Roe, M. V. Angel, J. Ardron, N. R. Bates, I. L. Boyd, S. Brooke, K. N. Buck, C. A. Carlson, B. Causey, M. H. Conte, S. Christiansen, J. Cleary, J. Donnelly, S. A. Earle, R. EDWards, K. M. Gjerde, S. J. Giovannoni, S. Gulick, M. Gollock, J. Hallett, P. Halpin, R. Hanel, A. Hemphill, R. J. Johnson, A. H. Knap, M. W. Lomas, S. A. McKenna, M. J. Miller, P. I. Miller, F. W. Ming, R. Moffitt, N. B. Nelson, L. Parson, A. J. Peters, J. Pitt, P. Rouja, J. Roberts, J. Roberts, D. A. Seigel, A. N. S. Siuda, D. K. Steinberg, A. Stevenson, V. R. Sumaila, W. Swartz, S. Thorrold, T. M. Trott, and V. Vats. 2011. The protection and management of the Sargasso Sea: The golden floating rainforest of the Atlantic Ocean. Summary Science and Supporting Evidence Case. Sargasso Sea Alliance, 44pp.

8. Haney, J. C. 1986. Seabird Patchiness in Tropical Oceanic Waters: The Influence of Sargassum "Reefs". The Auk 103:141-151.

9. Coston-Clements, L., L. Settle, D. Hoss, and F. Cross. 1991. Utilization of the Sargassum habitat by marine invertebrates and vertebrates: A review. National Marine Fisheries Service, NOAA, Beaufort, NC.

10. Witherington, B., S. Hirama, and R. Hardy. 2012. Young sea turtles of the pelagic Sargassumdominated drift community: habitat use, population density, and threats. Marine Ecology Progress Series 463:1-22.

11. Council, S. A. F. M. 2002. Fishery management plan for pelagic Sargassum habitat of the South Atlantic region: South Carolina.

12. Williams, A. and R. Feagin. 2010. Sargassum as a natural solution to enhance dune plant growth. Environmental Management 46:738-747.

13. Innocenti, R. A., R. A. Feagin, and T. P. Huff. 2018. The role of Sargassum macroalgal wrack in reducing coastal erosion. Estuarine, Coastal and Shelf Science 214:82-88.

14. Weis, J. S. 1968. Fauna associated with pelagic Sargassum in the Gulf Stream. The American Midland Naturalist 80:554-558.

15. Schoener, A. and G. T. Rowe. 1970. Pelagic Sargassum and its presence among the deep-sea benthos. Deep Sea Research and Oceanographic Abstracts 17:923-925.

16. Fleury, A. G. and J. C. Drazen. 2013. Abyssal scavenging communities attracted to Sargassum and fish in the Sargasso Sea. Deep Sea Research Part I: Oceanographic Research Papers 72:141-147.

17. Baker, P., U. Minzlaff, A. Schoenle, E. Schwabe, M. Hohlfeld, A. Jeuck, N. Brenke, D. Prausse, M. Rothenbeck, S. Brix, I. Frutos, K. M. Jörger, T. P. Neusser, R. Koppelmann, C. Devey, A. Brandt, and H. Arndt. 2018. Potential contribution of surface-DWelling Sargassum algae to deep-sea ecosystems in the southern North Atlantic. Deep-Sea Research Part II 148:21-34.

18. Krause-Jensen, D. and C. M. Duarte. 2016. Substantial role of macroalgae in marine carbon sequestration. Nature Geoscience 9:737-742.

19. Woodcock, A. H. 1950. Subsurface pelagic Sargassum. J. Mar. Res. 9:77-92.

20. Johnson, D. L. and P. L. Richardson. 1977. On the wind-induced sinking of Sargassum. Journal of Experimental Marine Biology and Ecology 28:255-267. 
21. Fabry, V. J. and W. G. Deuser. 1991. Aragonite and magnesian calcite fluxes to the deep Sargasso Sea. 38:713-728.

22. Siegel, D. A. and W. G. Deuser. 1997. Trajectories of sinking particles in the Sargasso Sea: modeling of statistical funnels above deep-ocean sediment traps. Deep Sea Research Part I: Oceanographic Research Papers 44:1519-1541.

23. Stoner, A. W. 1983. Pelagic Sargassum: Evidence for a major decrease in biomass. Deep Sea Research Part A. Oceanographic Research Papers 30:469-474.

24. Butler, J. N. and A. W. Stoner. 1984. Pelagic Sargassum: has its biomass changed in the last 50 years? Deep Sea Research Part A. Oceanographic Research Papers 31:1259-1264.

25. Gower, J. F. R. and S. A. King. 2011. Distribution of floating Sargassum in the Gulf of Mexico and the Atlantic Ocean mapped using MERIS. International Journal of Remote Sensing 32:1917-1929.

26. Gower, J., C. Hu, G. Borstad, and S. King. 2006. Ocean color satellites show extensive lines of floating Sargassum in the Gulf of Mexico. IEEE Transactions on Geoscience and Remote Sensing 44:3619-3625.

27. Gower, J. and S. King. 2008. Satellite images show the movement of floating Sargassum in the Gulf of Mexico and Atlantic Ocean. Nature Proceedings.

28. Franks, J. S., D. R. Johnson, D. S. Ko, G. S. Rubio, J. R. Hendon, and M. Lay. 2011. Unprecedented influx of pelagic Sargassum along Caribbean island coastlines during summer 2011. Pages 6-8 in Proceedings of the 64th Gulf and Caribbean Fishery Institute, Puerto Morelos, Mexico.

29. Gower, J., E. Young, and S. King. 2013. Satellite images suggest a new Sargassum source region in 2011. Remote Sensing Letters 4:764-773.

30. van Tussenbroek, B. I., H. A. Hernández Arana, R. E. Rodríguez-Martínez, J. Espinoza-Avalos, H. M. Canizales-Flores, C. E. González-Godoy, M. G. Barba-Santos, A. Vega-Zepeda, and L. ColladoVides. 2017. Severe impacts of brown tides caused by Sargassum spp. on near-shore Caribbean seagrass communities. Marine Pollution Bulletin 122:272-281.

31. Rodríguez-Martínez, R. E., A. E. Medina-Valmaseda, P. Blanchon, L. V. Monroy-Velázquez, A. Almazán-Becerril, B. Delgado-Pech, L. Vásquez-Yeomans, V. Francisco, and M. C. García-Rivas. 2019. Faunal mortality associated with massive beaching and decomposition of pelagic Sargassum. Marine Pollution Bulletin 146:201-205.

32. Putman, N. F., G. J. Goni, L. J. Gramer, C. Hu, E. M. Johns, J. Trinanes, and M. Wang. 2018. Simulating transport pathways of pelagic Sargassum from the Equatorial Atlantic into the Caribbean Sea. Progress in Oceanography 165:205-214.

33. Johns, E. M., R. Lumpkin, N. F. Putman, R. H. Smith, F. E. Muller-Karger, D. T. Rueda-Roa, C. Hu, M. Wang, M. T. Brooks, L. J. Gramer, and F. E. Werner. 2020. The establishment of a pelagic Sargassum population in the tropical Atlantic: Biological consequences of a basin-scale long distance dispersal event. Progress in Oceanography 182.

34. Franks, J. S., D. R. Johnson, and D. S. Ko. 2016. Pelagic Sargassum in the tropical North Atlantic. Gulf and Caribbean Research 27:SC6-SC11.

35. Johnson, D. R., D. S. Ko., J. S. Franks, P. Moreno, and G. Sanchez-Rubio. 2013. The Sargassum invasion of the Eastern Caribbean and dynamics of the Equatorial North Atlantic. in Proceedings of the 65th Gulf and Caribbean Fisheries Institute, Santa Marta, Colombia.

36. Djakouré, S., M. Araujo, A. Hounsou-Gbo, C. Noriega, and B. Bourlès. 2017. On the potential causes of the recent Pelagic Sargassum blooms events in the tropical North Atlantic Ocean. Pages 1-20. Copernicus $\mathrm{GmbH}$.

37. Louime, C, Fortune, J and Gervais, G. 2017 Sargassum invasion of coastal environments: a growing concern. American Journal of Environmental Sciences 13(1): 58-64

38. Sissini, M. N., M. B. B. de Barros Barreto, M. T. M. Széchy, M. B. a. de Lucena, M. C. Oliveira, J. Gower, G. Liu, E. de Oliveira Bastos, D. Milstein, F. Gusmão, J. E. Martinelli-Filho, C. c. AlvesLima, P. Colepicolo, G. Ameka, K. de Graft-Johnson, L. Gouvea, B. Torrano-Silva, F. Nauer, J. M. de Castro Nunes, J. B. Barufi, L. Rörig, R. Riosmena-Rodríguez, T. J. Mello, L. V. C. Lotufo, and P. A. Horta. 2017. The floating Sargassum (Phaeophyceae) of the South Atlantic Ocean - likely scenarios. Phycologia 56:321-328.

39. Oviatt, C. A., K. Huizenga, C. S. Rogers, and W. J. Miller. 2019. What nutrient sources support anomalous growth and the recent Sargassum mass stranding on Caribbean beaches? A review. Marine Pollution Bulletin 145:517-525.

40. Chávez, V., A. Uribe-Martínez, E. Cuevas, R. E. Rodríguez-Martínez, B. I. van Tussenbroek, V. Francisco, M. Estévez, L. B. Celis, L. V. n. Monroy-Velázquez, R. Leal-Bautista, L. Álvarez-Filip, M. 
García-Sánchez, L. Masia, and R. Silva. 2020. Massive influx of pelagic Sargassum spp. on the coasts of the Mexican Caribbean 2014-2020: challenges and opportunities. Water 12:2908.

41. James, R. K., R. Silva, B. I. van Tussenbroek, M. Escudero-Castillo, I. Mariño-Tapia, H. A. Dijkstra, R. M. van Westen, J. D. Pietrzak, A. S. Candy, C. A. Katsman, C. G. van der Boog, R. E. M. Riva, C. Slobbe, R. Klees, J. Stapel, T. van der Heide, M. M. van Katwijk, P. M. J. Herman, and T. J. Bouma. 2019. Maintaining Tropical Beaches with Seagrass and Algae: A Promising Alternative to Engineering Solutions. BioScience 69:136-142.

42. Cabanillas-Terán, N., H. A. Hernández-Arana, M.-Á. Ruiz-Zárate, A. Vega-Zepeda, and A. Sanchez-Gonzalez. 2019. Sargassum blooms in the Caribbean alter the trophic structure of the sea urchin Diadema antillarum. Peer].

43. Antonio-Martínez, F., Y. Henaut, A. Vega-Zepeda, A. I. Cerón-Flores, R. Raigoza-Figueras, N. P. Cetz-Navarro, and J. Espinoza-Avalos. 2020. Leachate effects of pelagic Sargassum spp. on larval swimming behavior of the coral Acropora palmata. Scientific Reports 10.

44. Gavio, B. and A. Santos-Martínez. 2018. Floating Sargassum in Serranilla Bank, Caribbean Colombia, may jeopardize the race to the ocean of baby sea turtles. Acta Biol. Col. 23:311-314.

45. Maurer, A., S. Stapleton, and C. Layman. 2018. Impacts of the Caribbean Sargassum influx on sea turtle nesting. In Proceedings of the 71st Gulf and Caribbean Fisheries Institute, San Andres, Colombia.

46. Alvarez-Filip, L., N. Estrada-Saldívar, E. Pérez-Cervantes, A. Molina-Hernández, and F. J. González-Barrios. 2019. A rapid spread of the stony coral tissue loss disease outbreak in the Mexican Caribbean. Peer] 7:e8069.

47. Doyle, E. and J. Franks. 2015. Sargassum Fact Sheet. Gulf and Caribbean Fisheries Institute.

48. Milledge, J. and P. Harvey. 2016. Golden tides: problem or golden opportunity? The valorisation of Sargassum from beach inundations. Journal of Marine Science and Engineering 4:60.

49. https://www.dcnanature.org/

50. Smetacek, V. and A. Zingone. 2013. Green and golden seaweed tides on the rise. Nature 504:8488.

51. Maréchal, J.-P., C. Hellio, and C. Hu. 2017. A simple, fast, and reliable method to predict Sargassum washing ashore in the Lesser Antilles. Remote Sensing Applications: Society and Environment 5:54-63.

52. Wang, M. and C. Hu. 2017. Predicting Sargassum blooms in the Caribbean Sea from MODIS observations. Geophysical Research Letters 44:3265-3273.

53. Wang, M., C. Hu, J. Cannizzaro, D. English, X. Han, D. Naar, B. Lapointe, R. Brewton, and F. Hernandez. 2018. Remote Sensing of Sargassum Biomass, Nutrients, and Pigments. Geophysical Research Letters 45:12,359-12,367.

54. Putman, N. F., R. Lumpkin, M. J. Olascoaga, J. Trinanes, and G. J. Goni. 2020. Improving transport predictions of pelagic Sargassum. Journal of Experimental Marine Biology and Ecology 529: 151398.

55. Sargassum Early Advisory System www.Seas-forecast.com

56. Sargassum Watch System www.optics.marine.usf.edu/projects/SaWS.html

57. CERMES Sargassum Outlook Bulletin www.cavehill.uwi.edu/cermes/projects/sargassum/outlookbulletin.aspx

58. SAMtool https://datastore.cls.fr/products/sargassum

59. Tjiong, W. 2020. Mapping Sargassum on beaches and coastal waters of Bonaire using Sentinel-2 imagery. [publisher not identified], [Netherlands].

60. https://www.theoceancleaner.com

61. Vos et al (2016) "Coastal Seaweed solutions" TU-Delft student report. Link: http://resolver.tudelft.nl/uuid:4de9aa1b-a9a9-4dcb-bfef-82fe4ae0584c

62. https://www.damen.com/en/news/2019/10/ damen partners with maris to consider seaweed solution

63. https://www.excelsior.com.mx/nacional/este-es-el-buque-sargacero-que-llego-a-playas-dequintana-roo/1364823

64. Milledge, J.J.; Heaven, S. Methods of energy extraction from microalgal biomass: A review. Rev. Environ. Sci. Biotechnol. 2014, 13, 301-320.

65. Bruton, T.; Lyons, H.; Lerat, Y.; Stanley, M.; Rasmussen, M.B. A Review of the Potential of Marine Algae as a Source of Biofuel in Ireland; Sustainable Energy Ireland: Dublin, Ireland, 2009.

66. Milledge, J.J.; Staple, A.; Harvey, P. Slow pyrolysis as a method for the destruction of Japanese wireweed, Sargassum muticum. Environ. Nat. Resour. Res. 2015, 5, 28-36. 
67. Milledge, J.J.; Harvey, P.J. Potential process "hurdles" in the use of macroalgae as feedstock for biofuel production in the British isles. J. Chem. Technol. Biotechnol. 2016, 91, 2221-2234.

68. Aresta, M.; Dibenedetto, A.; Barberio, G. Utilization of macro-algae for enhanced $\mathrm{CO}_{2}$ fixation and biofuels production: Development of a computing software for an LCA study. Fuel Process. Technol. 2005, 86, 1679-1693.

69. Fudholi, A.; Sopian, K.; Othman, M.Y.; Ruslan, M.H. Energy and exergy analyses of solar drying system of red seaweed. Energy Build. 2014, 68, 121-129.

70. Valderrama, D.; Cai, J.; Hishamunda, N.; Ridler, N. Social and Economic Dimensions of Carrageenan Seaweed Farming; FAO Fisheries and Aquaculture technical paper 580; FAO: Rome, Italy, 2014.

71. Brennan, L.; Owende, P. Biofuels from microalgae-A review of technologies for production, processing, and extractions of biofuels and co-products. Renew. Sustain. Energy Rev. 2010, 14, 557-577.

72. Oswald, W.J. Large-scale algal culture systems (engineering aspects). In Micro-Algal Biotechnology; Borowitzka, M.A., Borowitzka, L.J., Eds.; Cambridge University Press: Cambridge, UK, 1988.

73. Chan, J.C.C.; Cheung, P.C.K.; Ang, P.O. Comparative studies on the effect of three drying methods on the nutritional composition of seaweed Sargassum hemiphyllum (turn) C Ag. J. Agric. Food Chem. 1997, 45, 3056-3059.

74. Gupta, S.; Cox, S.; Abu-Ghannam, N. Effect of different drying temperatures on the moisture and phytochemical constituents of edible Irish brown seaweed. LWT Food Sci. Technol. 2011, 44, 1266-1272.

75. Ryckebosch, E.; Muylaert, K.; Eeckhout, M.; Ruyssen, T.; Foubert, I. Influence of drying and storage on lipid and carotenoid stability of the microalga Phaeodactylum tricornutum. J. Agric. Food. Chem. 2011, 59, 11063-11069.

76. Indrawati, R.; Sukowijoyo, H.; Indriatmoko; Wijayanti, R.D.E.; Limantara, L. Encapsulation of brown seaweed pigment by freeze drying: Characterization and its stability during storage. Procedia Chem. 2015, 14, 353-360.

77. Brennan, J.G.; Butters, J.R.; Cowell, N.D.; Lilly, A.E.V. Food Engineering Operation; Elsevier: London, UK, 1969.

78. Fellows, P. Food Processing Technology: Principles and Practice, 3rd ed.; CRC Press: Cambridge, UK; Woodhead Pub.: Boca Raton, FL, USA, 2009.

79. Molina Grima, E.; Belarbi, E.-H.; Acien-Fernandez, F.G.; Robles-Medina, A.; Yusuf, C. Recovery of microalgal biomass and metabolites: Process options and economics. Biotechnol. Adv. 2003, 20, 491-515.

80. Seagate Products. Seaweed Powder. Available online: http://seagateproducts.com/product/229/Seaweed-Powder-300-grams. html

81. Milledge, John J., and Supattra Maneein. "Storage of seaweed for biofuel production: Ensilage." Sustainable Seaweed Technologies. Elsevier, 2020. 155-167.

82. Milledge, John J., and Patricia J. Harvey. "Ensilage and anaerobic digestion of Sargassum muticum." Journal of Applied Phycology 28.5 (2016): 3021-3030.

83. Fleurence, J. (1999). Seaweed proteins: biochemical, nutritional aspects and potential uses. Trends Food Sci Technol, 10, 25-28.

84. Matanjun, P., Mohamed, S., Mustapha, N. M., \& Muhammad, K. (2009). Nutrient content of tropical edible seaweeds, Eucheuma cottonii, Caulerpa lentillifera and Sargassum polycystum. J Appl Phycol, 21(1), 75-80.

85. Thompson, T. M., Young, B. R., Baroutian, S. (2020). Pelagic Sargassum for energy and fertiliser production in the Caribbean: A case study on Barbados. Renewable and Sustainable Energy Reviews, 118, 109564.

86. Gorham, J., Lewey, S.A. Seasonal changes in the chemical composition of Sargassum muticum . Marine Biology 80, 103-107 (1984). https://doi.org/10.1007/BF00393133

87. Borines, M. G., de Leon, R. L., \& Cuello, J. L. (2013). Bioethanol production from the macroalgae Sargassum spp. Bioresource technology, 138, 22-29.

88. Kumar, S., \& Sahoo, D. (2017). A comprehensive analysis of alginate content and biochemical composition of leftover pulp from brown seaweed Sargassum wightii. Algal research, 23, 233-239.

89. Desrochers, A., S-A. Cox, H.A. Oxenford and B. van Tussenbroek. 2020. Sargassum uses guide: a resource for Caribbean researchers, entrepreneurs and policy makers. Report prepared for the Climate Change Adaptation in the Eastern Caribbean Fisheries Sector (CC4FISH) Project of the 
Food and Agriculture Organization (FAO) and the Global Environment Facility (GEF). Centre for Resource Management and Environmental Studies (CERMES), University of the West Indies, Cave Hill Campus. Bridgetown: Barbados. 159 pp.

90. Lopez-Contreras, A. M., Harmsen, P. F., Hou, X., Huijgen, W., Ditchfield, A. K., Bjornsdottir, B., Bjerre, A. B. (2017). Biorefinery Approach to the Use of Macroalgae as Feedstock for Biofuels. In Algal Biofuels (pp. 103-139). CRC Press.

91. Rajak, Rajiv Chandra, Samuel Jacob, and Beom Soo Kim. "A holistic zero waste biorefinery approach for macroalgal biomass utilization: A review." Science of The Total Environment 716 (2020): 137067.

92. Borines, M. G., de Leon, R. L., \& Cuello, J. L. (2013). Bioethanol production from the macroalgae Sargassum spp. Biores Technol, 138, 22-29.

93. Durbha, S. R., Tavva, S. S. M. D., Guntuku, G., Tadimalla, P., Yechuri, V. R., Nittala, S. R., \& Muktinutalapati, V. S. R. (2016). Ethanol production from the biomass of two marine algae, Padina tetrastromatica and Sargassum vulgare. Am J Biomass Bioenergy, 5, 31-42.

94. Dubey, K. K., Dhingra, A. K., \& Rana, S. (2015). Optimisation of process parameters for enhanced biobutanol production from Sargassum wightii hydrolysate. Int J Energy Technol Policy, 11, 303311.

95. Hou, X., From, N., Angelidaki, I., Huijgen, W. J., \& Bjerre, A. B. (2017). Butanol fermentation of the brown seaweed Laminaria digitata by Clostridium beijerinckii DSM-6422. Biores Technol, 238, 16-21.

96. Milledge, J. J., \& Harvey, P. J. (2016). Ensilage and anaerobic digestion of Sargassum muticum. J Appl Phycol, 28, 3021-3030.

97. Oliveira, J. V., Alves, M. M., \& Costa, J. C. (2015). Optimization of biogas production from Sargassum sp. using a design of experiments to assess the co-digestion with glycerol and waste frying oil. Biores Technol, 175, 480-485.

98. Milledge, John J., and Patricia J. Harvey. "Ensilage and anaerobic digestion of Sargassum muticum." Journal of Applied Phycology 28.5 (2016): 3021-3030.

99. Sterley, Anna, and Daniel Thörnkvist. "The feasibility of using macroalgae from anaerobic digestion as fertilizer in Grenada: A literature study of the potential use of residue as fertilizer in Grenada, and a complementary laboratory study to evaluate the biogas potential." (2020).

100. Costa, José C., et al. "Biohythane production from marine macroalgae Sargassum sp. coupling dark fermentation and anaerobic digestion." Bioresource technology 190 (2015): 251-256.

101. McHugh, D.J. A guide to the seaweed industry. FAO Fisheries Technical Paper, No. 441. FAO, Rome, 2003.

102. Abdel-Raouf, Neveen, A. A. Al-Homaidan, and I. B. M. Ibraheem. "Agricultural importance of algae." African Journal of Biotechnology 11.54 (2012): 11648-11658.

103. Nabti, E., B. Jha, and A. Hartmann. "Impact of seaweeds on agricultural crop production as biofertilizer." International Journal of Environmental Science and Technology 14.5 (2017): 11191134.

104. Crouch, I. J., and J. Van Staden. "Commercial seaweed products as biostimulants in horticulture." Journal of Home \& Consumer Horticulture 1.1 (1993): 19-76.

105. Prasedya, Eka S., et al. "Effect of solid and liquid extract of Sargassum crassifolium on growth and yield of rice plant." AIP Conference Proceedings. Vol. 2199. No. 1. AIP Publishing LLC, 2019.

106. El-Din, SM Mohy. "Utilization of seaweed extracts as bio-fertilizers to stimulate the growth of wheat seedlings." The Egyptian Journal of Experimental Biology 11 (2015): 31-39.

107. Latef, Arafat Abdel Hamed Abdel, et al. "Sargassum muticum and Jania rubens regulate amino acid metabolism to improve growth and alleviate salinity in chickpea." Scientific reports 7.1 (2017): 1-12.

108. Walsh, Kevin T., and Tina M. Waliczek. "Examining the Quality of a Compost Product Derived from Sargassum." HortTechnology 1.aop (2020): 1-6.

109. Sembera, Jen A., Erica J. Meier, and Tina M. Waliczek. "Composting as an alternative management strategy for sargassum drifts on coastlines." HortTechnology 28.1 (2018): 80-84.

112. Casas-Valdez, M., Hernández-Contreras, H., Marín-Álvarez, A., Aguila-Ramírez, R. N., Hernández-Guerrero, C. J., Sánchez-Rodríguez, I., \& Carrillo-Domínguez, S. (2006). El alga marina Sargassum (Sargassaceae): una alternativa tropical para la alimentación de ganado caprino. Revista de biología tropical, 54(1), 83-92. (in Spanish). 
113. Marín, A., Casas-Valdez, M., Carrillo, S., Hernández, H., Monroy, A., Sanginés, L., \& Pérez-Gil, F. (2009). The marine algae Sargassum spp.(Sargassaceae) as feed for sheep in tropical and subtropical regions. Revista de biología tropical, 57(4), 1271-1281.

114. Rajauria, G. 2015. "Chapter 15 - Seaweeds: a sustainable feed source for livestock and aquaculture." In: Seaweed Sustainability, edited by B. K. Tiwari and D. J. Troy, 389-420. San Diego: Academic Press.

115. http://www.salgax.com/galeria

116. https://www.renovareco.com (in Spanish)

117. Draget, K.I., 29 - Alginates, in Handbook of Hydrocolloids (Second Edition), G.O. Phillips and P.A. Williams, Editors. 2009, Woodhead Publishing. p. 807-828.

118. Draget, K.I., G. Skjåk-Bræk, and O. Smidsrød, Alginate based new materials. Int J Biological Macromolecules, 1997. 21(1): p. 47-55.

119. Fitton, J.H., D.N. Stringer, and S.S. Karpiniec, Therapies from Fucoidan: An Update. Marine Drugs, 2015. 13: p. 5920-5946.

120. Morya, V.K., J. Kim, and E.-K. Kim, Algal fucoidan: structural and size-dependent bioactivities and their perspectives. Appl Microbiol Biotechnol, 2012. 93: p. 71-82.

121. Ibañez, E., et al., Extraction and Characterization of Bioactive Compounds with Health Benefits from Marine Resources: Macro and Micro Algae, Cyanobacteria, and Invertebrates, in Marine Bioactive Compounds: Sources, Characterization and Applications, M. Hayes, Editor. 2012, Springer US: Boston, MA. p. 55-98.

122. Moubayed, N.M.S., et al., Antimicrobial, antioxidant properties and chemical composition of seaweeds collected from Saudi Arabia (Red Sea and Arabian Gulf). Saudi J Biol Sci, 2017. 24: p. 162-169

123. Mohapatra, B. R. (2018). Biocatalytic efficacy of immobilized cells of Chryseobacterium sp. AlgSU10 for simultaneous hydrolysis of urethane and urea. Biocatalysis Biotransformation, 36, 307315.

124. http://www.algopack.com

125. http://www.algeanova.com

126. http://abaplas.com

127. https://cordis.europa.eu/project/id/606032/reporting

128. Azizi, Nahid, Ghasem Najafpour, and Habibollah Younesi. "Acid pretreatment and enzymatic saccharification of brown seaweed for polyhydroxybutyrate (PHB) production using Cupriavidus necator." Int J Biological Macromolecules 101 (2017): 1029-1040.

129. Sudharsan S, Seedevi P, Ramasamy P, Subhapradha N, Vairamani S, Shanmugam A (2012) Heavy metal accumulation in seaweeds and sea grasses along southeast coast of India. J Chem Pharm Res 4(9):4240-4244

130. Rodríguez-Martínez RE, Roy PD, Torrescano-Valle N, Cabanillas-Terán N, Carrillo-Domínguez S, Collado-Vides L, García-Sánchez M, van Tussenbroek BI. (2020). Element concentrations in pelagic Sargassum along the Mexican Caribbean coast in 2018-2019. Peer] 8:e8667.

131. Battacharya D, Babbohari MZ, Rathor P, Prithiviraj B (2015) Seaweed extracts as biostimulants in horticulture. Sci Hortic 196:39-48

132. Zodape ST (2001) Seaweeds as a biofertilizer. J Sci Ind Res 60:378-382

133. Crouch, I. J., \& Van Staden, J. (1993). Commercial seaweed products as biostimulants in horticulture. J Home \& Consumer Horticulture (1), 19-76.

134. Wosnitza TMA, Barrantes JG (2003) Utilization of seaweed Ulva sp. in Paracas Bay (Peru): experimenting with compost. J Appl Phycol 18:27-31

135. ADEME presentation, October 2018, link: https://guadeloupe.ademe.fr/expertises/alguessargasses/voies-de-valorisation

136. Ma Z, Lin L, Wu M, Yu H, Shang T, Zhang T, Zhao M. (2018) Total and inorganic arsenic contents in seaweeds: Absorption, accumulation, transformation and toxicity. Aquaculture 497: 49-55.

137. Milledge JJ, Harvey PJ. (2016) Golden Tides: Problem or Golden Opportunity? The Valorisation of Sargassum from Beach Inundations. Journal of Marine Science and Engineering 4;3: 60.

138. Davis D, Simister R, Campbell S, Marston M, Bose S, McQueen-Mason SJ, Gomez LD, Gallimore WA, Tonon T. (2021) Biomass composition of the golden tide pelagic seaweeds Sargassum fluitans and S. natans (morphotypes I and VIII) to inform valorisation pathways. Science of the Total Environment 762, 143134 (in press). DOI 10.1016/j.scitotenv.2020.143134.

139. Han C, Cao X, Yu J-J, Wang X-R, Shen Y. (2008) Arsenic Speciation in Sargassum fusiforme by Microwave-Assisted Extraction and LC-ICP-MS. Chromatographia 69: 587-591. 
140. Rose M, Lewis J, Langrofd N, Baxter M, Origgi S, Barber M, MacBain H, Thomas K. (2007) Arsenic in seaweed - Forms, concentration and dietary exposure. Food and Chemical Toxicology 45: 12631267.

141. Ma Z, Lin L, Wu M, Yu H, Shang T, Zhang T, Zhao M. (2018) Total and inorganic arsenic contents in seaweeds: Absorption, accumulation, transformation and toxicity. Aquaculture 497: 49-55.

142. Serfor-Armah Y, Nyarko BJB, Carboo D, Osae EK, Anim-Sampong S, Akaho EHK. (2000) Instrumental neutron activation analysis of iodine levels in fourteen seaweed species from the coastal belt of Ghana. Journal of Radioanalytical and Nuclear Chemistry 245;2:443-446.

143. Roleda MY, Skjermo J, Marfaing H, Jónsdóttir R, Rebours C, Gietl A, Stengel DB, Nitschke U. (2018) Iodine content in bulk biomass of wild-harvested and cultivated edible seaweeds: Inherent variations determine species-specific daily allowable consumption. Food Chemistry 254: 333-339.

144. Oyesiku OO, Egunyomi A. (2014) Identification and chemical studies of pelagic masses of Sargassum natans (Linnaeus) Gaillon and S. fluitans (Borgessen) Borgesen (brown algae), found offshore in Ondo State, Nigeria. African Journal of Biotechnology 13;10: 1188-1193.

146. Thompson, T. M., B. R. Young and S. Baroutian (2020) Efficiency of hydrothermal pretreatment on the anaerobic digestion of pelagic Sargassum for biogas and fertiliser recovery. Fuel 279: 118527.

147. http://www.fao.org/3/y4765e/y4765e0c.htm 9.1 Fertilizers and soil conditioners

148. van den Burg, S., Selnes, T., Alves, L., Giesbers, E., Daniel, A. (2020) Prospects for upgrading by the European kelp sector. J Appl Phycol. https://doi.org/10.1007/s10811-020-02320-z

149. South Atlantic Fishery Management Council (2002) Fishery management plan for pelagic Sargassum habitat of the south Atlantic region.

https://www.oceanfdn.org/sites/default/files/SAFMC\%2BSargassum $\% 2$ B2002\%2B\%281\%29.com pressed.pdf

150. Laffoley, D.d'A., Roe, H.S.J., Angel, M.V., Ardron, J., Bates, N.R., Boyd, I.L., Brooke, S., Buck, K.N., Carlson, C.A., Causey, B., Conte, M.H., Christiansen, S., Cleary, J., Donnelly, J., Earle, S.A., EDWards, R., Gjerde, K.M., Giovannoni, S.J., Gulick, S., Gollock, M., Hallett, J., Halpin, P., Hanel, R., Hemphill, A., Johnson, R.J., Knap, A.H., Lomas, M.W., McKenna, S.A., Miller, M.J., Miller, P.I., Ming, F.W., Moffitt, R., Nelson, N.B., Parson, L., Peters, A.J., Pitt, J., Rouja, P., Roberts, J., Roberts, J., Seigel, D.A., Siuda, A.N.S., Steinberg, D.K., Stevenson, A., Sumaila, V.R., Swartz, W., Thorrold, S., Trott, T.M., and V. Vats. 2011. The protection and management of the Sargasso Sea: The golden floating rainforest of the Atlantic Ocean. Summary Science and Supporting Evidence Case. Sargasso Sea Alliance, 44 pp.

http://www.sargassoseacommission.org/storage/documents/Sargasso.Report.9.12.pdf

151. Verweij, P., Cormont, A., Nel, J., de Rooij, B., Jones-Walters, L., Slijkerman, D., Soma, K., van Eurpen, M., Pourier, S., Coolen, Q., Mone, G., Bervoets, T., Clarenda, J., van Slobbe, F., Christiaan, D., de Meyer, K., de Vries, Y., Eleana, R., Hoetjes, P., ... Dominguez Teles, I. (2020). A nature inclusive vision for Bonaire in 2050. (Wageningen Environmental Research report; No. 3023). Wageningen Environmental Research. https://doi.org/10.18174/526467

152. Martin, L. M. (2016). Pelagic Sargassum and its associated mobile fauna in the Caribbean, Gulf of Mexico, and Sargasso Sea. MSc thesis, Texas A \& M University

153. Prevention and clean-up of Sargassum in the Dutch Caribbean (2019) DCNA letter. https://www.dcnanature.org/wp-content/uploads/2019/02/DCNA-Sargassum-Brief.pdf

154. Boodoo, C. (2019) Sustainable energy, transportation, and resilience in the Caribbean: a White paper for the Caribbean Forum on Sustainable Energy, Transportation and Resilience. Report of The Caribbean Forum on Energy, Transport and Resilience congress (Bay Gardens Hotel, Rodney Bay, Saint Lucia, June 26-27, 2019). Published by Organization of American States, Department of Sustainable Development. (ISBN 978-0-8270-6993-0) https://ecpamericas.org/publications/

155. van Wassenaer, A., Hernández Garcia, R., (2018) Quintana Roo, recommendations on how to deal with urgent challenges posted by coastal erosion and sargassum. Final report from the Delta Cooperation Program Mexico - The Netherlands, and the workshop on 25 October 2018. Published by RvO, summary can be found in:

https://www.netherlandsworlDWide.nl/latest/news/2019/06/25/quintana-roo-recommendationson-how-to-deal-with-sargassum

156. van der Geest, M., D. M. E. Slijkerman, C. A. Mücher, A. O. Debrot, S. W. K. van der Burg, I. Dominguez Teles, R. J. H. G. Henkens, N. Ghasemi, H. Kramer, W. M. L. Meijninger, and L. A. P. Lotz. (2019) Nexus interventions for small tropical islands: case study Bonaire. Wageningen Marine Research. https://edepot.wur.nl/471567 
157. Elliott, D. C., T. R. Hart, G. G. Neuenschwander, L. J. Rotness, G. Roesijadi, A. H. Zacher and J. K. Magnuson (2014) Hydrothermal Processing of Macroalgal Feedstocks in Continuous-Flow Reactors. ACS Sustainable Chemistry \& Engineering 2(2): 207-215

158. Thompson, T. M., B. R. Young and S. Baroutian (2020) Efficiency of hydrothermal pretreatment on the anaerobic digestion of pelagic Sargassum for biogas and fertiliser recovery. Fuel 279: 118527

159. Steinbruch, E., D. Drabik, M. Epstein, S. Ghosh, M. S. Prabhu, M. Gozin, A. Kribus and A. Golberg (2020) Hydrothermal processing of a green seaweed Ulva sp. for the production of monosaccharides, polyhydroxyalkanoates, and hydrochar. Bioresource Technology 318: 124263

160. Castlehouse, H., C. Smith, A. Raab, C. Deacon, A.A. Meharg, J. Feldmann (2003) Biotransformation and accumulation of arsenic in soil amended with seaweed. Environ. Sci. Technol. 37 (5), 951-957

161. van Sebille E, Zettler E, Wienders N, Amaral-Zettler L, Elipot S, Lumpkin R (2021) Dispersion of Surface Drifters in the Tropical Atlantic. Front. Mar. Sci. 7:607426. doi: $10.3389 /$ fmars. 2020.607426

162. Mohammed A, A. Rivers, D.C. Stuckey, K. Ward (2020) Alginate extraction from Sargassum seaweed in the Caribbean region: Optimization using response surface methodology. Carbohydrate Polymers 245, 116419

163. Mohammed A, A. Rivers, D.C. Stuckey, K. Ward (2020) Datasets on the optimization of alginate extraction from sargassum biomass using response surface methodology. Data in Brief 31, 105837

164. Nielsen, C.W., Holdt, S.L., Sloth, J.J., Marinho, G.S., Sæther, M., Funderud, J., Rustad, T. (2020) Reducing the high iodine content of Saccharina latissima and improving the profile of other valuable compounds by water blanching. Foods 9, 569

165. Stévant, P., Marfaing, H., Duinker, A., Fleurence, J., Rustad, T., Sandbakken, I., Chapman, A. (2018) Biomass soaking treatments to reduce potentially undesirable compounds in the edible seaweeds sugar kelp (Saccharina latissima) and winged kelp (Alaria esculenta) and health risk estimation for human consumption. Journal of Applied Phycology, 30, 2047-2060

166. Devault, D.A., Pierre, R., Marfaing, H., Dolique, F., Lopez, P.J. (2021) Sargassum contamination and consequences for downstream uses: a review. Journal of Applied Phycology 33:567-60 



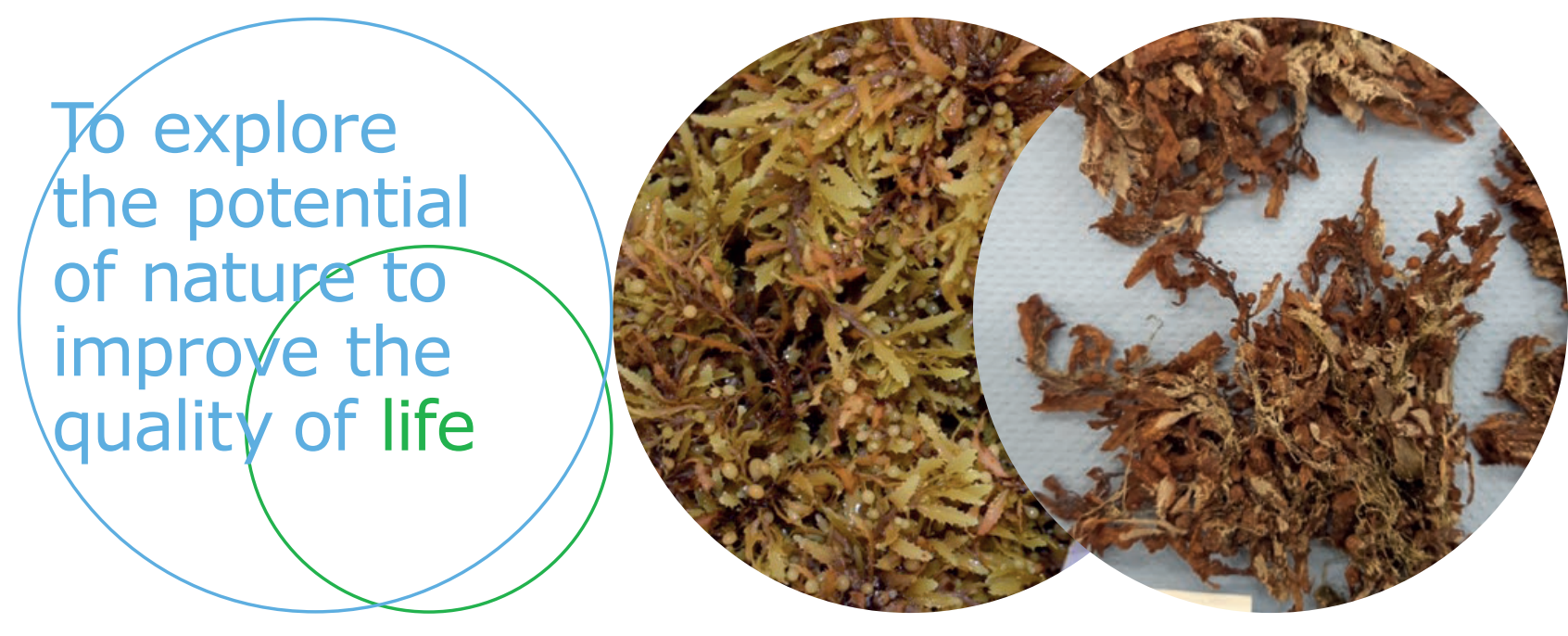

Wageningen Food \& Biobased Research Bornse Weilanden 9

6708 WG Wageningen

The Netherlands

www.wur.eu/wfbr

E info.wfbr@wur.nl

Report 2137

ISBN 978-94-6395-751-9
The mission of Wageningen University and Research is "To explore the potential of nature to improve the quality of life". Under the banner Wageningen University \& Research, Wageningen University and the specialised research institutes of the Wageningen Research Foundation have joined forces in contributing to finding solutions to important questions in the domain of healthy food and living environment. With its roughly 30 branches, 6,500 employees (5,500 fte) and 12,500 students, Wageningen University \& Research is one of the leading organisations in its domain. The unique Wageningen approach lies in its integrated approach to issues and the collaboration between different disciplines. 